\title{
NBS
}

1080 5438 1900 MAA

S C U L T U R A AFRICANA

EDIZIONI DI «VALORI PLASTICI» ROMA 
21

not

(11.20

(w) 


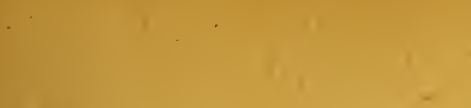

,

$$
\text { r }
$$

n

1

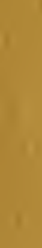

N

4

is

$i^{2}$

,

(

-

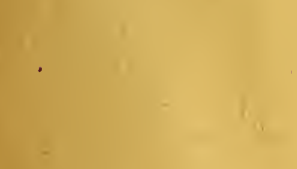





\title{
L A C I V I L T A A R T I S T I C A
}

\author{
VOLUME VIII
}

\section{SCULTURA AFRICANA}

CON UNO STUDIO CRITICO DI

CARLO EINSTEIN

EDIZIONI DI «VALORI PLASTICI»ROMA

JUN 1\% 1986

\section{LIBPARIES}


TUTTI I DIRITTI RISERVATI

Questo volume è apparso nella serie «Orbis Pictus» Tipografia Ernesto Wasmuth A.-G., Berlino 
$E_{\text {sotismo è spesso romanticismo improduttivo, alessandrinismo geografico. Ciò }}$ che non è originale non ha nessun valore. Tuttavia il valore dell'arte africana non viene diminuito dal giudizio che ne dànno gli incompetenti. Io voglio considerare l'arte africana soltanto in relazione coi principî che ispirano l'arte dei nostri tempi; non per recare un nuovo tesoro di forme, ma piuttosto per il desiderio che comincino indagini storico-artistiche sulla scultura e sulla pittura africana. L'etnografia ha risolto il suo primo problema procedendo con indagini di carattere generale: ora essa cambia metodo ed aspetto, venendo a trattare questioni singole. Lo storico dell'arte affronta nuovi problemi di mano in mano che gli appaiono distinte le caratteristiche dei varî popoli. Questo libro non vuole e non può essere che un modesto saggio, mancandoci l'ausilio d'importanti raccolte straniere; tuttavia, quello che più ci duole è che, nel considerare l'arte africana, siamo privi dell'appoggio di una storia univoca e precisa, poichè la storia africana s'annebbia in tradizioni di famiglie e di stirpi decadute una dopo l'altra. Tutto quello che noi sappiamo sull'Africa è solo un bel racconto senza fondamento: tempo e spazio rimangono indeterminati, come sopiti nel lieve sonno del mito. Quel che ci resta porta le tracce di una rapida rovina e di una tortuosa degenerazione, talchè quasi non lascia indurre dal presente stato quello antico. Le forze creatrici culturali dell'Africa sono presso che esauste e la vecchia tradizione s'è affievolita per opera della colonizzazione; ai valori indigeni si sono sovrapposte concezioni importate, onde dall'accoppiamento di opere spiritualmente estranee si è generato un ibridismo che a sua volta ha dato luogo all’intima incertezza e alla volubilità quasi infantile della mentalità africana. Da questa incerłezza, da questa volubilità, doveva alla fine determinarsi la sua caduta storica. Non senza cautela quindi dobbiamo procedere nella ricostruzione della storia africana, poichè facilmente si potrebbe rimanere ingannati dalla sua vita presente improntata a un ingenuo romanticismo. Il clima africano concede alle vestigia del passato soltanto una breve durata. D'altra parte, una conturbante influenza ha esercitato la penetrazione in Africa di altri popoli; la quale ha fatto si che riuscisse incerta e malsicura la sua formazione statale e culturale. Sembra che il rapido svolgimento artistico africano si trovi all'ultimo stadio della decadenza. Spesso gl' indigeni non intendono più il significato della loro arte antica e la gelosa cura da essi posta nel celare il loro retaggio artistico, grandemente venerato ed 
amato, si trasforma in un indifferente incomprensione della propria storia. Gli stati occidentali e centrali dell'Africa, che hanno lasciato dietro di sè una importante eredità artistica, non esistono più. E si pensi ai regni vicini di Benin, di Zenda, al regno di Kascembe e ad altri stati. Tuttavia cercherò di studiare l'arte africana, superando, come potrò, le difficoltà che mi si presenteranno. Con troppa facilità si attibuiscono a quest'arte gl'intenti e i problemi che affliggono l'artista d'oggi. Non mi pare che gli scultori africani abbiano risolto i problemi di forma intorno ai quali ci affatichiamo senza tregua. Nondimeno, non si riesce a trarre da questa affermazione un'adeguata spiegazione dell'arte africana. A prima vista può apparire seducente, anzi convincente, giungere a una determinazione storica a traverso lo studio evolutivo dei varî stili. Ma, coscienziosamente, dobbiamo confessare di non conoscere nessuna legge che regoli l'evoluzione dei vari stili nell'arte. Il primitivismo può indicare inizio o decadenza di un'arte: il grado raggiunto, tanto tecnicamente quanto formalmente, è determinato non solo dai varî momenti in cui l'arte si svolge, ma anche dalle doti personali degli artisti. Il rapido svolgimento artistico africano non trova riscontri nè può essere imprigionato da un uggioso e sterile espressionismo: con alcuni concetti in voga, o con qualche trucco descrittivo, poco s'ottiene. Per fortuna, l'arte africana è più forte della moda africana. A che cosa si può mai riuscire con sentimenti ingannevoli e truccati a nuovo che hanno similianze sconcertanti con le fantasmagorie? Prima di tutto non si deve voler trovare nelle opere africane la meschina rappresentazione di un arte primitiva. Un numero importante di sculture africane è tutt'altro che primitivo, ma costruttivo sotto ogni punto di vista. La difficoltà di analizzare la forma ci spinge a penetrare l'essenza dell'opera, non appena possiamo ben concepire l'obiettivo e spirituale contenuto di questi lavori. Allora si parla acutamente con gran piacere di espressioni artistiche che vi si potnebbero osservare e si fa gran chiasso di una cosa non compresa e soltanto immaginata. Invece il problema dell'arte africana può esser risolto solo mediante lo studio dello spirito (individuale), oppure da quello della stirpe (collettivo). Per questo ci vuole la collaborazione degli etnologi e degli storici dell'arte. Già il tentativo di fissare in modo convicente lo svolgersi dell'arte africana presenta insolite difficoltà e ci fa sentire quanto sia meschina la nostra conoscenza dell'Africa. La divisione regionale dell'arte africana, che da principio è chiara, si presenta subito insufficente. In regioni simili noi troviamo spesso disegni di forme contrastanti che risalgono allo stesso tempo; è facile trarre dall'insieme di un paesaggio un determinato quadro, senza prendere in considerazione $\mathrm{i}$ contrasti che vi si trovano. Prendiamo per esempio ad esaminare un opera artistica del bacino del Congo: spesso è difficile determinare a quale tribù appartenga; giacchè in codesto paese lè popolazioni si sovrappongono e si urtano continuamente. Le tribù sono non soltanto accampate regionalmente una accanto all'altra, ma nella stessa misura si mescolano. Come si può riconoscere senz errore una tribù che, dopo la sparizione del regno di cui faceva 
parte, si è totalmente perduta nell'unirsi con altre famiglie? Quando esistevano i grandi regni, alcune tribù furono assorbite e le antiche famiglie dei capi furono tratte nel grande complesso politico dello stato. Tribù significa, piuttosto che una decisa separazione etnica, una semplice derivazione o un rapporto di parentela con qualche famiglia di capi, cioè con una famiglia di sangue santo. Bisogna distinguene dalla tribù il regno, che costituisce un legame più lieve e più elastico e che abbraccia alcune tribù, le quali sono sottoposte a una tribù dominatrice più forte. Per queste ragioni essenziali è stato agevole il tentativo di rilevare in modo speciale, forse a scopo di determinare qualche particolarità tecnica, l'arte di una tribù o di una regione e di trarne una conclusione stilistica. Così è avvenuto, per esempio, con l'arte dei Benin e con quella dei Boschimani. Dal particolare tecnico, che emerge chiaro dalla confusione dell'insieme, si potrebbe riconoscere lo stile comune. Le opere in bronzo dei Benin, per esempio, perdono il carattere incerto di un'anormalità tecnica, quando si esaminino in relazione coll'arte dei Joruba e si ricerchi il loro sviluppo ulteriore a Camerun.

Tuttavia tentativi di spiegazione possono essere accolti e considerati entro certi limiti; perchè dappertutto, qualora non volessimo gettare uno sguardo sull'Africa, troviamo che l'impostazione del problema è molto delicata. Il problema sull'arte dei Joruba $\grave{e}$ insoluto, come pure quello sulle opere in bronzo dei Benin oppune quello sulle sculture dei Simbabje. Sempre ci si presenta il problema della provenienza e della migrazione delle forme artistiche africane. $\mathrm{Ci}$ si potrebbe servire dell'aiuto chiarificatore dei miti per determinare almeno il senso delle immagini. Però miti e sculture spesso appartengono a correnti tradizionali interamente diverse. Nuove tribù attraggono $\mathrm{i}$ vecchi abitanti con una mitologia diversamente colorita; la tribù conquistatrice impone al retaggio artistico indigeno la propria mitologia; i miti degenerano a poco a poco cristianizzandosi e il significato dell'opera si sposta e viene offuscato. Davanti a opere antiche dell'Africa noi dobbiamo rispondere come gl'indigeni: - Non sappiamo. - L'Africa, in cui si avvicendano popoli in decadenza $\mathrm{e}$ in ascensione, si sottrae subdolamente alla sete europea di sapere.

Spesso le statue Africane sono chiamate feticci, e tutti adoprano questa parola; essa però non spiega niente e significa tutto quello che si vuole; nasconde il senso di quelle sculture, nasconde anzitutto la nostra ignoranza. Sotto il peso significativo di questa parola si dilegua il senso chiaro dell'oggetto in questione. Tuttavia non si procede in modo migliore colle così dette concezioni artistiche d'oggi, le quali si lasciano definine a piacere. Che cosa non chiamiamo spirito, forma, ecc.? Il filosofo dà la definizione del suo concetto di forma, non appena abbia abbracciato l'insieme del contenuto del concetto, il labile e disperso complesso del significato che il tempo unisce. Vien dato un colore, un accento. Queste cose vissute rimangono teoreticamente inconcepibili, perchè esse furono vissute e sentite con infinite variazioni. L'astrazione si ostina a straniarsi dall'oggetto, e ciò non può mutarsi per i commenti, 
siano pure numerosi. Io ho mostrato prima quanto pericoloso sia vóler spiegare lo stato d'animo d'un'opera esotica. Si può quì cadere nei soliti errori. L'espressione di un viso, che ci sembra serena, può produrre un grande terrore in un negro, e un aspetto, che ci sembra orrido, può avere su di lui una benefica influenza. Le coseche consideriamo come particolari secondari possono essere per un negro d'importanza non comune e dare alla statua il diritto di esistere. Il sentimento psicologico, come pure la semplice osservazione formale, sono di un limitato valore per la conoscenza e generano confusione, qualora vengano trattati unilateralmente. Occupandosi un po' a lungo dell'arte africana, si rafforza il sentimento di profondo rispetto verso la sua penosa incertezza e si diventa più cauti. Nell'osservare le singole opere, s'áffollano piacevolmente svariate ipotesi. Rapiti dall'estasi, crediamo d'avvicinarci a una soluzione che è valsa come norma di lunghi periodi di lavoro, e che vediamo dileguare, nel nostro caso particolare, con rincrescimento. Ciò nostante, più delle ipotesi, ci convince un fatto: l'unità stilistica dell'arte africana. Evitando i problemì etnologici, noi dobbiamo esaminare la parentela formale delle sculture africane; ma ciò non offre che un debole conforto. Siccome le possibilità di espressione formale sono limitate, occorre molta ingenuità per esaminare il complesso delle opere artistiche di ogni tribù o di ogni regione. Le nostre cognizioni e l'aiuto della stilistica comparata non arrivano così lontano. Viceversa diffenenti tempi e paesi diversi, osservati rispetto alla forma, rivelano molto spesso delle somiglianze. Si pensi al legame della cosidetta arte primitiva, per esempio, con le pitture delle caverne, o si rifletta alla tendenza che le epoche in decadenza ostentano di sentirsi primitive e di imitare gli arcaismi. Già presso il singolo artista osserviamo cambiamenti non comuni di espressione stilistica e tecnica e, soltanto per una conoscenza accidentale, possiamo stabilire che tutte queste opere discordi derivano dallo stesso artista. Il temperamento artistico, ricco di tentazioni, va contemporaneamente verso risoluzioni contrastanti. Possiamo così addirittura parlare di dialettica per le creazioni di Poussin, di Dürer, oppure per quelle di Cézanne. Poichè si è notato il fatto banale e senza importanza, che opere diverse fra loro provengono da una stessa mano, volentieri si arrischiano supposizioni estetiche o psicologiche. Ciò è impossibile per l'arte africana, visto che di essa non conosciamo gli autori, onde le ipotesi svaporano facilmente in belle fiabe. Definitive potevano apparirci talune interpretazioni formali; ma chi può dire se le nostre conclusioni sono giuste dal punto di vista africano? L'arte certamente deve seguire norme fisse o almeno così deve sembrare ai contemporanei. Non sempre però essa si viene formando con la coscienza di queste norme. Io non parlo qua dell'inetto, del timido genio che scaturisce dai cattivi romanzi: ma l'intento di un artista è spesso in una direzione diversa da quella che ci indica il critico a mente fredda, l'interprete artistico non sempre felice. Io cerco sempre di difendere le osservazioni del mio primo libro: la scultura africana ci mostra risoluzioni cubiche di grande purezza e 
di una rara conseguenza. Essa persegue il problema del collegamento di spazio e di concentrazione; in ciò si avvicina alla plastica egiziana. In contrasto coll'arte africana, quella australiana ricerca nel suo grande insieme i problemi ornamentali e decorativi della dissoluzione dello spazio e si serve in modo perfetto dell'interruzione spaziale, dell'intervallo spaziale variato senza posa. Abbiamo esaminato le opene artistiche africane dal punto di vista cubistico e abbiamo trovato degli esempi compiuti. Ma, da questo punto di vista, le opere d'arte tanto apprezzate della terra di Jorouba a di Benin, nonostante la loro bellezza tecnica, non significano per noi, nulla di decisivo per l'arte africana. Per formulare un giudizio non basta soffermarsi all'espressione tecnica e neppure mettere in evidenza la così detta espressione viva. Gli artisti di quelle regioni, però, c'insegnano che l'arte africana non dev'essere osservata a base di formule ben fisse. Si parla spesso della differenziazione della cultura e dell'arte continentale. Non meno difficile ci si presenta il riscontro frammentario dell'arte africana. Non bisogna lasciarsi condurre ad una falsa e meschina tregua dalla pàrola d'oraine di -- Arte primitiva di popoli naturali -. Il fatto della decadenza dell'arte africana rivela una lunga evoluzione anteriore, di cui sono finora sconosciuti l'inizio e lo svolgimento. Anche se l'arte africana ha ricevuto influenze altrui e forme estranee all'Africa, qualche cosa rimane: una straordinaria e originale serie di forme che appartiene alla terra africana. L'arte africana contiene risoluzioni di scultura, di decorazione e di pittura che le dànno il diritto di esser posta accanto ad ogni altra arte. Quando verranno spiegati il contenuto e le espressioni formali, che per ora non sono determinati, allora essa dovrà esser posta senza limitazionì nel ciclo dell'indagine artistica accanto all'arte australiana e americana.

Nell' introduzione io osservo che in questo volume offro esempi d'arte africana della terra di Joruba, di Benin, di Gabon, di Angola, del paese di Vatchivokoe, del territorio di Kasai, di Urua, come pure offro un esempio dell'arte di Simbabye del paese di Mashona. Perciò lo svolgimento dell'arte africana, che in questo studio e prospettato non è completo. Ho lasciato da parte l'arte della Sierra Leone, della Costa d'Avorio, come pure quella troppo arabizzata del Nigherboghen settentrionale. Il Congo Francese è poco rappresentato; numerosi esempi significativi della Costa d'Avorio e del Congo francese si possono trovare nel mio primo volume. Nonostante ciò il pnesente lavoro getta un colpo d'occhio sul ciclo artistico dell'Africa occidentale e intuisce ciò che in esso è racchiuso. Con l'arte di Joruba noi arriviamo al punto centrale di questo ciclo. Si esamini questa provincia artistica non come una meraviglia isolata, ma piuttosto in relazione con l'arte dei Benin e dei Camerun. Qui ci si presenta un complesso strettamente unito, che, certo, in corrispondenza con la diversità storica e geografica, ci appare tecnicamente modificato. Presso la gente di Benin si trovano animali simbolici, decorazioni e composizioni artistiche come presso gli abitanti di Joruba. Inoltre l'Ankermann ha potuto constatare che gli abitanti del Grasland di Camerun sono emigrati dal nord esportando l'arte dell'incisione, della 
scultura e della ceramica. Nello stesso modo, con le stirpi refugiatesi nel Grasland venne dal nord-ovest di Tikar a Camerun l'uso dello smalto giallo. Con ciò è provata la connessione storica di queste provincie artistiche, intimamente unite. $E$ per far vedere quanto tale processo artistico si sia spinto verso sud, notiamo affinità tra l'ornamentazione di Joruba e la decorazione praticata dagli abitanti di Bakuba, che abitano tra Sankuru e Kasai. Anche qua c'è una tradizione che ci narra come queste tribù siano venute dal nord. Noi constateremo spesso la parentela e il legame fra le varie manifestazioni artistiche dell'Africa occidentale, derivandole dall'affinità stilistica e dalla somiglianza dei motivi. Osservando il legame che corre tra Joruba e Bemin, troviamo le stesse espressioni d'arte oggettivate, gli stessi animali t o te m, cioè serpenti, siluri, montoni, lucertole, ecc; uno stesso modo di rappresentare i cavalieri. Gli oggetti chiamati dal Frobenius tavole Ifa somigliano e s’identificano con le lastre di bronzo di Benin, come le ha riprodotte Pitt Rivers nel suo libro. Le teste di terraccotta trovate nella terra di Joruba dal Frobenius, che adesso sono nel Museo etnologico di Berlino, ci appaiono come isolate meraviglie dell'abilità artistica africana onde siamo tentati di attribuirle a tempi assai remoti. Per ragioni stilistiche bisogna metterle in relazione con le teste di Benin, che devono essere un po' più antiche delle opere in bronzo di Benin: le affinità che corrono tra le teste di terracotta trovate dal Frobenius e le opere d'arte di Benin si possono osservare nella testa di Benin di Rushmor, che è riprodotta nell' "Antichità di Benin» del Luschan.

La simiglianza tra $\mathrm{i}$ motivi aristici del Benin e quelli di Joruba vien giustificata dalla identità stessa dei culti. Un vecchio relatore inglese, il Burton, scrive: «La religione degli abitanti di Benin si riconosce a prima vista dalla confusa e misteriosa mitologia di Joruba, dove si adora anche Schango, il dio del tuono. - Gallaway, un altro relatore, chiama Benin una forte teocrazia, che somiglia a quella di Joruba. Visto che il grado di cultura di Benin e di Joruba dovrebb'essere il medesimo, non è necessario datare, senza speciali ragioni, le plastiche di Joruba come molto anteriori alle opere di Benin. Ad ogni modo le teste di Joruba del Museo di Berlino, dal punto di vista stilistico, appartengono al ciclo delle opere in bronze di Benin.

Tavola 1. - Questa testa di montone presenta la stessa espressione stilistica delle teste più conosciute di leopardi e di elefanti di Benin, eseguite in avorio o in metallo. Gli artisti di Joruba, come quelli di Benin, scolpiscono le corna in bassorilievo. Gli occhi, appena modellati, sono circondati da una raggiera. Allo stesso modo che nelle figure di animali di Benin, il naso è messo attraverso il muso come un asse longitudinale. Simili maschere di montoni furono trovate nel Grasland di Camerun.

Tavola 2. - Abbiamo già fatto osservare la parentela che esiste fra le tavole Ifa e le lastre di bronzo di Benin. Le tavole Ifa servono per profetizzare adoperando dei noccioli di palma. Il nobile rilievo stilistico si può osservare nelle 
incisioni d'avorio dei Bini, e, soprattutto nei grandi denti incisi d'avorio. La piatta maschera, che troviamo per lo più nelle tavole, ci fa ricordare le numerose teste di Benin e gli ornamenti da ballo di Camerun. Vorrei far rilevare a questo proposito che $\mathrm{i}$ coperchi delle cassette, le quali venivano costruite dagli abitanti di Bakuba per custodire la materia colorante, sono incisi a simiglianza delle maschere in bassorilievo, come ci appaiono sulle tavole Ifa.

Tavola 3. - Una tavola che rappresenta l'acconciatura di un sacerdote di Schango.

Si confronti il fregio ornamentale di quest'opera con la decorazione delle seggiole, delle lastre di bronze, oppure dei vasi di Benin. Al tempo stesso è evidente che esiste un legame con la decorazione delle tribù di Kasai e, anzitutto, con quella di Bakuba. Fare un indagine profonda sulla ornamentazione africana non è il compito del nostro libro. L'armonia plastica della testolina posta in mezzo ci ricorda senz'altro le teste di Benin e di Camerun.

\section{Tavola 3, a destra. - Un frammento d'avorio di Benin.}

Una posizione simile delle ginocchia la ritroviamo in uno scavo di Joruba, in un capitello di quarzo di Ifa, della lunghezza di 8 cent, che è esposto nel Museo etnologico di Berlino. In tutti e due $\mathrm{i}$ frammenti $\mathrm{i}$ piedi sono alla stessa altezza dell'articolazione dei gomiti e il viso poggia sulle mani. Eguali posizioni riscontriamo in alcune piccole figure di feticci cameruniani in terracotta. Noi constatiamo che nel Grasland di Camerun lo stile di Benin s'è mantenuto più a lungo. Le stirpi che vi abitano sono state risparmiate, forse in grazia della loro emigrazione, anteriore alla decadenza dello stile beniniano, forse perchè lo stile della costa, già degenerato, è penetrato nel Grasland. L’ultima supposizione è la più probabile, poichè si ritrovano in molti ornamenti da ballo di Camerun tipi dello stile posteriore di Benin. Nell'isolamento di Camerun, difeso dai monti, lo stile beniniano, sviluppatosi con le sue sole forze, è pervenuto a un rustico rinascimento spogliandosi delle influenze europee, che hanno invece influito sullo stile dei paesi della costa, ritornando ad essere originalmente africano. Ad ogni modo la tecnica della fusione del metallo era nel Grasland poco diffusa, giacchè difettava l'importazione europea del metallo.

Tavola 4. - Rappresenta un monumento di cavalieri. Questa opera vuol forse raffigurare il dio del tuono di Joruba, Schango, sostenuto dalla dea Oja. Noi troviamo presso i Bini rappresentazioni di cavalieri affatto simili quanto allo stile. Anzitutto ci richiamano alla memoria i rilievi che riproducono nobili di Benin, a lato dei quali sono poste piccole figure. Per altri rispetti, a questa esposizione di rilievi corrispondono composizioni eseguite sui vasi in terracotta di Joruba. In tutto simile per la composizione al rilievo di Benin, sul quale sono riprodotti uomini e ossa di 
siluri, è un vaso in terracotta di Joruba, che si trova nel Museo di Berlino. La portatrice del cavaliere ci ricorda il seggio scolpito di Camerun e quello di Urua, che si vedranno nelle pagine seguenti del nostro libro. Risulta così una determinata serie di motivi artistici africani i quali si combinano e si elaborano durante tutto il ciclo culturale dell'Africa occidentale. La tavola che rappresenta il cavaliere di Joruba ci richiama spontaneamente alla memoria i primi lavori romani. Ho notato una rassomiglianza straordinaria con una figura di una scacchiera della Germania del Sud, del $14^{0}$ secolo, che si trova nel Museo dell'imperatore Federico. L'intimo legame di tutte le sculture africane ci spinge a sostenere che esse hanno avuto un'origine comune; poichè, mentre oggi le popolazioni sono divise, così che appena l'una sa dell'esistenza dell'altra, in passato esse erano più strettamente unite fra loro, prima che, venendo forse dall'Abissinia, matrice di popoli, emigrassero verso sud, e verso ovest. Noi potremmo ricordare ancora una volta come dall'affinità della plastica di Benin con quella di Joruba, si può trarre la conclusione che quest'ultima non doveva essere più antica di quella di Benin.

Tavola 5. - Un rilievo in legno di Joruba. Mentre la scultura africana mostra una singolare energia nell'espressione plastica, i rilievi spesso si adagiano in un tranquillo e semplice sistema di piani, senza rilievi prestabiliti. 'Badiamo però a non generalizzare. Infatti le opere più antiche. come la riprodotta tavola Ifa e il rilievo di Benin, sono composte con intensa mobilità. La tavola Ifa è certamente più antica di questo bassorilievo, il quale, di origine più recente, è eseguito con un'arte più semplice e più primitiva. L'arte non si sviluppa sempre movendo dal semplice al complesso, anzi spesso si possono notare variazioni di stile in senso contrario. Questo rilievo è una bella opera arcaicizzante; il suo autore preferiva probabilmente una concezione armonica e calma alla selvatichezza dello stile indigeno. È questa espressione primitiva una arcaicizzazione cosciente, oppure esistevono al tempo stesso due generi di stile contrapposti e paralleli, come nell'antico Egitto? È difficile rispondere all'una o all'altra domanda. Ad ogni modo in queste opere primitive si rivela qualche cosa di più di un procedimento limitato e ottuso, perchè, quando esisteva dovunque una tradizione artistica, si può senza dubbio affermare che in Africa, dove l'esercizio dell'arte è legato ancora a determinate famiglie, dove al tempo del grande impero v'era un arte di corte o sacerdotale, essa veniva esercitata da una casta. Dalle tradizioni allora esistenti nasce per necessità una coscienza artistica di grande valore, che senza dubbio oggi è offuscata.

Con i regni africani e con le dinastie, la tradizione si è spezzata e con essa non solo l'arte, ma anche tutti i sistemi religiosi dell'Africa centrale. Troviamo tuttora reliquie di una tradizione artistica, che ha mantenuto coscienziosamente una distinta espressione formale, presso gli abitanti di Bakuba, i quali indicano con nomi diversi ogni lavoro di tessitura o d'üncisione. Lo stile armonico e piano dei 
nostri rilievi di Joruba lo troviamo fino a Nasai, a fino a Sankuru, in molte porte, in molti architravi e in molti cofani. La più bella opera di questo genere è certamente un cofano di Tervu nel Museo del Congo, il quale è considerato un lavoro dei Bakuba. Quest'opera ci permette di riscontrare un legame sorprendente tra $\mathrm{i}$ rilievi in legno dell'Africa centrale e le pitture di Buschmann. L'affinità stilistica con quest'ultima colpisce in modo singolare, così che il dottor Maasz del museo Congo ritiene questo cofano un lavoro di Boschimani. Ora veniamo all'arte del bronzo di Benin. Questa, secondo il Maasz, si avvicina di più all'arte europea in voga. Egli vi trova un naturalismo troppo forte per essere d'ispirazione africana e si compiace dello stupore che ha destato in lui l'abilità tecnica. Tuttavia non mette in dubbio gli intimi pregi artistici di queste opene in bronzo, create da un ispirazione tormentata, che trascende il gusto medio europeo. Questo perfezionamento della creazione artistica africana appare nelle teste in terracotta, tanto apprezzate, e nella testa di bronzo di Olokun della terra di Joruba. Dal punto di vista tecnico sono dei veri e propri capolavori, ma da quello stilistico sono opere deficienti. Se vogliamo conoscere un arte africana stilisticamente pura, occupiamoci dell'arte di Camerun, dove non si segue la forma artistica raffinata di Benin, in cui si sentono elementi importati, e dove troviamo ancora espressioni semplici e grandi; si osservino le opere della Costa d'Avorio, del Gabon, del Kasai e del circondario di Tanganjika. Ma come mai quest arte raffinata è venuta a Benin? Secondo una tradizione dei Bini, la tecnica della fusione in bronzo fu introdotta in modo mirabile dal re Essige, il $10^{\circ}$ della dinastia. Tuttavia c'è un'altra tradizione più verosimile secondo la quale i re di Benin sono venuti da Ifa, dalla terra di Joruba, e di là hanno portato con loro quest'arte. Quest'ultima congettura è corroborata dalle caratteristiche comuni delle culture di Benin e di Joruba. La gente di Benin acquistava il metallo per la fusione in particolar modo da commercianti che viaggiavano per mare, per lo più da Portoghesi e da Olandesi, i quali sono spesso riprodotti nei rilievi. Vediamo anche su numerose lastre, i così detti manillas, braccialetti di rame e di piombo, che servivano come metallo da fusione. L'arte di Benin è completamente pervasa dallo stile dell'Africa occidentale. Abbiamo sottolineato la sua stretta parentela con l'arte di Joruba e di Camerun; in tutte e due troviamo gli stessi temi riprodotti nelle effigi e gli stessi animali to te m: il siluro, il leopardo, il serpente, il montone ecc. - Così ai lavori di Joruba corrispondono le tavole di Benin qui riprodotte, le quali, in luogo delle gambe, hanno anche la coda di un siluro. Ricordo pure la cassetta di legno di Joruba che si trova ad Amburgo, su cui è rappresentato un pesce che finisce con una testa di uomo. Ora mostreremo la stretta parentela tra le basi delle seggiole di Benin e tra il plinto delle teste e la decorazione delle tavole Ifa. Le sculture di Benin e di Joruba mostrano di quale perfezione tecnica l'Africano fosse capace; non sappiamo in quale epoca si è giunti a tale grado di abilità. Le opere africane antiche rimangono finora inesplicabili. Forse in avvenire l'arte egiziana non sarà più considerata come 
un fenomeno isolato, ma si vedranno in modo evidente $\mathrm{i}$ suoi rapporti coll'arte dell'Africa centrale, rapporti dei quali adesso ci permettiamo di dare la prova. Intanto non crediamo esatte le date indicate da alcuni autori di statue di legno, come per esempio le misteriose lot te rie che si fanno risalire al $12^{0}$ secolo. Si può supporre che nel $12^{\circ}$ secolo si fossero già esaminate le antiche opere africane, ma tuttavia non siamo in grado di affermarlo. Le opere in bronzo di Benin venivano scelte soltanto a seconda dei loro pregi. Non possiamo passare in rivista quest'arte cosi molteplice. Non vorrei pronunziarmi a proposito di queste teste, ma esse non sono certo della stessa specie dei bronzi che sostenevono $\mathrm{i}$ denti incisi di avorio. Le tavole 6 e 7 dànno l'impressione di ritratti. Seguendo l'opinione arbitraria che l'arte del ritratto sia arte primitiva, non si può vedere nel ritratto africano la bellezza della sua ascensione. L'arte africana, come quella egiziana, trae origine dal culto dei morti e degli antenati. Con ciò tocchiamo il fulcro religioso della creazione artistica africana. A questo cerchio magico appartengono anche le rappresentazioni di animali. In generale si tratta di ritratti di animali t o te m. Ankermann analizzò nel suo classico lavoro «La fede nell'anima e nel culto degli antenati presso i popoli africani», efficacemente e con straordinaria acutezza le idee di quei popoli intorno all'anima. Egli mostrò la molteplicità delle loro concezioni e pervenne al concetto unico dell'anima del ritratto, che serve a mantenere il ricordo, concetto più antico di quello dell'anima puramente spirituale. Infatti, così risposero i Zulu al missionario Gallawaj, quando egli chiese loro se la sua ombra fosse uno spirito: "No, non è il tuo Itongo, ma dopo la tua morte diventerà l'Itongo, ossia lo spirito degli antemati dei tuoi figli.» Spesso gl'indigeni esitano di entrare in una stanza dove siano appesi ritratti "a causa delle anime che si trovano nei ritratti.» I Wasu risposero a Daunholtz: "Ciò che vien diviso dal corpo dopo la morte è l'ombra.» Un racconto simile ha fatto anche Nyendal sui Bini: "Essi chiamano l'ombra dell'uomo "passeggiero» oppure "guidatore», e da essa appare se l'uomo ha condotto una vita buona o malvagia.» Anche qui dunque, troviamo la concezione dell'ombra, cioè l'anima del ritratto. Cosi dissero anche i Bini ad Appert: "Le immagini delle ombre degli antenati appaiono al dormiente.» Siffatte concezioni fanno ricordare l'importanza che gli Egizî davano al $\mathrm{Ka}$. La concezione magica della rappresentazione dell'uomo e la relazione degli antenati con l'animale t o te $\mathrm{m}$, spingono con facilità l'artista a forme miste religioso-fantastiche. La rappresentazione di un antenato prende forma di ritratto più o meno definita, secondo che l'immagine del defunto è più o meno forte. Non di meno conosciamo effigi autentiche di viventi. Così, secondo la tradizione di Bakuba, il capo Shamba Bulongongo si fece erigere, quand'era ancora in vita, una statua, perchè le generazioni future si ricordassero di lui e trovassero conforto nel rimirare la statua nelle grandi sventure; è degno di nota che le statue di viventi erano erette coscienziosamente, giacchè venivano considerate come statue di antenati per i posteri. Così le effigi in bronzo degli antenati di Benin furono quasi certamente 
nello stesso tempo anche ritratti. Una quantità di teste di data recente è stata trovata sugli altari Juju. La antiche opere in bronzo sono state scoperte dai membri della spedizione punitiva inglese e son rimaste dimenticate, come se si trattasse di vecchiumi.

Tavola 6. - Forse è un ritratto come nella tavola 7. Questo bronzo può rappresentare una nobile o una principessa. Ciò si deduce dal numero dei vezzi di corallo che distinguono la nobiltà presso la gente di Benin. Infatti essi festeggiano come una delle loro feste più importanti, la festa del corallo alla presenza del re, il quale generalmente non si esibisce al popolo. Vengon fatti allora sacrifizi ai coralli che si spruzzano col sangue delle vittime decapitate. È giunta fino a noi una preghiera che il re pronunziava sopra $\mathrm{i}$ coralli consacrati col sangue: "O perle, quando io $\mathrm{mi}$ adorno di voi, datemi saggezza; non permettete che mi siano vicini nè Jugu nè cattivi stregoni.» Su la testa, la principessa ha un diadema di perle in forma di rete, sul plinto è riprodotto un animale simbolico della stirpe nobile, cioè un pesce. La testa rivela l'arte ritrattistica dei Beniniani nella sua perfezione. Nonostante la diversità del materiale e del tempo a cui esse risalgono, noi riconosciamo un legame fra quest'opera e le teste di Camerun, che sono scolpite in legno e ricoperie con pelli d'animali, specialmente con quella di antilope.

Tavola \%. - Prima di tutto si osservi l'asse obliqua del viso di bambino. Noi troviamo questo sistema di condurre l'asse in alcune teste in terracotta di Joruba, e specialmente nelle sculture di Majombe, che mostrano spesso delle simiglianze con lo stile degenerato di Benin. Antichi autori hanno già dimostrato che tra Benin e la maggior parte del Congo esistevano rapporti marittimi. Anche qui manca un forte contrasto di direzione tra la posizione verticale del mento e l'asse obliqua del volto. L'opera è fusa a parete sottile e sembra che appartenga alla serie delle opere più antiche. Abbiamo ragione di credere che nell'Africa fossero apprezzate sopra tutto le opere fuse a parete sottile. Io mi ricordo di una tradizione di Bakuba, secondo la quale due personaggi di sangue santo lottarono per il titolo di capo. E la vittoria doveva arridere a colui che avesse saputo fondere una lastra di metallo più sottile di ogni altra.

Tavola 8. - Opera notevole di cui non si conosce il significato. Gli occhi messi in piano, la forma del naso, della bocca e di tutto il viso ricordano molto le teste di Majombe. Una simile posizione degli occhi si osserva nelle opere di Urua. L'acconciatura del capo ci richiama lontanamente alla memoria le maschere di Camerun, nelle quali l'acconciatura è molto ben decorata e di dimensioni anche maggiori.

Tavole 6, 7 e 8. - Rappresentano lavori che dànno l'impressione di ritratti. L'arte africana modella con grande varietà di forme il suo ricco patrimonio artistico che sta fra il ritratto individuale e la semplice rappresentazione magica, cioè il 
simbolo. Il ritratto è ispirato dal culto degli antenati, che spinge l'Africano a un'attività continua nel campo dell'arte ritrattistica. Nelle rappresentazioni degli antenati si arriva talvolta fino ad abolire l'immagine, sostituendola con un simbolo e, invece degli antenati, si modella l'animale to te $\mathrm{m}$ o sincide un segno simbolico; questa sostituzione avveniva già nel tempo in cui si ritraevano i viventi e le loro effigi individualizzate. Le stesse attitudini ritrattistiche si possono osservare nelle maschere. In generale l'arte che si ispira al culto degli antenati, evita ogni dinamismo psicologico. Ciò è evidente anche nella plastica egiziana. L'idea della morte, che pervade queste creazioni, dà impulso al risorgimento dell'arte monumentale. Il compito di questi ritratti è quello di suscitare effetti magici; per riuscire a questo, l'autore si rappresenta $\mathrm{i}$ defunti con meravigliosa evidenza, e allora sorgono le magnifiche statue d'estasi, sorge il desiderio intenso d'ottenere dalla scultura una suggestione magica o religiosa e vien fuori un'opera che è piuttosto un medium magico che un ritratto. Questo simbolismo trova la sua corrispondenza religiosa nel totemismo: l'animale simbolo della nobiltà sostituisce l'antenato. Spesso il simbolismo fa prevalere la concezione fantastica al concetto oggettivo di parentela. Così vien costruita ancor oggi la capanna degli spiriti e, invece di un ritratto, viene innalzato qualche oggetto, al quale si commettono le forze magiche del defunto. Questi oggetti magici non possono spiegarsi animisticamente; non sono animati essi stessi, ma la forza dell'anima dell'antenato s'impadronisce di loro o abita in essi. Così comprendiamo, secondo la mentalità europea, le deviazioni dell'arte religiosa. Il concetto religioso può prendere uno sviluppo immaginativo straordinario, ma nello stesso tempo può esercitare un'azione distruttiva, dando luogo a immagini prive di forma plastica. È per l'appunto l'elemento fantastico, insito nella religione, che dissolve le forze nettamente plastiche onde vengono alla luce opere che possono trovare una giustificazione solo nelle credenze magiche.

Tavole 9 e 10. - Rappresentano due famose figure d'animali dei Bini. È interessante vedere come nella tavola 9 il paesaggio è disposto all'intorno a scopo decorativo. Noi scorgiamo in questa tavola un conseguente parallelismo. $\mathrm{Si}$ osservi la rotazione dell'asse intorno al corpo degli animali. La posizione dell'anca posteriore è ritratta in modo esatto in superficie. L'anca, la gamba posteriore e la coda sonc rotate lateralmente. Questi rilievi di animali, come pure la rappresentazione plastica dei leopardi, sono così indipendenti dal punto di vista artistico e hanno così compiutamente in sè stessi la loro ragion d'essere, che guardandoli si pensa appena di trovarsi davanti a oggetti religiosi. Tuttavia la religione africana cinsegna che anche queste figure di animali, nonostante un giusto naturalismo, si devono ricollegare alle intuizioni mistiche del totemismo e al culto degli antenati.

Tavola 11. - Una maschera Ekoi. A proposito di questo lavoro mirabile cito due motti degli Ekoi, che tolgo dall'opera di Ankermann; gli Ekoi hanno descritto 
gli spiriti dei morti in questo modo: "Quando il corpo dell'uomo si decompone, da esso si forma una nuova immagine, che è in tutto simile all'uomo, quando era ancora sulla terra.» $\mathrm{Ma}$ di rado una maschera africana è così mirabilmente naturalistica. Noi sentiamo tuttavia dinanzi a questo tondo di legno che esso dovrebbe rassomigliare in tutto all'uomo, quando era ancora sulla terra, così da poter dire come gli Ekoi: "Essa voleva esprimere la forma dell'anima, concentrandola in un piccolo spazio.» La maschera si avvicina per qualche rispetto ai rilievi di Benin; certamente, però, io non conosco nessun lavoro benininano in cui la bocca sia rappresentata cosi al naturale. Qualche cosa di simile si riscontra nei lavori dei Juju di Camerun, nei quali si trovano denti lavorati con diligenza particolare. Gli Ekoi abitano lungo il Grande Fiume, e così questa maschera può essere per qualche aspetto considerata come un anello di congiunzione tra Benin e Camerun. Dalla tavola 12 fino alla tavola 20 ci vien concesso di gettare un colpo d'occhio sull'arte del Grasland di Camerun. La cultura aulica e campanilistica di Benin, ormai tramontata, è, nella forte terra rustica, pervenuta ancora una volta a forme possenti, e la tradizione della costa, già in decadenza, s'è rinnovellata in un tardo arcaismo. Gli abitanti del Grasland sono fuggiti dalle minacciose bufere del settentrione nel tranquillo rifugio di Camerun, e insieme con i fuggiaschi è probabilmente venuta a Grasland la tradizione dell'arte dei paesi della costiera. Questa civiltà rustica di Camerun fa l'impressione di un idillio preomerico. L'arte posteriore a Benin è superione per raffinatezza e per abilità tecnica; ma a Camerun l'arte ha trovato la sua naturale risoluzione nelle grandi forme costruttive e si è creata uno stile in corrispondenza coll'ambiente mutato. Vengono ripristinati i semplici possenti temi dell'arte originale africana; non si modellano più $\mathrm{i}$ fini ritratti di cortigiani e di nobildonne; la sana fantasia rustica ritorna, lontana da aberrazioni, alla forma costruttiva e agli antichi temi. La plastica architettonica delle città di Benin si esprime in figure rustiche e il motivo africano della maschera e l'inizio della danza vengon concretati instancabilmente in grandi tipi. A Benin s'è giunti a un'arte complessa rispondente ai molteplici aspetti della religione. A Camerun si facevano opere in cui appena appariva il rituale senso del ballo; si incidevano di nuovo maschere, si innalzavano immagini di antenati, che venivano a ballare di notte, si modellavano teste secondo vari motivi che indicavano in modo chiaro il culto del teschio. Senza dubbio le teste di Benin dovevan la loro origine al culto del teschio a al culto degli antenati e a questi servivano; tuttavia esse fanno parte per se stesse, spesso ci ricordano poco o niente il culto e non ci appaiono più come espressioni di un'arte interessata, dandoci una netta impressione di qualche cosa di africano. Queste opere in bronzo mancano di originalità di costruzione e rivelano una meticolosa leziosità accademica. Sono manierate, ma non stereotipate; di una tecnica pienamente classicista, ma non di una rigorosità canonica e perciò piacciono anzitutto all'errabondo spirito eunopeo. A Camerun si plasmavano maschere che ci dànno l'impressione di solenni cappelle di morti e mostrano come il 
sottostrato del sentimento religioso di timore e di esaltazione fosse ritornato alla superficie nella semplice campagna.

Tavola 12. - Questa maschera non ha nulla di comune col ritratto di Benin; è un'opera artistica che deve servire da testa e dev'esser portata dal ballerino. Quì non abbiamo piani uniti con armonia; il cranio è costruito semplicemente. Questo lavoro precede in un certo senso il Cubismo; le sopracciglia sono smerlate a sesto acuto, i globi dell'occhio hanno la forma di palle elittiche, il naso fa da legame alle parti separate, le guance si dividono per dar luogo alla bocca, per mezzo della quale il ballerino respira; il coperchio del cranio è montuoso. Sulla sommità del capo sta adagiato l'animale to te $\mathrm{m}$, il ragno. $\dot{E}$ mirabile come questo animale, che $\dot{e}$ stato spesso usato come decorazione elegante, viene quì riprodotto plasticamente. Dietro l'animale si trova l'acconciatura formata da due palle intagliate e smerlate. Dal punto di vista della composizione la maschera mostra lo stretto legame esistente tra l'antenato e l'animale simbolo della nobiltà. Una grande distanza passa tra il tondo individualizzato delle maschere degli Ekoi e questo lavoro. In quello è la psicologia e l'uso di espedienti plastici, in questo è il tentativo vittorioso di ricondurre ogni parte al suo elemento cubico.

Tavole 13 e 14 . - Una maschera di grande formato. Il volto è diviso in significanti parti plastiche. Mentre la maschera col ragno è fatta di legno duro, qui l'artista ha scelto un legno morbido e può perciò permettersi d'essere audace, anche levigando la materia nelle singole parti. Considerando il viso come un cubo puro, la sfera della parte occipitale si stende in un piano un po" incurvato, ciò che permette all'artista di raggiungere il contrasto fra il volume esteriore e la superficie sovraccarica d'ornamenti. La divisione dell'acconciatura arriva fino al cono nasale. Questa maschera offre un efficace esempio del modo con cui l'artista africano sa servirsi del volume naturale per raggiungere forme coscientemente volute. Ricordiamo ancora altri tipi di maschere di Camerun, che non possiamo riprodurre per mancanza di spazio. Troviamo a Camerun la maschera doppia, la testa di Janus, un motivo che abbiamo notato a Kasai, nei calici di Bakuba, i quali senza dubbio servivano al culto del teschio. Un simile tema vien trattato dagli artisti di Camerun con grande libertà plastica; essi raffigurano uomo e donna, messi schiena contro schiena, strettamente uniti per la composizione, come le maschere. Poi troviamo grandi maschene che hanno una acconciatura ornamentale, potremmo dire una specie di corona, spesso formata da animali t o te m accoppiati. In altri casi la forma d'animale si perde nella forma ornamentale. Io credo che l'acconciatura fatta a guisa di un'immagine d'animale appartenga all'arte più antica, ancora annebbiata dalle antiche rappresentazioni dell'animale tote m. L'animale è spesso accovacciato sulla maschera, sulla testa dell'antenato; vi sono alcune raffigurazioni nelle quali possiamo ancora, da certi 
ornamenti, riconoscere le mani che tenevano l'animale to tem. A questo proposito faccio osservare che nel Congo, sulla maschere che deve rappresentare l'antenato, il più delle volte, invece dell'animale tote $\mathrm{m}$, viene raffigurata l'effige di un antenato più lontano (v. tavola 46); quì si tratta senza dubbio di un'interessante scelta di pali, su cui sono impresse immagini d'antenati. Noi troviamo riproduzioni d'animali simboli della nobiltà, come pure di teste di antenati, specialmente nel Camerun, sui pali che venivano messi dinanzi alle case dei Juju e dei capi, in onore degli antenati, per vigile difesa. Ho già parlato dell'affinità tra le corone-maschere e le corone di bronzo o d'avorio di Benin, che forse si approssimano a fibbie. Simili affinità troviamo ancora a Taganjika (v. tavola 42). Le belle e lavorate maschere di animali in bronzo di Benin le rivediamc in una semplice tipisezione a Camerun. Esiste forse un legame anche tra la testa di montone di Schango di Joruba e la maschera di montone del Grasland, come pure un legame crediamo vi sia tra la testa di bronzo di Olokun e le corone-maschere di Camerun. Non è del tutto impossible che la composizione di ballo (tavole 13 e 14) sia una variante delle corone-maschere.

Tavola 15. - Questa maschera ci riporta senz'altro all'antica tradizione di Benin. Uguale la tecnica dell'occhio e della bocca. Presso i Bini, bellezza raffinata e delicata congiunzione dei piani, presso i contadini di Camerun, ritorno alle grandi forme ispirate dal fanatismo. La divisione della testa in due zone vien fatta risaltare con una colorazione in bianco. Il bianco doveva avere significato religioso, perchè ancora oggi, mentre si fanno le funzioni religiose ,le immagini degli antenati vengono ricoperte con terra bianca, detta pembe, e anche quelli che pregano si coprono il corpo con segni bianchi.

Tavole 16 e 17. - Due vasi per olio di palma. L'africano è il trafficante d'arte per eccellenza. L'arte laggiù non va per un solitario cammino; il vaso e la scultura formano un tutto indiviso. La circonferenza del vaso (tavola 16) ripete il motivo del pesce a spirale. Questi pesci noi li abbiam veduti nelle opere di Joruba e di Benin, dove molto spesso si trovano riprodotti. L'animale sul coperchio ha una direzione contrastante. Questi animali to tem servivano a proteggere il contenuto del vaso, il cibo e colui che lo mangiava.

Tavola 17. - Tutti e due i portatori del vaso ci ripetono un motivo africano. Gli abitanti di Camerun raffigurano molto volontieri un uomo e una donna, messi schiena contro schiena. A Camerun molto spesso si trova raffigurata una donna che tiene un piatto per vivande o un vaso per vino di palma. La tavola 33 mostra che il motivo di quest'opera domina tutta la regione dell'Africa occidentale fino a Tanganjika. Riguardo a questo lavoro si potrebbe pensare a un motivo religioso, forse 
a una Cerere. A Camerun si ritrae anche spesso una madre col figlio in braccio; pure questo motivo non è di una singola provincia artistica, ma di tutta la regione dell'Africa occidentale. Degni di speciale considerazione sono i lavori rappresentanti madre e figlio; li troviamo presso le genti di Vatchivokoe e di Kasai.

Tavole 18 e 19. - Queste tavole dànno saggi della plastica architettonica di Camerun. Le porte e le finestre delle case dei capi, come pure di quelle dei Juju, vengono adornate plasticamente. Le composizioni si adattano alla forma architettonica. Gli antenati sono rappresentati come custodi, stanno uno sopra l'altro, come nei pali innalzati in onore degli antenati, e si protendono nell'entrata della casa da entrambi i lati dell'architrave della porta. A capo della fila degli. antenati sta seduto l'animale totem. La tavola 19 rappresenta $\mathrm{i}$ frammenti di una porta; ancora figure di custodi, uniti per mezzo di una traversa, sulla quale si scolpiscono maschere oppure animali totem. I pali formati dalle effigi degli antenati sono di un semplice parallelismo e le immagini, di uomo e di donna, variano quasi all'identica maniera. La plastica architettonica trae forse origine da un antico stile architettonico africano, perchè a stento si può accettare la supposizione che, dalla costruzione di capanne primitive, possa esser nata una plastica architettonica con caratteri cosi grandiosi. L'arte di Camerun si volge per tutti i riguardi verso la civiltà costiera degli antichi regni dell'Africa settentrionale, la tradizione dei quali s’è rifugiata e conservata a Camerun.

Tavola 21. - Questa testa è un saggio dell'arte dei Fan, chiamati anche Mpangwe. Di essi conosciamo una serie di teste cosi lavorate da colpire profondamente. Ho veduto due generi di lavori dell'arte dei Mpangwe. In primo luogo alcune teste dall'acconciatura ricadente in giù. Il capo è un triangolo concavo, il mento è plasmato a forma di cuneo nella parte anteriore, il collo è un cilindro rotondo, l'acconciatura piatta e ricadente a mo' di cuffia fa da sfondo alla testa, posteriormente. Si dice che i Fan siano venuti dal Nord-Est e lo confermano le opere del Sudan meridionale, che hanno punti di contatto con le sculture dei Fan. In modo del tutto' originale sono trattati nelle teste dei Fan gli occhi con le orbite scavate nella testa. E presso quella tribù troviamo un altro genere di scultura, che si ritrova anche più lontano fino al Congo. Si tratta di sculture in legno; le loro teste sono per lo più simili al frammento riprodotto, mentre i corpi hanno uno stile notevolmente barocco. Le membra girano a spirale, a forma di vite. Degna di particolare studio è la mitologia strana e bella delle tribù dei Mpangwe.

Tavola 22. - Un saggio dell'arte del sud-ovest del Congo. La testa di piccole dimensioni è collocata sopra uno zoccolo adorno, a mỏ di bastone, il cui significato è sconosciuto. Nel Museo etnologico di Berlino si trovano bei saggi dell'arte dei 
Vatchivokoe. Accanto all'arte costiera in decadenza notiamo alcune statuette del territorio dei Vatchivokoe, statuette che appartengono alla scultura veramente originale dell'Africa. Ricordo, tra le statuette conosciute di questa regione, quelle mirabili intitolate "Madre e figlio». Così ritroviamo nel territorio dei Vatchivokoe un motivo che è stato elaborato a Camerun, e più tardi fissato nell'interno del Congo belga, specialmente presso i Bahuana nel distretto Lualaha-Kasai. I motivi delle tavole del ciclo artistico dell'Africa occidentale sono simili nel loro complesso. La bellezza dell'arte dei Vatchivokoe ci rivela il tramonto di un'età antica. Forse queste sono le reliquie dell'arte dell'impero del Congo. Sulla loro origine c'è poco da dire. I Vatchivokoe, secondo le relazioni del Dottor Schachtzabel, loro profondo conoscitore, vennero, come i Baluba, dal sud-est nel Congo, sotto la pressione della migrazione dei Dschagga. Questa migrazione ha certo avuto luogo nel sedicesimo secolo. Sarà difficile stabilire se l'arte dei Vatchivokoe, come pure quella dei Baluba, sia venuta con queste tribù dal sud, oppure se gl'immigrati si siano impadroniti di un'arte che già esisteva, presso la foce del Congo e dell'Urua. C'è poi affinità tra le statuette "Madre e figlio» del territorio dei Vatchivokoe e le statue dei capi dei Bakuba, una delle quali è riprodotta nelle tavole 38 e 39. Potrei fare osservare un frammento dell'arte dei Vatchivokoe, posto nel Museo etnologico di Berlino, cioè una statuetta rappresentante un uomo che sta sopra una tartaruga. Questa statuetta di legno mostra una tecnica dei dettagli simile a quella delle opere di Benin e rivela un certo naturalismo psicologico che contrasta, riguardo allo stile, con gli oggetti religiosi, per esempio con la custodia da specchio, posta nella statuetta. Questa custodia da specchio serve al mago per gli scongiuri. In essa dovrebbe esser racchiusa la potenza magica della statuetta, il Ndozi. Quando s"interroga la statuetta, essa risponde con debole voce umana. Numerose statuette di data più recente e di minor valore si trovano ancora alla foce del Congo, statuette in cui sono infissi degli uncini. Ecco un"invocaziona che spiega il significato di quest'usanza. Si dice a questa statuette: "Se N. N. è portatore del male, trafiggi il suo corpo con la punta dei tuoi uncini e fa che torni sotto terra.»

Ora veniamo all'arte dell'Africa centrale del bacino Congo-Kasai, centro artistico dei Bantu, dove dal punto di vista stilistico si è creata la più pura arte africana. Gli esaurienti lavori di Ankermann permettono di stabilire relazioni tra queste tribù. Esploratori tedeschi hanno per i primi scoperto le importanti tribù del territorio di Kasai, la Baluba e la Bakuba. Wiszmann scoprì la tribù Baluba sotto la guida di Kalamba che, sostenuto da sua sorella, voleva introdurre il culto della canapa. I vassalli e i sotto-capi furono costretti a distruggere le loro antiche immagini di antenati e il culto di Riamba soffocò le antiche usanze; si cominciarono a distinguere due generi di divinità: gli dei dell'Oriente, fumatori di canapa, e i falsi Dei dell'Occidente, che vengono riprodotti in immagini 
che non fumano. I Baluba non sono gli abitanti originari del loro territorio. Essi provengono dal sud-ovest, probabilmente dal medio Zambesi, al principio del $16^{0}$ secolo, sotto la spinta dei Dschagga. Baluba significa gente di Luba, cioè del grande mitologico fondatore dell'impero; Luba significa malattia, difetto, errore. Oltre questa grande migrazione abbiamo anche una serie di migrazioni laterali, che portarono alla divisione della gente Baluba in Bena Luluas (Baluba occidentale) $\mathrm{e}$ in Bahemba (Baluba orientale). I Baluba orientali fondarono il regno di $\mathrm{Ka}$ simba nel territorio Urua (circondario di Katanga). Là non è penetrato il culto di Riamba, così che v'era una serie di statue molte più numerosa che presso i Baluba occidentali. I migliori frammenti dei Bena Luluas ci sono pervenuti grazie alla spedizione Wiszmann. Sono figure di antenati dei grandi capi. La statua della tavola 23 è stata acquistata da Wolff. Egli l'ha tolta a un Baluba, un sottocapo ribelle, il quale ha detto che rappresentava Makabu Buanga, dio tutelare dei Baschilange. Il capo quì riprodotto porta, come segno della sua dignità, una spada a forma di tridente e intorno alle anche ha una pelle di leopardo. Questa figura ci dà un saggio dell'antica arte di Kasai. Vuol ritrarre un Buloweh, un inviolabile principe di sangue santo, dio tutelare della razza e dell'affinità di sangue, forse l'uomo che ha guidato i Baschilange alla conquista dei luoghi in cui ora risiedono $\mathrm{e}$ in cui hanno costituito le loro tribù. Così questa figura può essere il simbolo dell'indipendenza delle tribù del Baschilange. Ovunque, presso i Bantu, si trovano questi grandi condottieri, che spiccano tra tutti per il loro spirito ribelle e che trascinano seco un gruppo di seguaci. In questi Bulowehs si cristallizza la storia delle tribù; il capo è di origine soprannaturale, è in relazione con forze divine e la genealogia dei capi corrisponde alle storia delle tribù. A nostro parere si può ricostruire una storia molto limitata da simili genealogie. perchè $\mathrm{i}$ capi per lo più hanno gli stessi nomi. La storia delle tribù non è altro per quelle regioni che la genealogia dei capi e si limita a una cronaca dei $\mathrm{Bu}-$ loweh. L'unità della civiltà di Kasai si manifesta nelle relazioni di parentela delle famiglie dei Buloweh. Questa civiltà è civiltà proveniente dai Bantu e venuta con essi nel territorio del Congo, perchè la tradizione di queste tribù attesta che prima di loro abitavano in quella regione $\mathrm{i}$ Batuas, popolo cacciatore, di piccola statura, - i piccoli vinti delle montagne. - I Buloweh conservano i t o te $\mathrm{m}$ simbolici e i feticci della tribù a cui è legata la Bufumuh, cioè la dignità di capo. Così si può dire che il capo dei Baschilange, con la consegna della Makabu Buanga, ha perso la sua autorità di capo, la sua Bufumuh, nel senso deil'antica tradizione. Wiszmann riportava anche qualche frammento di quest'arte, per esempio un feticcio femminile, difesa dei campi, una donna che porta un mazzo e una buccia di maniok. Queste statue sono immagini di antenati e appartengono alla classe dei Mikisi Mihasi, sono cioè ritratti eseguiti in memoria dei morti e portano il loro nome. Questi ritratti vengono anche detti Bimnvekelo, cioè la 
"sembianza»; vengono eseguiti da determinati scultori chiamati Bwana Mutumbo. In tutta l'Africa vi sono scultori ufficiali di feticci. Spesso queste opere artistiche vengono anche chiamate Ndozzi, che significa pressapoco "corpi astrali» e si dice che in esse si conservi l'ombra del defunto. I morti, per mezza dell'opera artistica, conservano in qualche modo la loro persona. Chi sopravvive si lamenta innanzi alla statua: "Miseria, miseria è sopra di me; ho perso quello che amavo la mia gioia; quello che mi dilettava con le sue parole, quello che mi consolava col suo aspetto, non c'è più. Infelicità sopra di me. Che sarà mai di me? Spiriti crudeli, voi che me l'avete rapita fatemi morire. Spiriti tutelari dell'amato, spiriti tutelari miei, ridonatemelo; perchè io muoio, sono già morta.» Il solitario defunto si lamenta: "Signore, io sono afflitto e senza amici nella terra dei morti. Desidero ardentemente d'avere accanto a me l'amico che amavo, desidero d'aver la pace che può darmi solo la sua amicizia, dolce consolazione in questa fredda, umida terra.»

Presso la statua avviene la comunione tra il superstite e il morto; per suo mezzo si conserva l'immagine dell'ombra del morto, per suo mezzo si conserva il suo nome, che passa a un neonato. La vita si perpetua nell'effigie; quando i Baluba si ungono con l'olio, ungono anche la statua. Ballano dinanzi ad essa e, coll'animale tote $\mathrm{m}$ in mano, le rivolgono la parola: "Noi balliamo con gli antenati, o madre, essi ballano separatamente.»

Durante il novilunio i Baluba espongono i feticci alla benefica luce della luna, li spalmano con terra bianca, il colore degli spiriti, e dipingono anche il loro corpo con lo stesso colore. Le statue portano il nome del defunto.

Nella tavola 23 riproduco il Makuba Buanga, un raro frammento antico. Involontariamente si pensa, davanti a questa statua di capo, alle riproduzioni di cavalieri di Benin. Anzitutto le si avvicinano dal punto di vista puramente tematico; questo motivo veniva spesso usato a Benin. Il guerriero ritto, con l'elmo, con la spada in mano, con lo scudo nella mano sinistra, col vello di leopardo e con l'amuleto sul petto è un soggetto che abbiamo veduto a Benin. I Baluba forse se ne sono impadroniti prendendolo da una tribù emigrata dal nord; o forse il centro artistico dell'Africa occidentale si è spinto sino a Sambesi. Ad ogni modo, noi troviamo presso i Baluba occidentali, come presso quelli orientali, motivi che abbiamo già trovati a Joruba, a Benin e a Camerun. Qua e là si sarebbe anche tratti a pensare che i Bacuba avessero portato quest'arte dal nord; essa in ogni modo non appartiene alla popolazione originaria della foce del Congo.

Nelle tavole 24 e 25 sono riprodotti due antichi tamburi dei Baluba e anche per questi dobbiamo esser grati alla spedizione di Wiszmann. I due tamburi rivelano una caratteristica generale dell'arte africana; l'opera d'arte serve laggiù a un determinato scopo pratico. È difficile decidere quando il negro pensi di servirsi di un'opera d'arte oppure quando il feticcio esplichi, indipendentemente, 
in una certa misura, una funzione. $E$ spesso può essere l'una e l'altra cosa insieme. Gli abitanti di Kasai distinguono due generi di statuette: le Mikisi Mihasi, delle quali abbiamo già parlato, e quelle puramente magiche, le Mikisi Mihake, vale a dire statuette che sono dotate di mezzi tali da potere esercitare la magia. In queste l'equa rappresentazione di un' immagine, che richiami alla memoria qualche cosa d'individuale, cioè l'antenato, ha poca importanza, giacchè esse servono anzitutto come strumenti del mago. Si traforano per mettervi dentro alcune medicine, si adatta al loro corpo uno specchio (p. e.), perchè si possa così guardare il nemico durante lo scongiuro, oppure si mettono nella loro testa aperta doni di consacrazione. Una di queste statuette viene (p. e.) interrogata come se si trattasse di un oracolo, mentre essa risponde con un sibilo sottile attraverso i denti, con debole voce di bimbo. La giusta esecuzione dell'immagine viene posposta allo scopo magico. Questa credenza nella magia sembra che sia una degenerazione del culto degli antenati e, se osserviamo queste immagini create per operare la magia, dobbiamo constatare che le statue di antenati, eseguite per lo più in istili più antichi, rivelano un congegno più forte delle statuette magiche. E possibile senza dubbio che il capriccioso negro butti subito via o distrugga il suo feticcio, se non ha raggiunto lo scopo magico. In oltre queste statuette vengono molto spesso tagliate a pezzi e gettate nell'acqua bollente; esse hanno il potere d'individuare e di uccidere un nemico, per mezzo di questa procedura. Il voler ordinare le sparse opere africane in uno schema è rischioso. V'è abbondanza di transazioni e di formazioni oscure e ibride. Ho parlato di queste figure magiche solo per mostrare come poco esauriente sia il nostro lavoro.

Un'antica leggenda dei Baluba cerca di spiegare l'origine delle Mikisi Mihake: «Un giorno Ngoi, uno spirito, andò a trovare Nkulu; gli disse: Grande spirito, non vedi tu come sono miseri gli uomini?! Malattie, guerre, carestie li tormentano ed essi sono privi d'aiuto. Dammi un rimedio per queste sofferenze. Nkulu acconssenti alla domanda. Egli prese dal fondo del mare di sale, suo luogo di residenza, una statuetta lunga un pollice, destinata a servire come saggio (Kanon). Ngoi, disse, ecco qua l'infallibile rimedio contro ogni sofferenza. Va e di agli uomini che essi possono crearsi dei feticci come questo. Dopo riportamelo.»

Ngoi eseguì a perfezione il comando. Chiamò il mago Bwana Kilumba e gl'insegnò a preparare statue simili. Il mago creò diverse imitazioni, poi consegnò a Ngoi la statua modello e Ngoi la riportò a Nkulu.

Nkulu forniva il sapere, le formule magiche, gli oggetti che si dovevan mettere nei feticci; egli determinò la forza degli spiriti e comandò ai morti di esser loro compagni.

I tamburi delle tavole 24 e 25 erano certamente insegne della dignità di capi o parti del Bufumu. Richiamano alla memoria i tamburi di Benin, come 
sono riprodotti da Ling Roth, e inoltre fanno ricordare un tamburo di Bakuba, che è esposto nel Museo etnologica di Amburgo. Il legame tra figura umana e oggetto a fine pratico si riscontra in tutta l'Africa; un'affinità speciale esiste tra queste opere e $\mathrm{i}$ calici-teschio di Bakuba, dove spesso e volentieri si dava la forma di calici a intere figure umane, in qualche modo stilizzate e raccorciate. Lo stretto legame tra figura umana e oggetto si giustifica con gli antichi culti. Noi conosciamo un'antica leggenda dei Bakuba sull'origine di questi tamburi: "La depravata moglie di un $\operatorname{Re}$ ha commesso adulterio con un uomo di umile origine ed è stata colta in flagrante dal marito. Questi si adirò violentemente, si mise agli angoli della bocca alcune piume del ciuffo di un aquila, si gettò sull'adultero e lo amazzò col suo coltello. E quando il popolo domandò che cosa fosse avvenuto di quell'uomo, il re rispose: «Kojnahula, il leopardo del villaggio lo ha divorato.» $\mathrm{Da}$ quel tempo si fanno olocausti umani al suono di questi tamburi.» $\mathrm{Nel}$ tamburo della tavola 25 sorprende che gli orecchi, i quali nel tempo stesso servono da manici, siano fatti a guisa di c ro ci $\mathrm{K}$ at ang a. Queste noi le conosciamo dall'arte copta e dall'abissina.

Nelle tavole 27-34 noi riproduciamo lavori dei Baluba orientali, che abitano nel circondario Manijema, presso la Tanganjika. Dinanzi a queste sculture noi dobbiamo riconoscere la nostra ignoranza. $\dot{E}$ cosa oltremodo difficile riuscine a saper veramente qualche cosa di esatto sul significato di esse. Le antiche tradizioni africane, per quanto abbiano trovato forme salde, si sono dissolte in un'infinità di credenze magiche e spiegazioni arbitrarie; prive di significato, hanno offuscato le antiche regole. I residui dell'antica tradizione si trascinano forse ancora nelle cerimonie delle società segrete, dove gli aderenti si servono di una lingua arcaicizzante, dove sistemi totemistici hanno tuttora salde forme e ogni feticcio porta un simbolo particolare, al quale è legato un determinato senso. Si conosce un numero considerevole di simboli di statue, di usanze totemistiche, di società segrete, ecc, del territorio di Urua. A questo proposito l'informatore più attendibile è Pater Colle. Se confrontiamo però i simboli dei feticci, adoperati nelle società segrete, con le statue più antiche, allora dobbiamo riconoscere che $\mathrm{i}$ nomi nuovi significano poco o nulla di quel che significavano gli antichi lavori artistici. Ho trovato una sola statua sotto il nome di feticcio delle sette segrete, e precisamente la figura della tavola 33, la donna accosciata, che vien chiamata Kabila, la mendicante oppure la figlia dello spirito. Pare che i lavori da noi riprodotti traggano origine dal tempo in cui il regno dei Baluba era dominato da un potere centrale e perciò predominava la religione delle tribù più forti, cioè un culto di corte. In generale vediamo che con lo sgretolamento del regno comincia il dissolvimento del canone artistico e delle forme religiose; le associazioni segrete poi sono addirittura un istituto antistatale, poichè si sottraggomo a ogni controllo. Infatti a Camerun capi molto influenti hanno combattuto con energia la formazione 
di società segrete. Probabilmente le rappresentazioni religiose, che osserviamo nelle nostre statue, erano di moda. Sembra che le tavole 27 e 28 siano i frammenti più antichi di Urua. .Frammenti più recenti dovrebbero essere quelli delle tavole 31 e 33; sono collegati tra loro dal punto di vista stilistico e il simbolo tematica della tavola 33 si conosce anche oggi in Urua. I due reggitori d'arco (Tav. 30) provengono da Urua. Questa supposizione è suffragata anche dall'acconciatura dei capelli. Il tatuaggio della figura sinistra, e più ancora la posa decorativa dei reggitori d'arco, richiama alle sculture dei Bena Luluas. Forse in questi lavori possiamo osservare qualche punto di contatto con i due stili dei Baluba; quest'affinità ci fa supporre che lo stile più antico dei Baluba sia sorto quando le tribù adesso divise abitavano ancora insieme. I Baluba portarono la loro arte dal nord nello Zambesi e di là introdussero il loro patrimonio di civiltà nel territorio di Kasai e in quello di Tanganjika. Il processo artistico dell'Africa occidentale sembra dunque che si sia diffuso fino allo Zambesi.

Tavole 35-39. - Le tavole 35-39 ci dànno saggi dell'arte dei Bakuba. Il primo esploratore che abbia visitato quel popolo è stato il Dottor Wolff, membro della spedizione di Wiszmann. Egli narra che quella tribù, fino all'epoca della sua visita, viveva in perfetto isolamento e si distingueva nettamente dalle popolazioni vicine. I Bakuba mostrano di possedere forti caratteristiche etiopiche. Secondo la loro tradizione, essi vengono dal nord; avrebbero dovuto passare quattro fiumi: Ubanghi, Congo, Busira e Lukenje. Contro questa leggenda sta il fatto che la loro ornamentazione si approssima all'arte di Joruba e, ancor di più, all'arte di Camerun, pùu vicino per posizione geografica. Si deve così probabilmente pensare che essi emigrarono dal nord e, ad ogni modo, non attraversarono il Grasland di Camerun. È certo che l'arte dei Bakuba mostra di avere più caratteristiche comuni con quella di Joruba che non con quella di Benin. Possiamo forse perciò considerare la migrazione dei Bakuba come anteriore al sorgere dell'arte di Benin da noi conosciuta. È caratteristico come, dove troviamo una forte arte africana, esistano tradizioni che attribuiscono a quest'arte un' origine nordica. Quando noi osserviamo i saggi d'Urua delle tavole 31 e 32, ci tornano alla memoria, senza allontanarci troppo, i seggi simili, a noi noti, della terra di Joruba e di quella di Camerun. L'uniformità dei motivi si spiega soltanto coll'ammettere che quei popoli abitavano un tempo più vicini gli uni agli altri, ciò che ci appare anche dalla direzione quasi identica nelle migrazioni delle tribù. $\mathrm{Ci}$ si potrebbe domandare se l'arte dei Baluba, e più ancora quella dei Bakuba, sia un'arte venuta da un'altra regione interna o se dipenda direttamente da un'arte costiera più antica di Loango e di Angola. Le opere esistenti dell'arte costiera del Congo dimostrano che questa congettura è senza fondamento. $\mathrm{Ma}$, soprattutto, i Bakuba mostrano di possedere marcate caratteristiche etiopiche e ben si distinguono dai vicini. I lavori dei paesi della costa più 
antichi poco somigliano ai lavori dei Bakuba. Pare che i Bakuba, spinti dal nordovest, abbiano portato seco la loro arte; del resto anche il patrimonio artistico della costa occidentale è stato introdotto in qualche modo dal nord. Tordaj ci ha dato diverse notizie intorno ai Bakuba Non mi arrischio a basarmi sui lavori di questo esploratore, perchè mi è stato riferito da un etnologo degno di fiducìa, rimasto per qualche tempo presso questa tribù, che, per esempio, tutta la cronologia della dinastia, così com’è fatta da Tordaj, ̀̀ sconosciuta all'attuale re Lukengo e ai suoi ministri.

I calici delle tavole 35, 36, 37 devono esser derivati senza dubbio dal culto del teschio. In questi calici-teste si mettono doni consacrati. Molto spesso vengono riprodotte figure umane in cui le gambe sono rattrappite e le braccia aderiscono strettamente al naso. Talvolta le teste sono poste sopra uno zoccölo decorato artisticamente. Come a Camerun troviamo spesso doppie maschere, cosi anche presso i Bakuba troviamo calici con due teste, che rappresentano uomo e donna (marito e moglie). Vi sono innumerevoli variazioni, dal calice in forma di testa fino al calice con semplice decorazione artistica. Nel museo «Congo» di Bruxelles si trova una statua di legno dipinto, di $139 \mathrm{~cm}$. d'altezza, che dev'essere senza dubbio anch'essa un lavoro dei Bakuba. Dal punto di vista stilistico si avvicina molto al calice della tavola 37; è ıperò di corpo più grosso, interamente coperto e decorato da un tatuaggio. Quella statua mostra che accanto al calice-teschio si eseguivano alcune statue libere in rispondenza allo stile del calice.

Nelle tavole 38 e 39 è riprodotta una delle famose statue di capi dei Bakuba. Per quanto sappia, noi europei ne possediamo due esemplari. Tordaj dice che la statua da noi riprodotta rappresenta il capo dei Bakuba Misa Pelenge, il quale regnò intorno al 1780 . In tutte e due quelle statue di capi, in quella di Bruxelles $\mathrm{e}$ in quella di Londra, ci colpisce la conformazione delle gambe molto gracili in confronto al corpo massiccio, ciò che ci ricorda le sculture di Urua (Tav. 27 e 29). La buona conformazione del volto avvicina questa statua alle figure di madri del territorio dei Vatchivokoe, già da noi esaminate. A giudicane dall'aspetto più composto, le statue di Bakuba si direbbero anteriori alle opere dei Vatchivokoe. Noi abbiamo già detto a tal proposito che il patrimonio artistico dei Vatchivokoe s'approssima ad alcune opere statuarie di Benin e forse, con grande cautela, potremmo per mezzo suo stabilire un ponte di passaggio tra l'arte di Bakuba e quella di Benin.

Nelle tavole 42, 43 et 47 si dànno saggi dell'arte d'incidere l'avorio nel Congo belga. La statuetta della tavola 43, rappresentante una donna accosciata, ̀̀ un tema tipico dei Bahuana. La tecnica e la decorazione delle membra ci riportano al piccolo frammento di Benin accosciato. La posizione rattrappita delle gambe si trova, per esempio, anche nella statua del capo dei Bakuba, come pure nelle figure femminili di Urua. L'Africano rappresenta spesso donne, partico- 
larmente quando la purezza del sangue gli viene dalla discendenza materna. I Bahuana hanno, riguardo alle loro statue, idee molto complicate, per noi oscure. Queste statuette hanno senza dubbio relazione col culto degli antenati; perchè $\mathrm{i}$ Bahuana dicono: "I feticci hanno il Doshi, cioè sono i messi degli antenati defunti. Il Doshi cosi riferisce Tordaj sta nell'aria, va a trovare $i$ suoi amici e a cercare fin dentro casa $i$ suoi nemici; perseguita $i$ suoi parenti, se il suo cadavere non è stato regolarmente tumulato. Adesso noi riusciamo ad intendere una breve preghiera: «Padri rniei, madri mie, allontanatevi dal bambino perchè possa prosperare.»

I piccoli lavori della tavola 32 sono, ad eccezione della statuetta femminile, incisioni in osso dei Warega, tribù che abita nelle vicinanze di Tanganjika. Oltre a piccole maschere dal viso in avorio, essi ne preparano anche altre di maggiori dimensioni in legno. Le statuette femminili della tavola 47 appartengono all'arte piccola dei Baluba orientali. E facile riconoscere che appartengono alla serie già riprodotta delle statue in legno del territorio Mamjema. Mette conto l'esaminare separatamente l'arte piccola, già fiorente e matura, che si svolgeva nel territorio sud-ovest del Congo fino a Tanganjika.

Nelle tavole 44, 45 e 46 noi riproduciamo maschere da ballo. La maschera è un antico soggetto africano. Già nel 1352 il viaggiatore arabo Ibg Batuta vide maschere e balli con maschere nel Sudan meridionale. Questo soggetto ha subìto infinite variazioni per opera degli scultori africani. La tavola 46 presenta una maschera del territorio di Kasai. Spesso viene raffigurato sopra la maschera un animale totem invece di una statuetta. A proposito della tavola 46 riferisco due leggende di Sankuru, per spiegare l'origine delle maschere: "Qualche tempo dopo le nozze di Samba Mikepe con Kashashi, questa ebbe un bambino. Un giorno Kashashi si allontanò dal villaggio per andare a cercare acqua e il bambino le corse dietro.» Ella gli disse: "Torna al villaggio e rimani con tuo padre, mentre io vado in cerca d'acqua.» $\mathrm{Ma}$ il bambino non volle ubbidire e, nonostante i rimproveri, continuò a tenerle dietro. Kashashi, per sorvegliare il bambino, versò la maggior parte dell'acqua e fu costretta a ritornare al fiume; ma ancora una volta il bambino si mise ostinatamente a seguirla. Le minacce, le punizioni, anche del padre, non approdarono a nulla. Il bambino gridò e pianse senza posa, finchè gli permisero d'andare con la madre. Kashashi era una donna ingegnosa e passò la notte a riflettere come avrebbe potuto impedire d'essere ostacolata nel suo lavoro. Finalmente trovò un mezzo. Sulla corteccia della sua "Calabasse» disegnò e dipinse un'orribile viso. Quando il bambino le corse dietro, ella si pose dinanzi al volto la «Calabasse» e si voltò. Il bambino ebbe paura: «Questa non è la mia mamma, ma uno spettro spaventoso! - gridò, e se ne ritornò di corsa al villaggio. Questa fu Kashashi, colei che inventò la maschera.» 
- Viveva una volta nelle acque uno spirito che si chiamava Mashamboj, il quale entrava nelle case del popolo con una malattia detta Goji. Quelli che erano afflitti da questa malattia perdevano la luce degli occhi e cadevano a terra come se avessero bevuto, poi morivano. Quando Bo Kona era capo, un uomo di nome Bokoboko andò nel bosco e vide improvvisamente questo spirito. Tutto spaventato egli ritornò di corsa al villaggio e raccontò quello che aveva visto. Bo Kona gli disse di descrivergli lo spirito, allora Bokoboko rispose: «Egli è così orribile da non potersi descrivere con parole; ma dammi tempo e mezzi e io te lo raffigurerò.» Bo Kona acconsentì, Bokoboko si costruì una capanna lontana dal villaggio e si mise a lavorare. Egli chiese un drappo fatto di corteccia d'albero, piume d'uccello e la pelle di un gran pipistrello. Bo Kona gli dette le due prime cose e ordinò alla gente del villaggio di cercare un pipistrello e, appena l'ebbero trovato, glielo mandò. Allora Bokoboko scolpì una maschera che riproduceva Mashamboj. Egli si servì per questo lavoro di due alberi, fabbricò due colori, uno giallo e l'altro nero; con questi colori e con la terra bianca dipinse la maschera che aveva fatto. Con drappo si fece un mantello e se ne ricopri. Questo mantello era molto ben fatto e aderiva perfettamente agli abiti. Era composto con piccoli triangoli di panno, colorati in bianco e nero e cuciti insieme. Poi che l'ebbe finito lo mostrò al re: "Ah!» disse il re «E proprio quello che mi ci vuole.» Alcuni giorni dopo sparì il re; le sue mogli e i suoi sudditi ne piansero la morte e si chiesero: «Dov’è il Nijni?» Quando il sole tramontò, apparve nel villaggio una cosa strana, mai s'era vista prima una cosa simile: il re con la maschera di Mashamboj. Ma nessuno lo riconobbe. Egli entrò ballando, mise una gran paura alle donne e ai bambini e finalmente sparì. Rimise allora la maschera e il mantello nel bosco e li nascose con gran cura. Poi andò con i suoi soliti abiti nel villaggio, dove fu accolto con profonda gioia. Donne e bimbi gli parlaronó delló spettro spaventoso che avevan veduto il giorno prima. "Io so che cos'era,» disse il Re. "Era Mashamboj che ci portava il Goji. E venuto per vedere se nel villaggio ci siano donne cattive e bambini capricciosi. Se ne avesse trovati, egli li avrebbe colpiti col suo male spaventoso. Allora le donne e $\mathrm{i}$ bambini hanno avuto una gran paura e hanno promesso d'essere ubbidienti e buoni.»

Nella tavola 48 riproduciamo la così detta scultura di Simbabye, un frammento che si trova nel Museo etnologico di Berlino. Si sono trovati nella Rödhesia meridionale edifizi pubblici indigeni in pietra e fortezze elittiche con torrette in forma di cono. L'olandese Dappert riferisce che il palazzo reale Simbaboe si trova a 5 miglia a ovest di Sofala. Il dominatore di questo paese, in cui si scavano miniere d'oro, viene chiamato Monomotapa, cioè «il signore dei monti» o «il signore del lavoro». Le notizie, intorno a quel paese eccitano in modo speciale la fantasia. Si crede d'avere scoperto la terra dell'oro Ophir o Punt. Prima si riteneva che queste fortezze fossero state erette dagli Egiziani, dai Fenici oppure dagli 
Arabi. Adesso si opina piuttosto che là abitassero popolazioni Bantu, le quali, per difendersi contro i popoli immigrati dal nord e contro le genti delle foreste, avrebbero costruito quelle fortezze. Ad ogni modo si sono trovati presso queste rovine due teschi ed alcune ossa e si è osservata una rasomiglianza tra questi teschi e quelli dei Bantu. In queste rovine si rinvennero accanto ad altri frammenti, come pezzi di pentole e oggetti d'ornamento, un notevole numero di sculture di steatite, che rappresentano avvoltoi appollaiati su lunghi pali di pietra. Gli oggetti trovati vicino a queste sculture non risalirebbero oltre il $14^{0}$ secolo. Quest'opera, che riproduciamo alla fine del nostro libro, mostra con rozza evidenza la complessità del problema, in cui ci siamo imbattuti esaminando l'arte africana. Dinanzi a questi frammenti di Simbabye ci vien fatto di ricordare un enigmatico frammento del Museo di Berlino, un antico palo di pietra su cui è raffigurata un immagine, dalla regione del Grande Fiume. Il fatto che il lavoro di Simbabye sia una scultura in pietra, non ci impedisce affatto di credere che si tratti d'una scultura africana. Si osservi prima di tutto l'alce che è stato messo sullo zoccolo della scultura rappresentante un avvoltoio. Sembra che il grande uccello tenga l'alce tra gli artigli e così si spiega la posizione opposta dell'alce. Una cosa ci pare molto importante. Noi conosciamo quest'alce appunto dalle pitture dei Boschimani; si confrontino col rilievo in pietra le pitture dei Boschimani, del circondario di Molteno, e precisamente i quadri menzionati nelle pubblicazioni Tongue. Anzitutto sorprende il legame esistente tra questo rilievo frammentario e il rilievo di pietra completamente simile della gente della foresta. Stow giudica l'arte dei Boschimani antica di 5 secoli e presso a poco una tale età le attribuiscono gli scultori di Simbabye. Il contrasto di direzione tra l'avvoltoio e l'alce è del tutto africano, come pure l'accoppiamento della scultura di tutto tondo col rilievo elaborato. La parte di rilievo di questa scultura mostra, nonostante la diversità della tecnica, una stretta relazione con l'arte di Boschimani e la concentrazione di forme comune ci fa pensare di trovarci dinanzi, per questa scultura di Simbabye, a un lavoro africano. 


\section{INDICE DELLE RIPRODUZIONI}

I. Una testa di montone: immagine di Schango, Joruba. $30 \mathrm{~cm}$ di altezza, legno, nel Museo Folkwang, Hagen.

2. Tavola Ifa, Joruba, $50 \mathrm{~cm}$ di larghezza, $30 \mathrm{~cm}$ d'altezza, legno. Collezione C. E.

3. A sinistra: una tavola di ornamenti della tomba di un Sacerdote di Schango, Joruba, alta $38 \mathrm{~cm}$, legno, nel Museo Folkwang, Hagen. A destra: un frammento d'avorio, Benin, Io cm d'altezza. Berlino, Museo etnologico, $\mathrm{III}^{0}$ C. $17-373$.

4. Effigie di Schango a cavallo; la portatrice è veramente la dea Oja, Joruba, I m d'altezza, legno. Berlino, Museo etnologico, III $^{\circ}$ C. 27-410.

5. Un frammento d'anguinaia di legno, Joruba, $30 \times 20 \mathrm{~cm}$. Berlino, Museo etnologico, $\mathrm{III}^{\circ} \mathrm{C} .27-235$.

6. Testa di donna, Benin, bronzo, $16^{0}$ secolo, $48 \mathrm{~cm}$ d'altezza. Berlino, Museo etnologico, $\mathrm{III}^{0} \mathrm{C}$. 12-507.

7. Testa di ragazza, Benin, $16^{0}$ secolo; Luschan indica questo frammento come - "Testa di ragazza rachitica con naso schiacciato », bronzo, $15 \mathrm{~cm}$ d'altezza. Berlino, Museo etnologico $\mathrm{III}^{0} \mathrm{C}$. $12-514$.

8. Testa, Benin, bronzo, $15 \mathrm{~cm}$ d'altezza. Berlino, Museo etnologico, $\mathrm{III}^{\circ} \mathrm{C}$. $\mathrm{I}_{2}-5 \mathrm{I} 3$.

9. Due pantere, rilievo in bronzo, Benin $30 \mathrm{~cm}$ di lunghezza, $20 \mathrm{~cm}$ d'altezza. Berlino, Museo etnologico, III $^{0}$ C. $18-486$.

ı. Pantera, Benin, bronzo, $48 \mathrm{~cm}$ d'altezza, $29 \mathrm{~cm}$ di lunghezza. Berlino, Museo etnologico, III $^{0}$ C. $10-877$

I I. Maschera, Ekoï, Groß-River, 26 cm d'altezza, legno. Berlino, Museo etnologico, $\mathrm{III}^{0} \mathrm{C}$. I2-606.

12. Maschera da ballo: un uomo con un ragno in testa, legno, Camerun, cam pagna di Bafum, territorio Mhang, $20 \mathrm{~cm}$ d'altezza, $22 \mathrm{~cm}$ di larghezza. Collezione C. E.

I 3 e I4. Composizione di testa fantastica, legno, Camerun, Bamendjo, $67 \mathrm{~cm}$ d'altezza, $52 \mathrm{~cm}$ di larghezza. Collezione privata.

I 5. Composizione di testa fantastica, legno, al N. O. di Camerun, Fungang, $38 \mathrm{~cm}$ d'altezza. Collezione C. E.

16. Un vaso da olio di palma da Wum, campagna di Bafum, Camerun, $37 \mathrm{~cm}$ d'altezza, $32 \mathrm{~cm}$ di diametro. Collezione C. E.

17. Un vaso di Wum, campagna di Bafum, Camerun, $36 \mathrm{~cm}$ d'altezza, $31,5 \mathrm{~cm}$ di diametro.

18. Pali di capanna di un capo di Bangu, Camerun, $3,20 \mathrm{~m}$ di lunghezza, $28,5 \mathrm{~cm}$ di larghezza. Collezione privata.

19. Cornici da porta della capanna del; capo Bangu a Camerun, I,85 m d'altezza, I,23 $\mathrm{m}$ di larghezza. Collezione C. E.

20. Un seggio di Bandenkop, suonatori di flauto, Camerun, $49,5 \mathrm{~cm}$ d'altezza, $47 \mathrm{~cm}$ di diametro. Collezione privata.

2r. Una testa, Congo francese, Pahouin, Gabon, $26 \mathrm{~cm}$ d'altezza. Collezione Paul Guillaume, Parigi.

22. Una testa con ornamento d'acconciatura, Vatchivokoe, Gongo belga, $35 \mathrm{~cm}$ d'altezza. Berlino, Museo etnografico, III $^{0}$ C. 778.

23. Una figura di feticcio della Baschilange, chiamata Makabu Buanga, $62 \mathrm{~cm}$ d'altezza. Berlino, Museo etnografico $\mathrm{III}^{0}$ C. 3246 . 
24. Un tamburo di Baluba, $120 \mathrm{~cm}$ d'altezza. Berlino, Museo etnologico III ${ }^{0}$ C. 2672.

25. Un tamburo di Baluba, $100 \mathrm{~cm}$ d'altezza. Berlino Museo etnologico $\mathrm{III}^{0}$ C. I962.

26. Figura di ragazza, Urua belga, $48 \mathrm{~cm}$ d'altezza. Collezione C. E.

27. Una figura femminile, Urua, territoria di Taganjika, $38 \mathrm{~cm}$ d'altezza. Berlino, Museo etnologico, III $^{0}$ E. 1363 .

28. Un manico d'ascia, Urua, la grandezza della testa è di $4 \mathrm{~cm}$. Berlino, collezione privata.

29. Figura di ragazza, Urua, $53 \mathrm{~cm}$ d'altezza, legno. Berlino, Museo etnologico, $\mathrm{III}^{0} \mathrm{E} .1879$.

30. Un portatore d'arco, Urua, $60 \mathrm{~cm}$ d'altezza, legno. Berlino, Museo etnologico, $\mathrm{III}^{\circ} \mathrm{E} .159 \mathrm{I}$. Un portatore d'arco, Urua, $50 \mathrm{~cm}$ d'altezza, legno. Berlino, Museo etnologico, III ${ }^{0}$ E. 4882.

31. Seggiola, Urua, $57 \mathrm{~cm}$ d'altezza, legno. Berlino, Museo etnologico, III ${ }^{0}$ C. 14966.

32. Seggiola, Urua, $43 \mathrm{~cm}$ d'altezza, legno. Berlino, Museo etnologico, III ${ }^{0}$ E. 6699.

33. Una donna accovacciata con un vaso del mare Moreo, $55 \mathrm{~cm}$ d'altezza. Bruxelles, Congomuseo.

34. Maschera, Urua, $37 \mathrm{~cm}$ d'altezza, legno. Berlino, Museo etnologico, III ${ }^{0}$ E. 2453.

35. Calice, Bakongo, Congo belga, $20 \mathrm{~cm}$ d'altezza, legno. Francoforte, collezione privata.

36. Calice, Bakongo, avorio con sostegno di legno, $15,5 \mathrm{~cm}$ d'altezza.

37. Calice, Bacuba, $27 \mathrm{~cm}$ d'altezza, legno. Francoforte, collezione privata.

38 e 39. Statua di Misa Pelenge, capo di Bushongo verso il $1780,54,5 \mathrm{~cm}$ d'altezza, legno. Bruxelles, Congomuseo.

40. Scettro di Bakuana, Congo belga, grandezza della figura di $23 \mathrm{~cm}$, legno.

41. Coltello, Bakongo, il manico è lungo ro $\mathrm{cm}$. Berlino, collezione privata.

42 a) Una piccola maschera per viso, $5 \mathrm{~cm}$ d'altezza, avorio, della tribù dei Warega presso Tanganjika.

b) Una statuetta femminile di Negula (polvere di legno rosso), avorio dipinto, della tribù dei Bahuana, Congo belga, $5,5 \mathrm{~cm}$ d'altezza. Berlino, collezione privata.

c) Una maschera per viso avorio, della tribù-dei Warega, Congo belga, $4 \mathrm{~cm}$ d'altezza, Berlino, collezione privata.

d) Cucchiai, Warega, avorio, $16 \mathrm{~cm}$ d'altezza. Berlino, collezione privata.

43. Una statuetta accosciata, tribù dei Bahuana, Kasai, leggermente colorata di Neguba, $9 \mathrm{~cm}$ d'altezza, collezione C. E.

44. A destra: una maschera, Congo francese. - A sinistra: una maschera di Joruba, legno. Tutte e due nel Museo di Folkwang a Hagen.

45. Maschera, Congo belga, Bapende, l'altezza del volto è di $30 \mathrm{~cm}$. Berlino, collezione privata.

46. Maschera, Congo belga, Bajaka. Museo Folkwang di Hagen.

47. Sopra: tre statuette femminili d'avorio, dipinte con Neguba, dal cirondario di Manjema, Urua. Sotto a sinistra: una placca d'avorio, del circondario di Djuma, Congo belga.

Sotto nel mezzo: una statuetta d'avorio, Manjema.

Sotto a destra: una piccola maschera d'avorio, Warega. Collezione privata, Hannover.

48. Frammento di un' immagine d'uccello, Simbabye, Mashonal, $47 \mathrm{~cm}$ d'altezza, di pietra rossa. Berlino, Museo etnologico, $\mathrm{III}^{0}$ D. 3170. 


\section{BIBLIOGRAFIA}

Bernhard Ankermann: Il culto dei morti e la credenza nell' anima presso i popoli africani.

- Sull' attuale stato etnografico delle regioni di Sud-Africa.

- Una relazione sopra un viaggio d'indagine etnografica nel Grasland di Camerun.

Dott. Schachtzabel: Relazioni orali.

Von Luschan: Le antichità di Benin.

K. Ling Roth: Great Benin.

Pitt Rivers: Antique Works of art.

Hagen: Antichità di Benin. 2 volumi.

Paolo Gehrmann: L'arte industriale plastica figurata nel Grasland di Camerun.

Wolff: Una relazione sul suo viaggio nella terra di Bakuba.

British Museum: Handbook to the ethnographical collections.

Tordaj-Joyce: Les Boushonge.

- Notes on the ethnography of the Ba-Huana.

Delhaise: Les Warega.

Colle: Les Baluba.

Schmitz: Les Baholoholo.

Trilles: Le totemisme chez les Fan.

Ellis: The Joruba-speaking peoples of the Slave Coast of West Africa.

Bent, J. Theodore: The ruined cities of Mashonaland.

R. N. Hall et W. G. Neal: The ancient ruins of Rhodesia.

R. N. Hall: The great Zimbabwe.

R. Poch: Per il problema di Simbabye.

Helen Tongue: Bushman Paintings. 



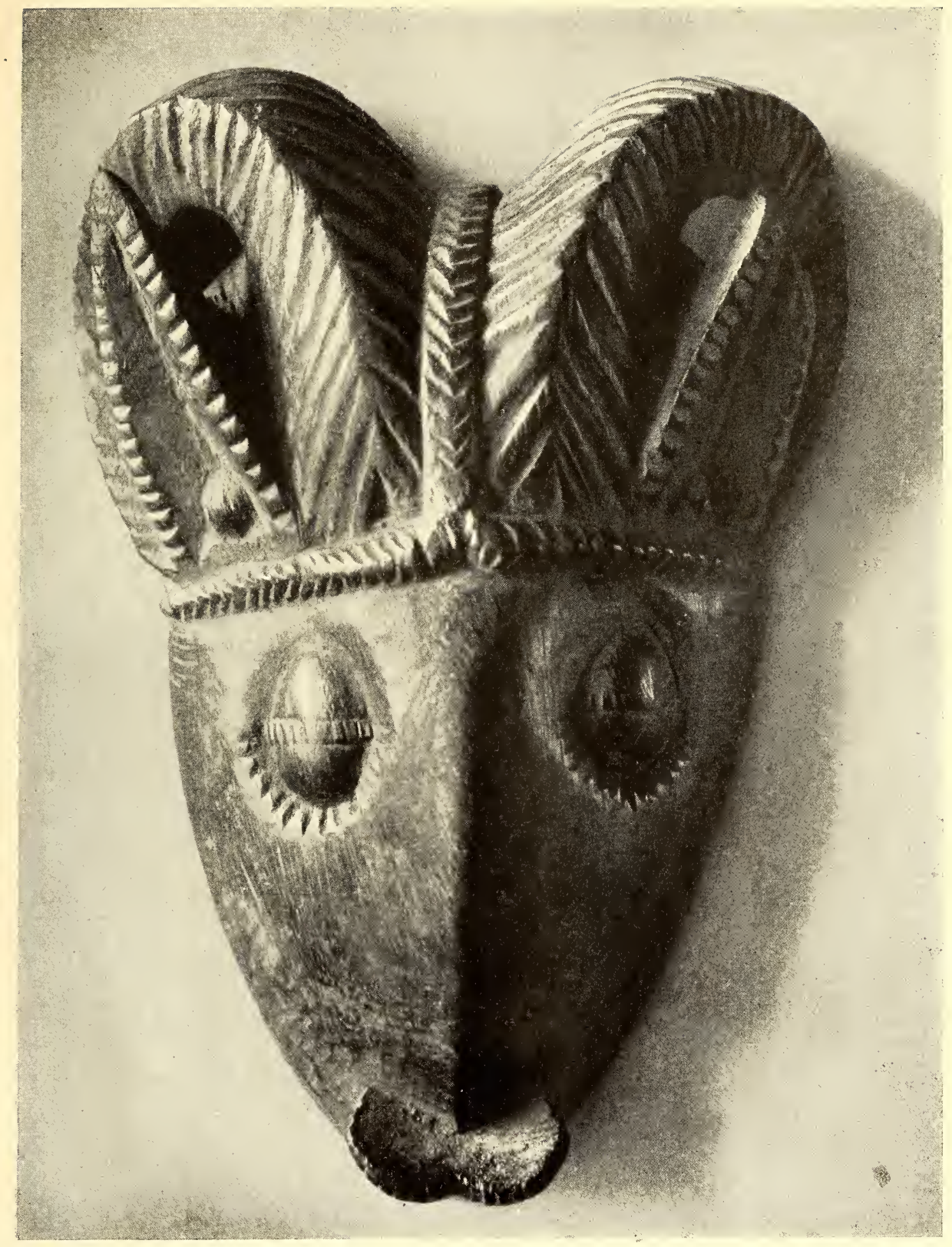




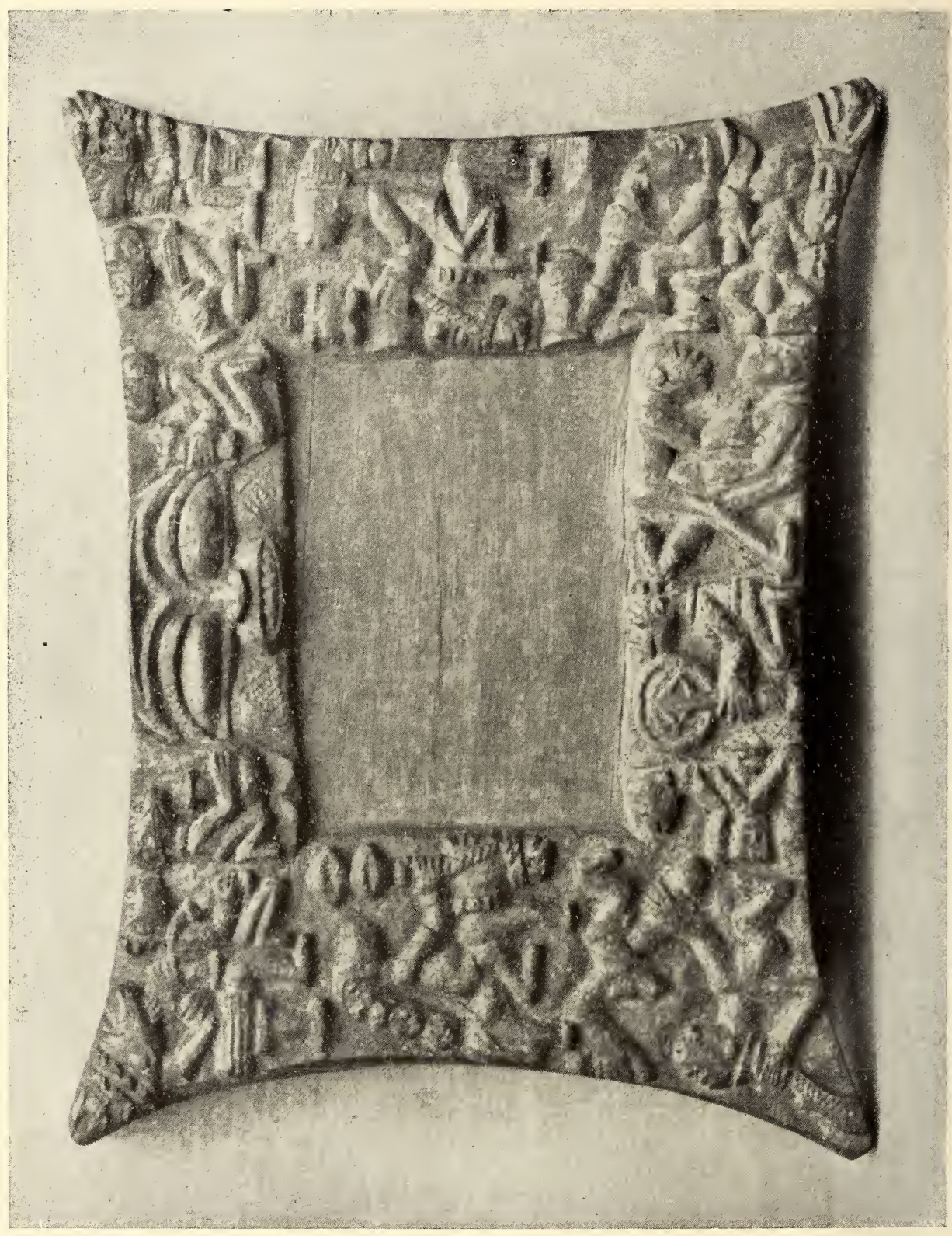



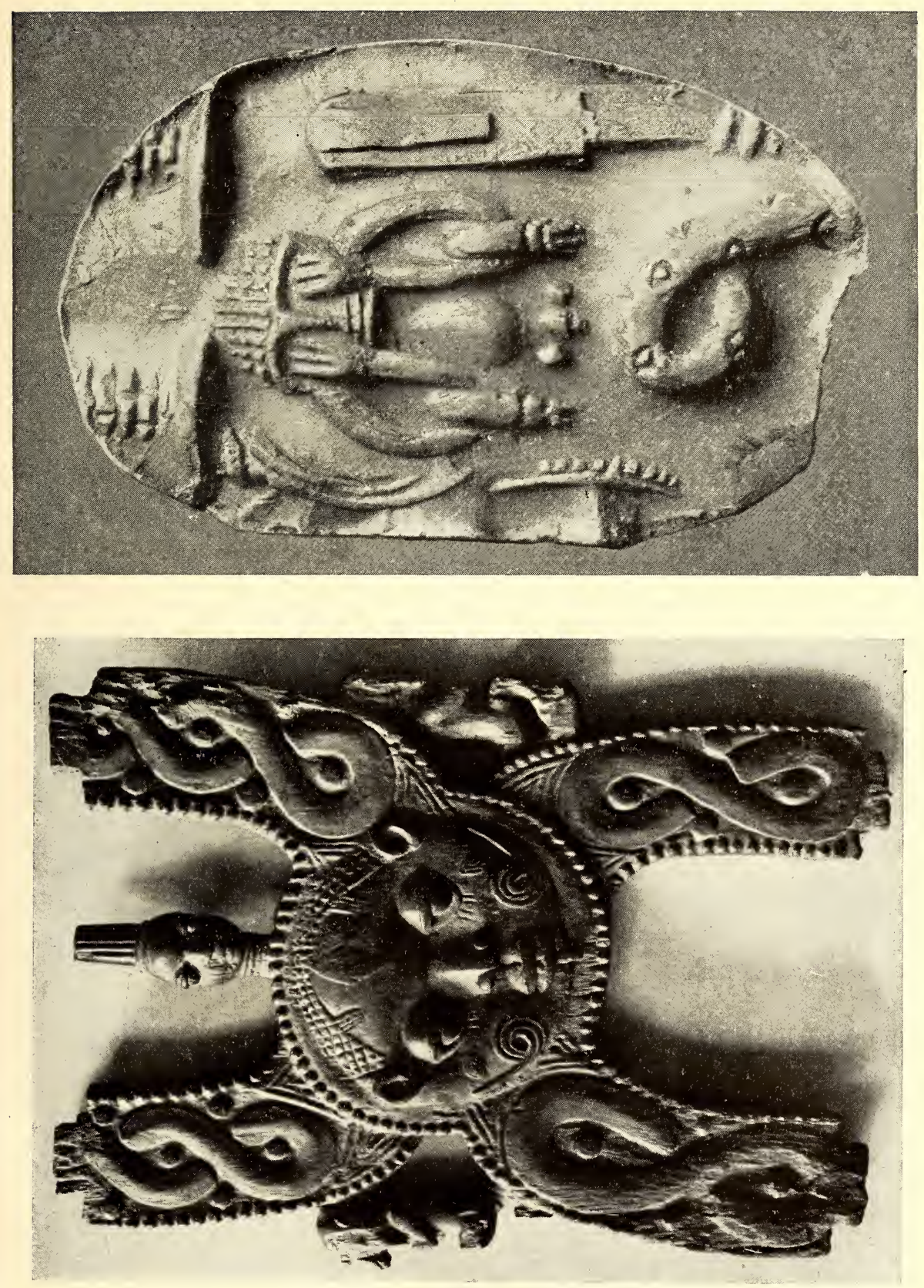

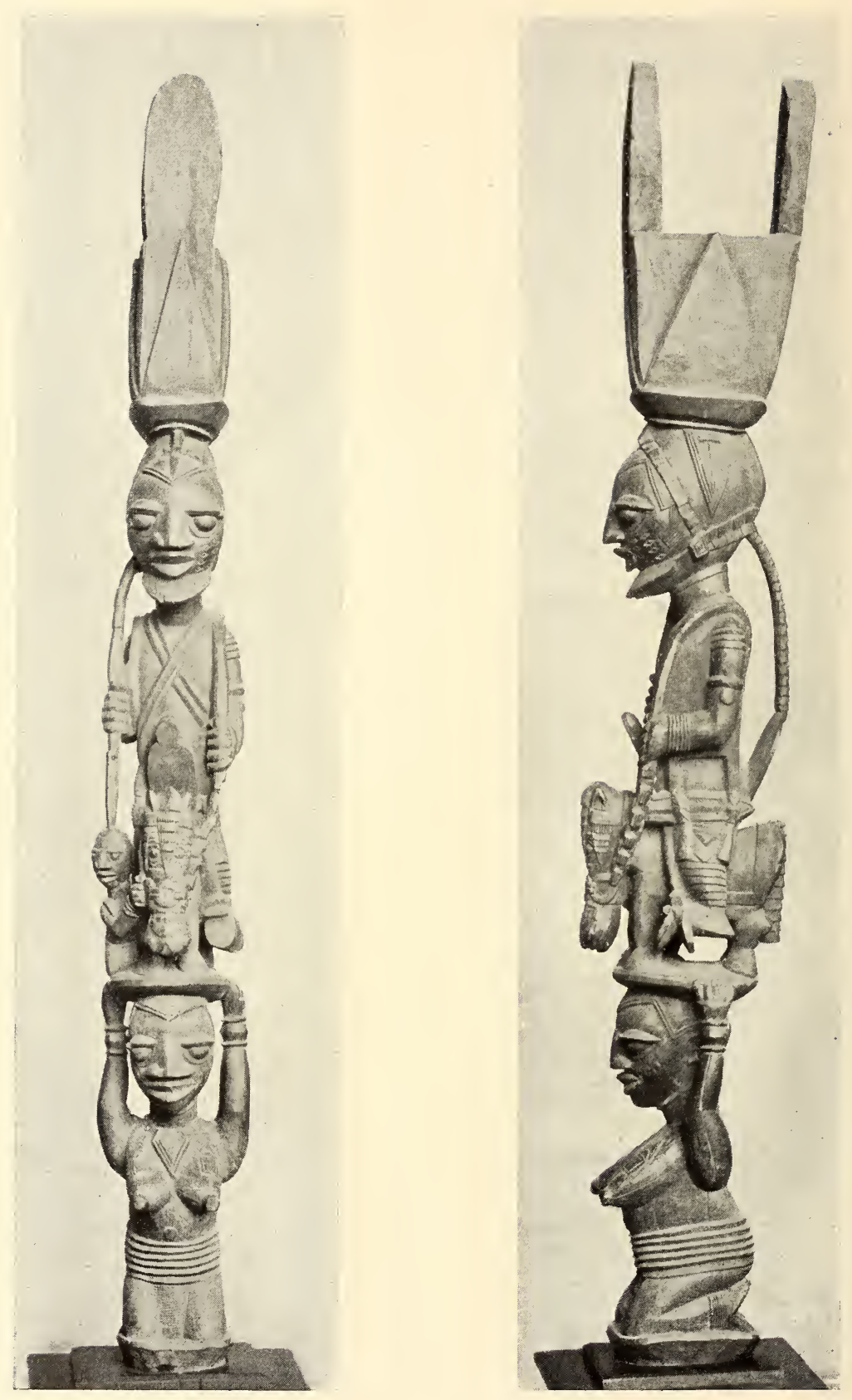


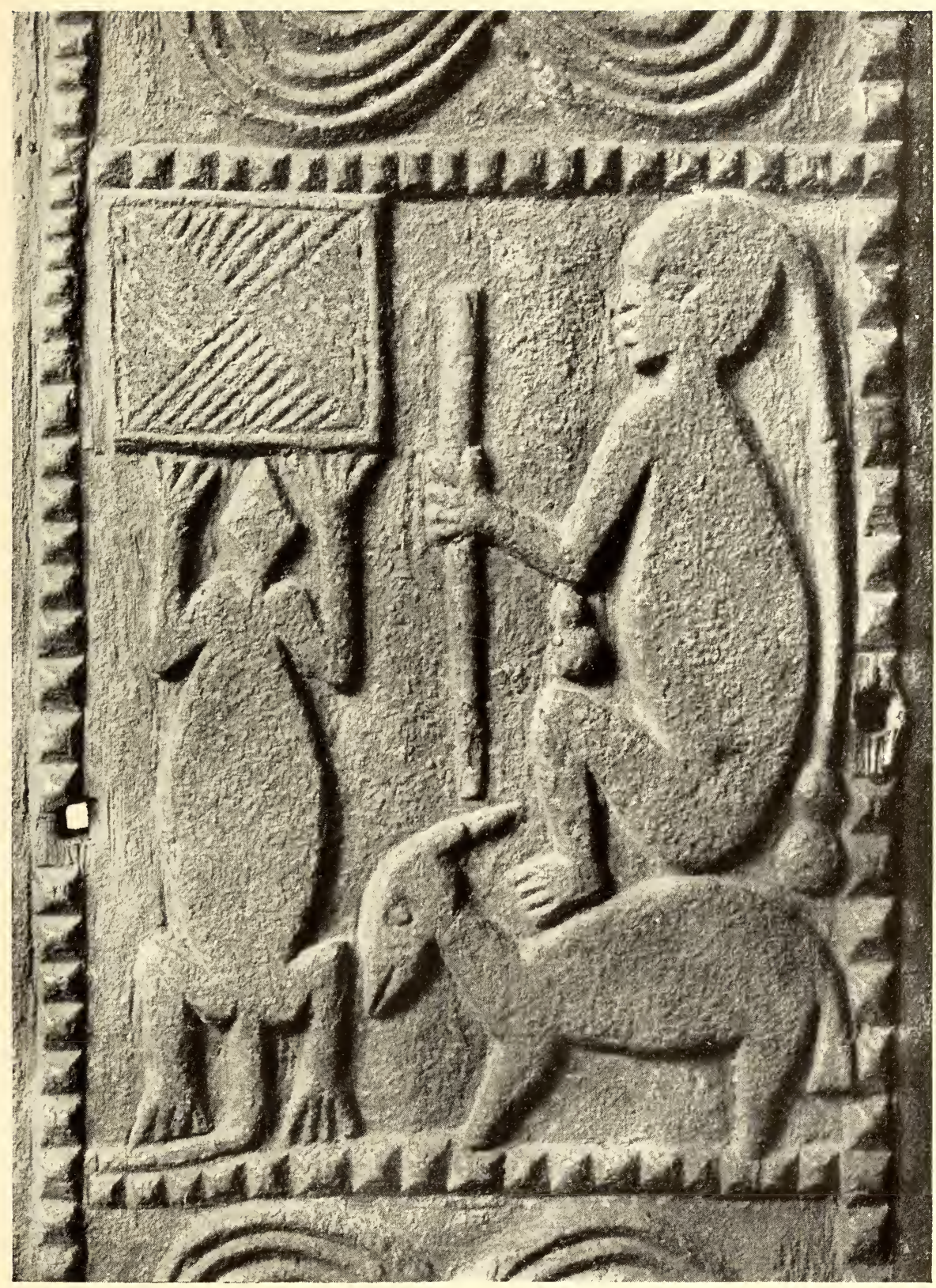




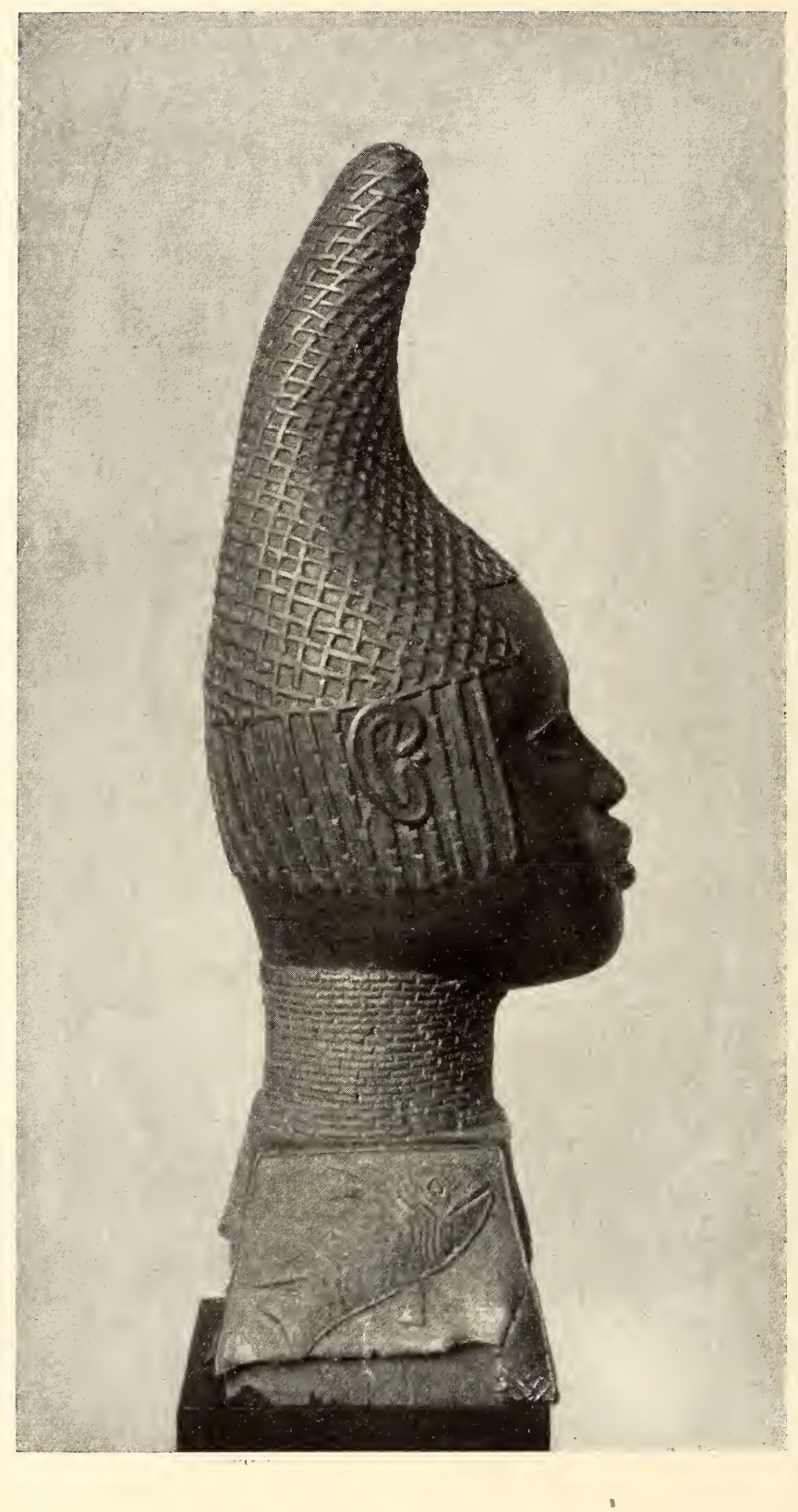




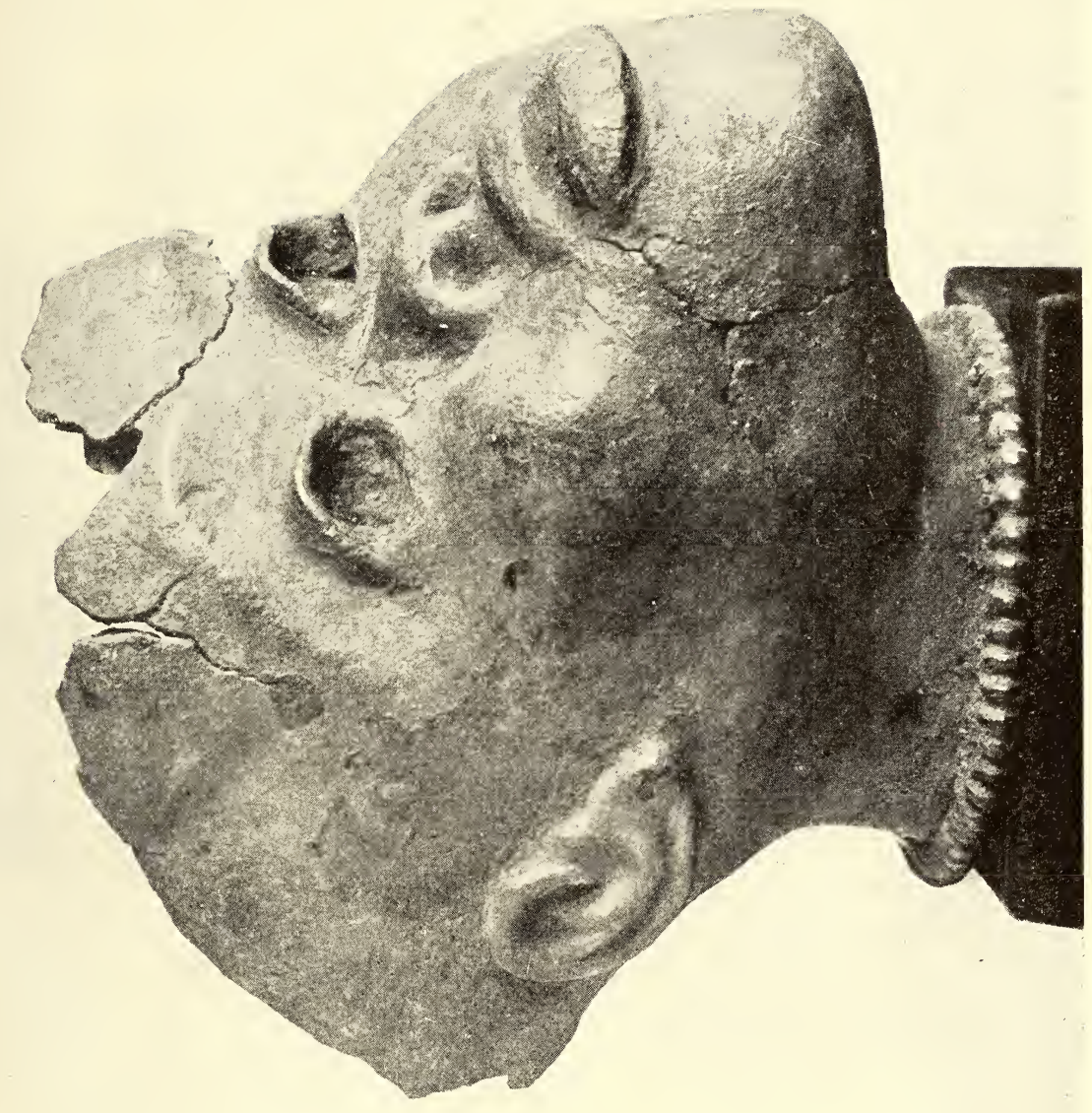




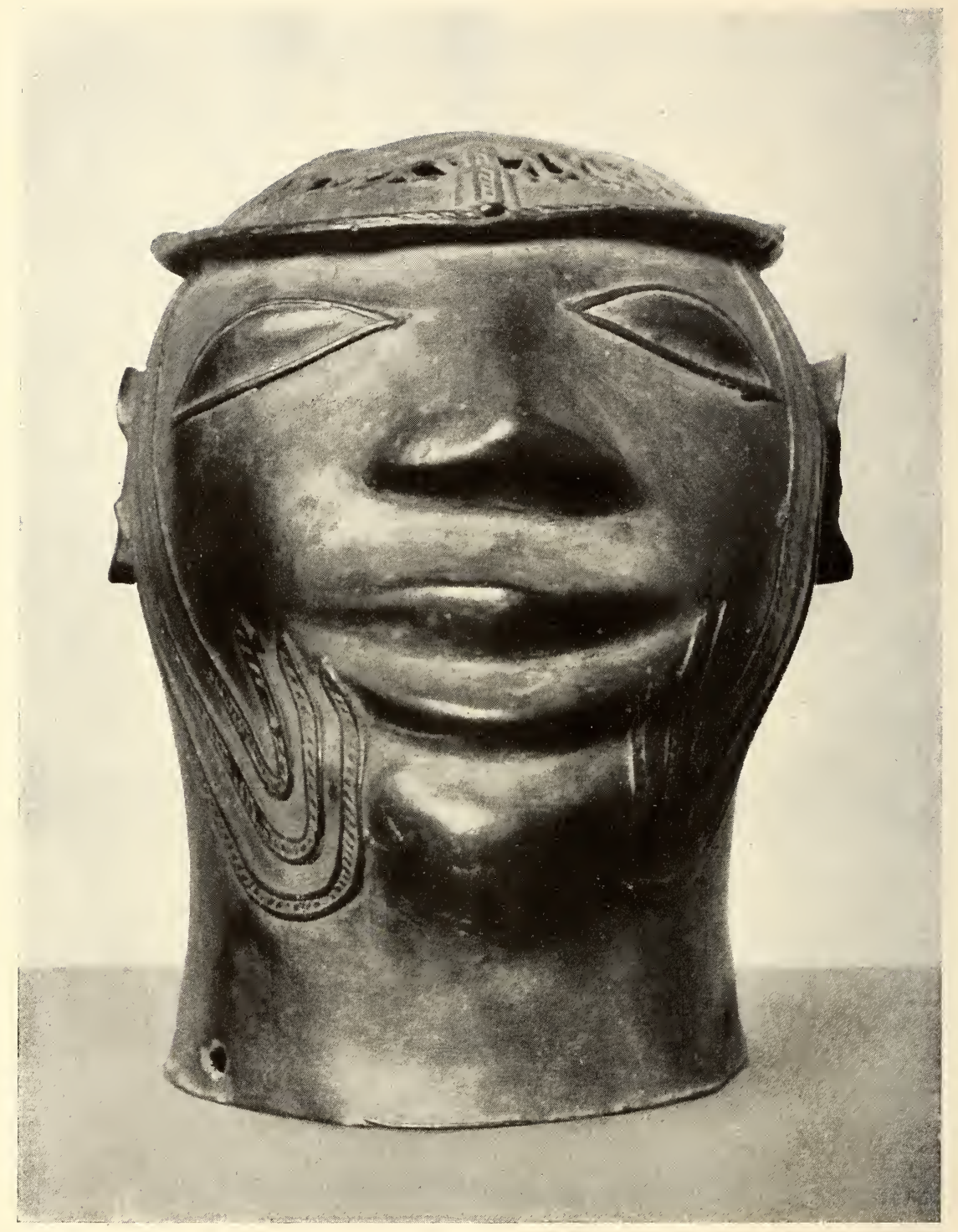




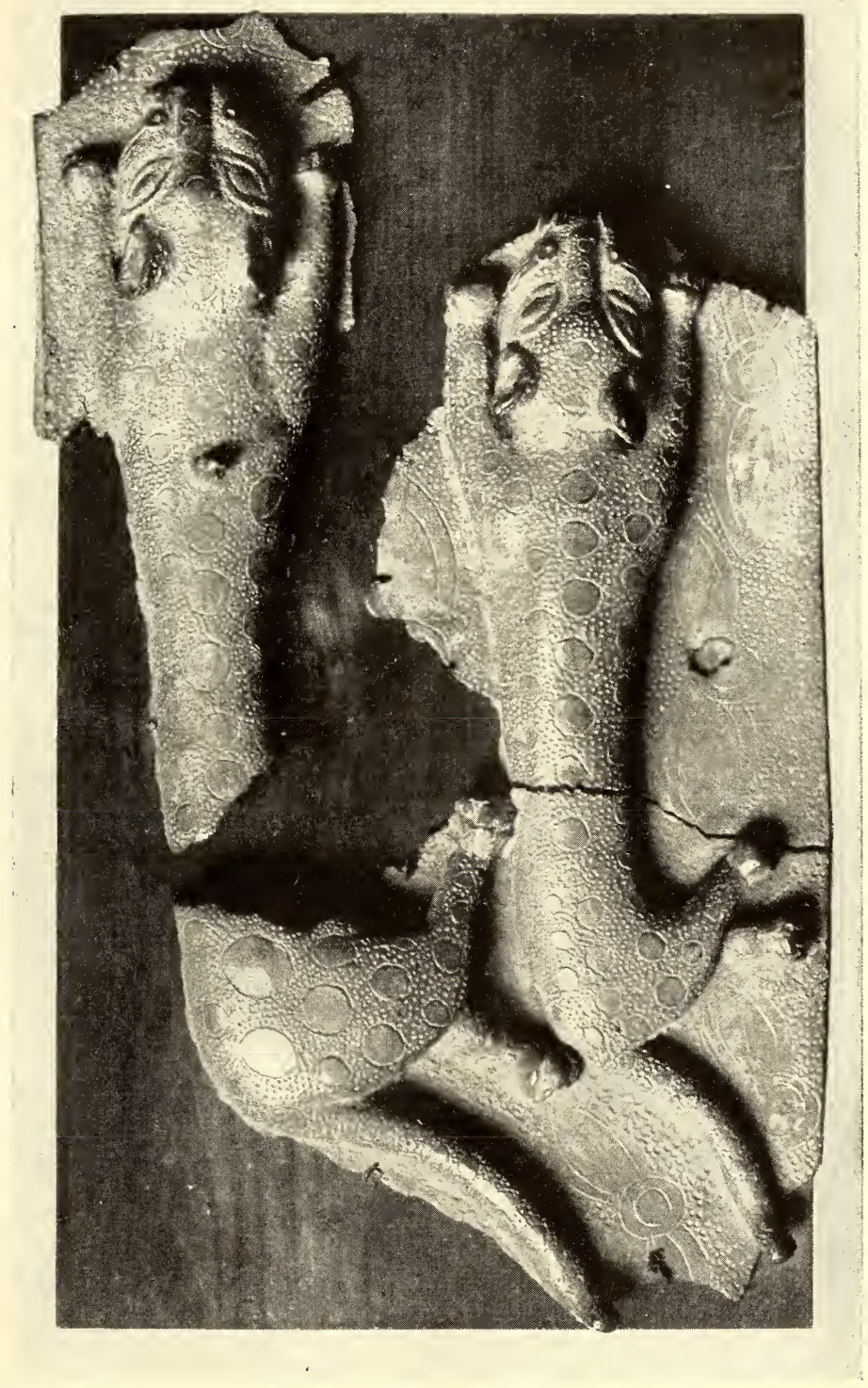




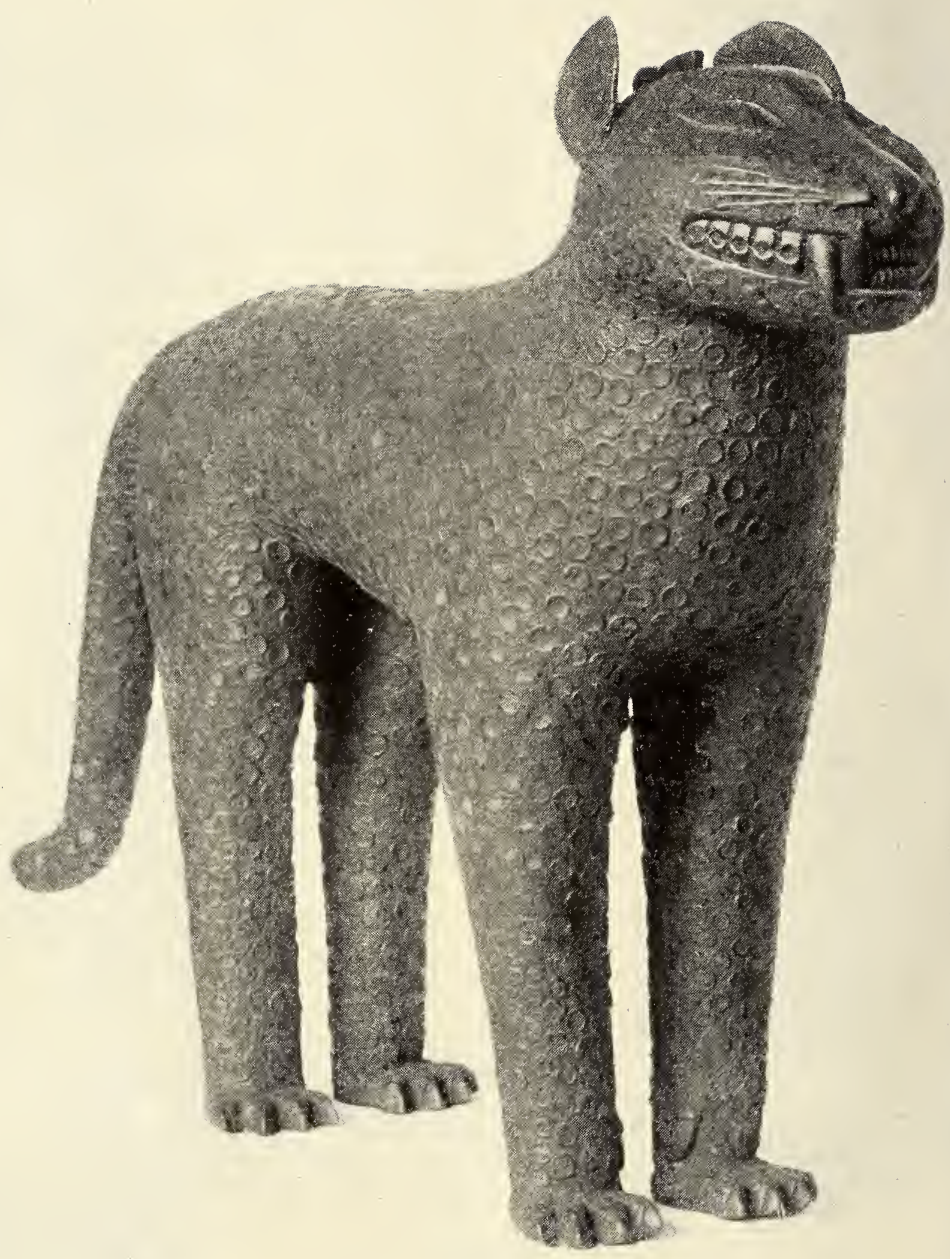




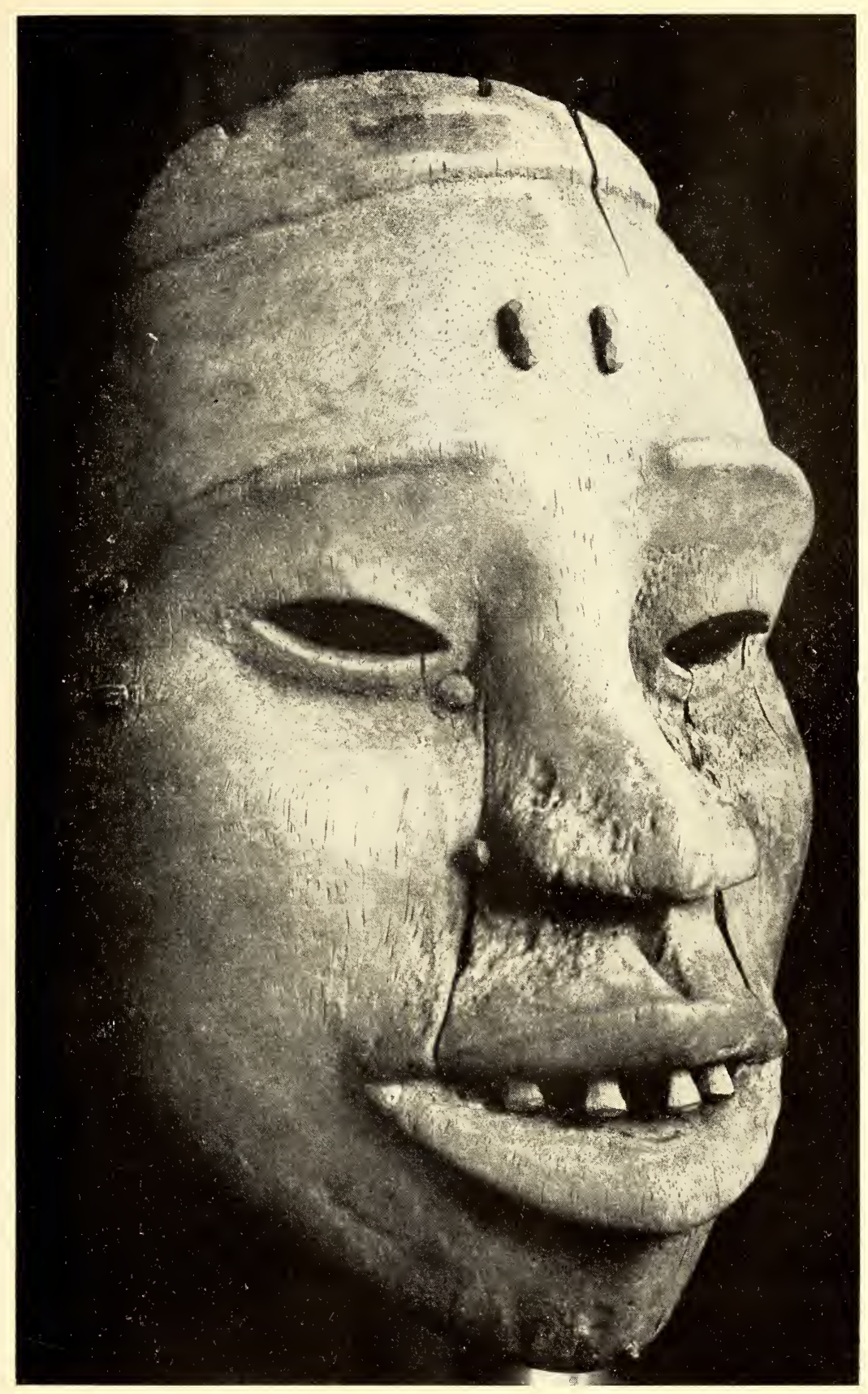




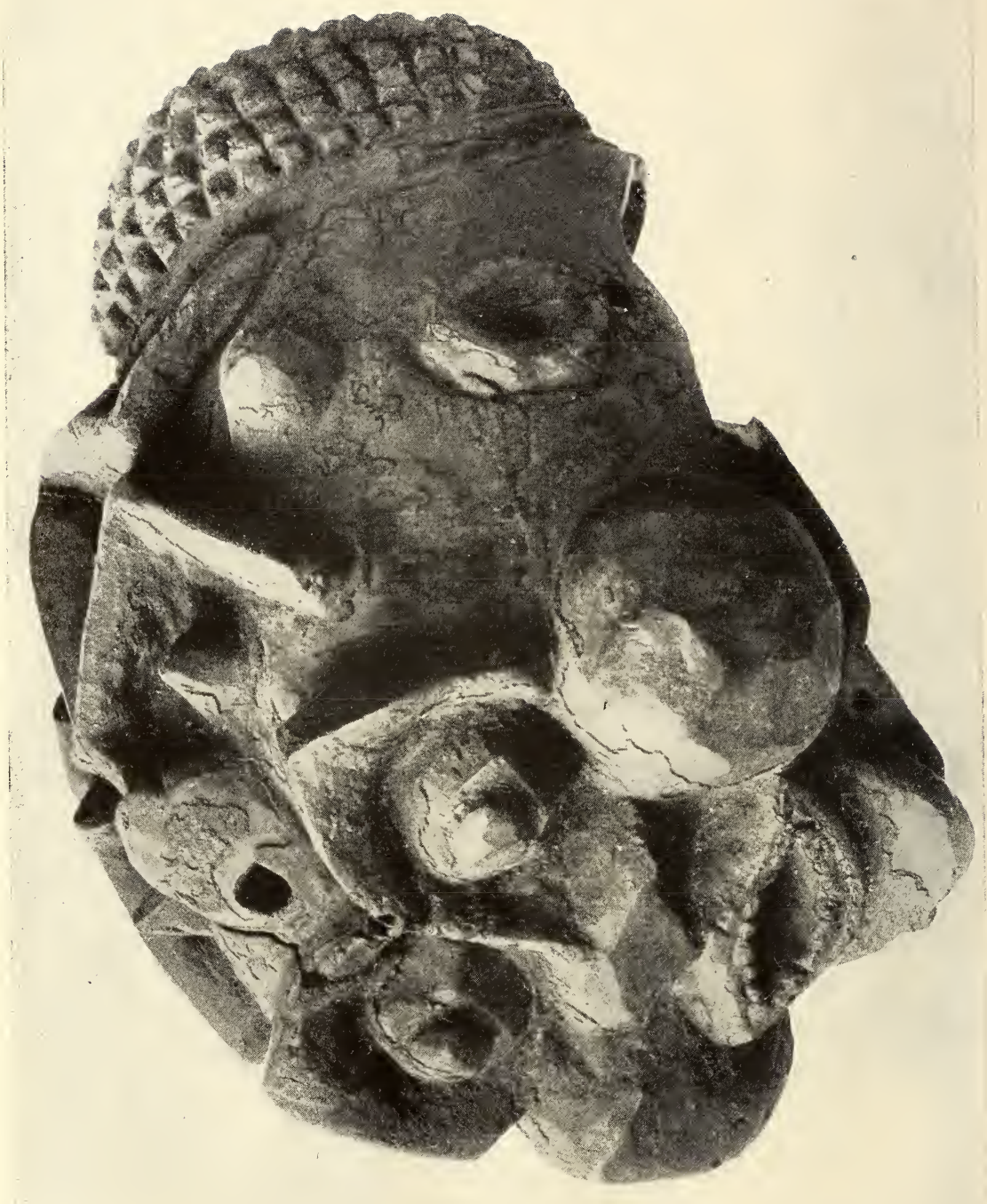




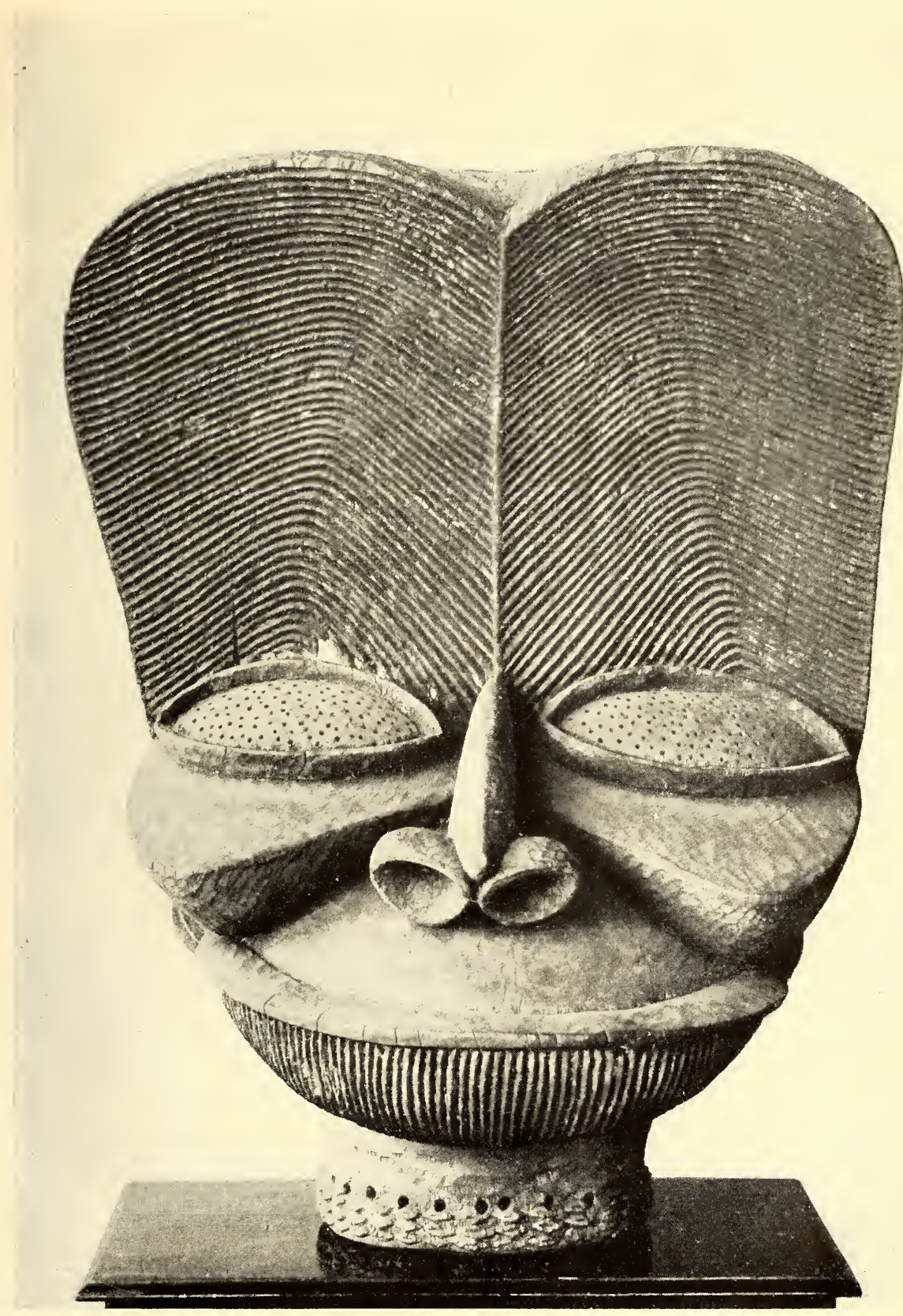




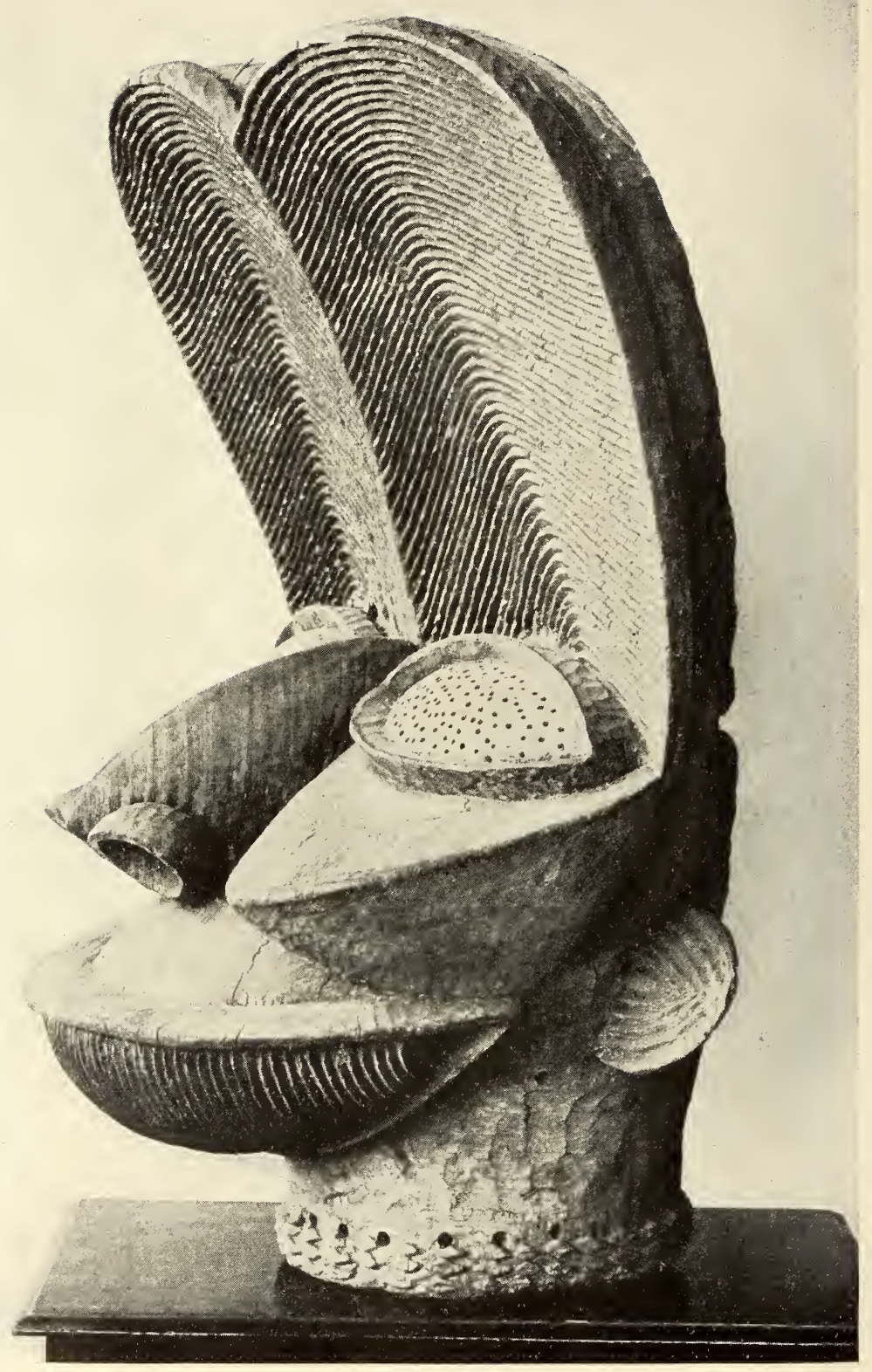




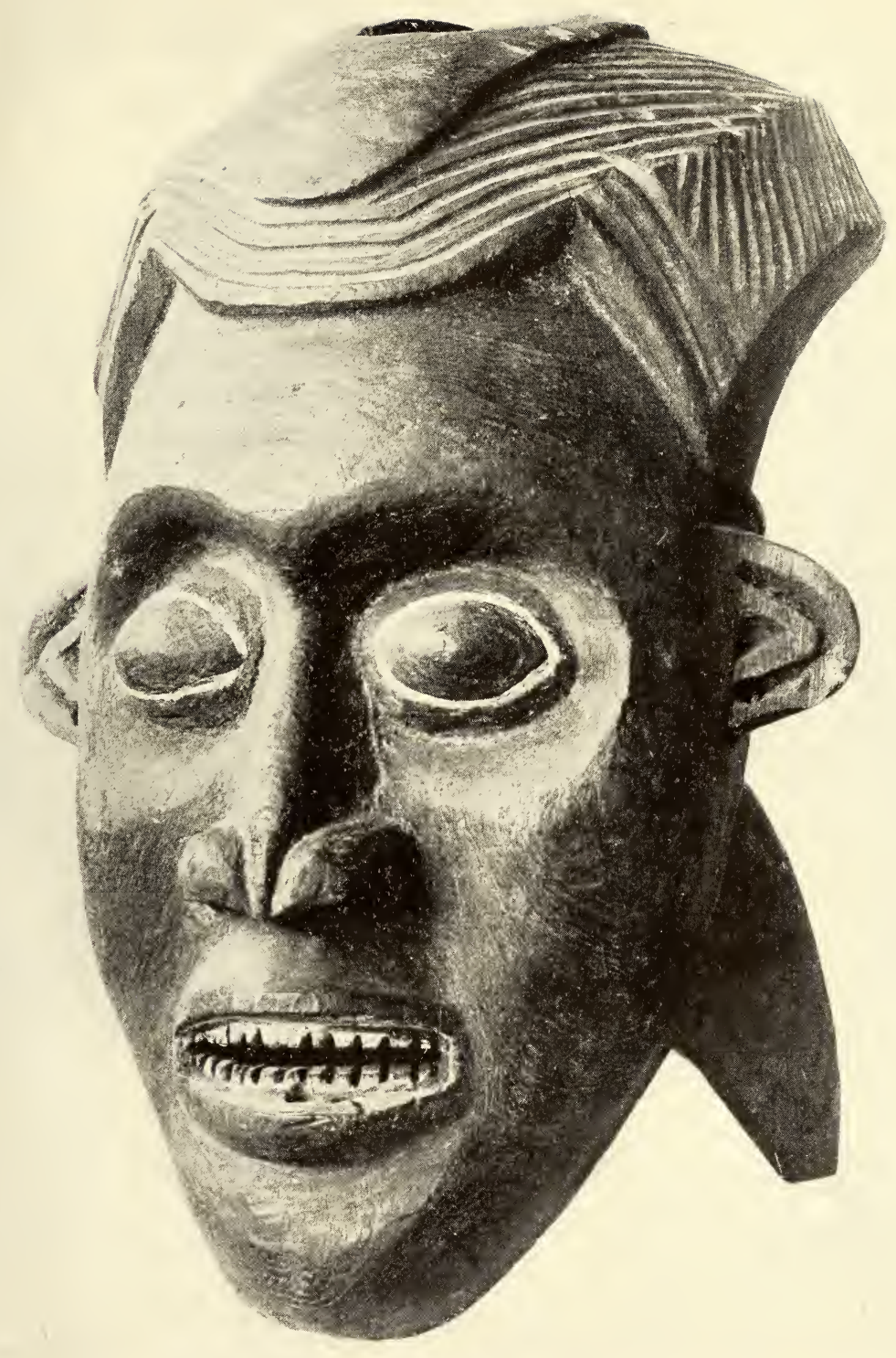




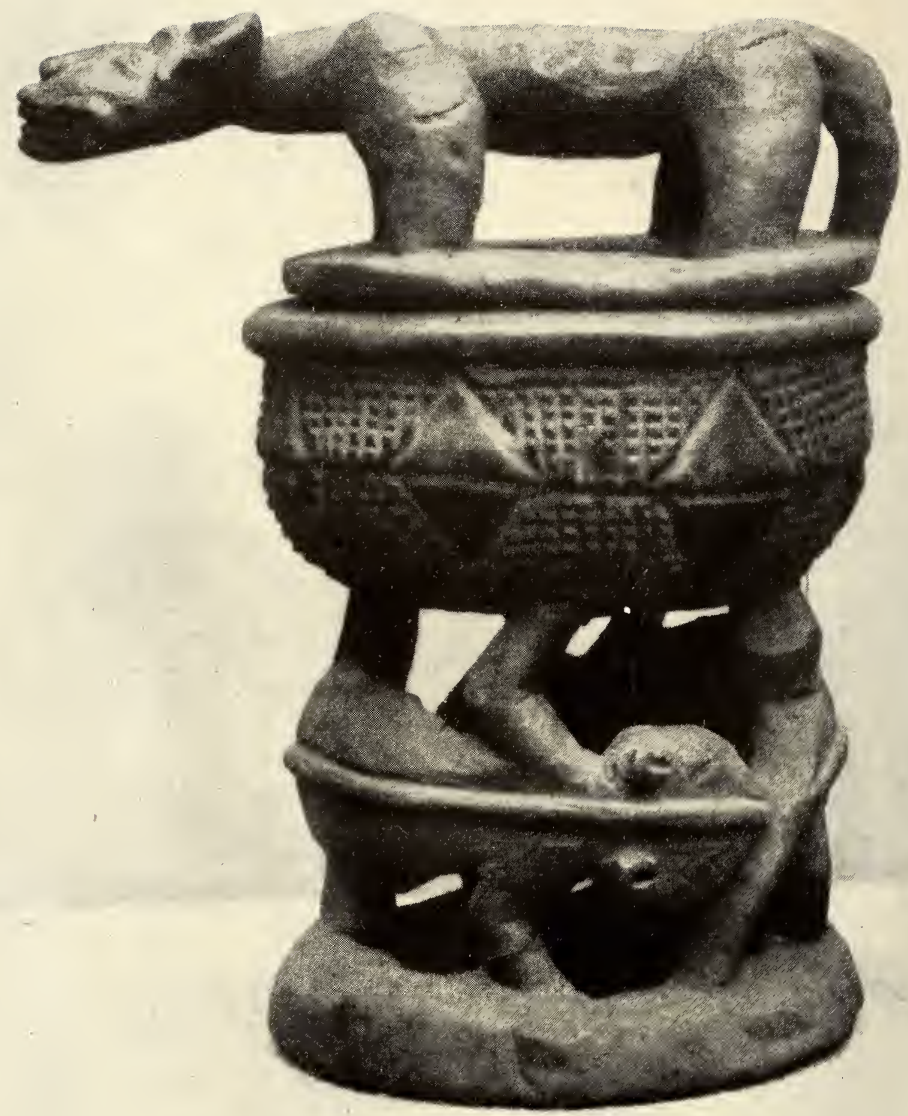




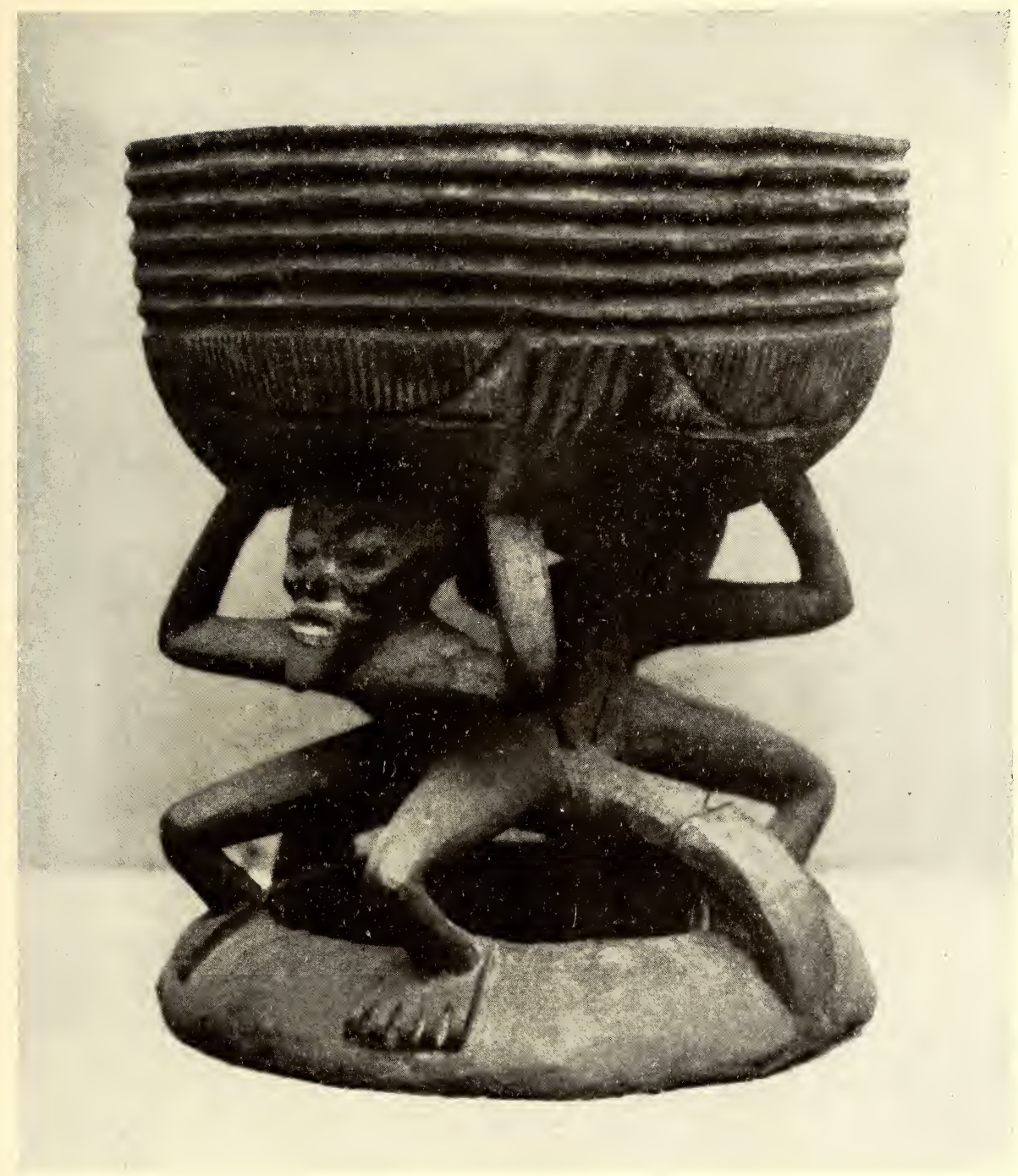




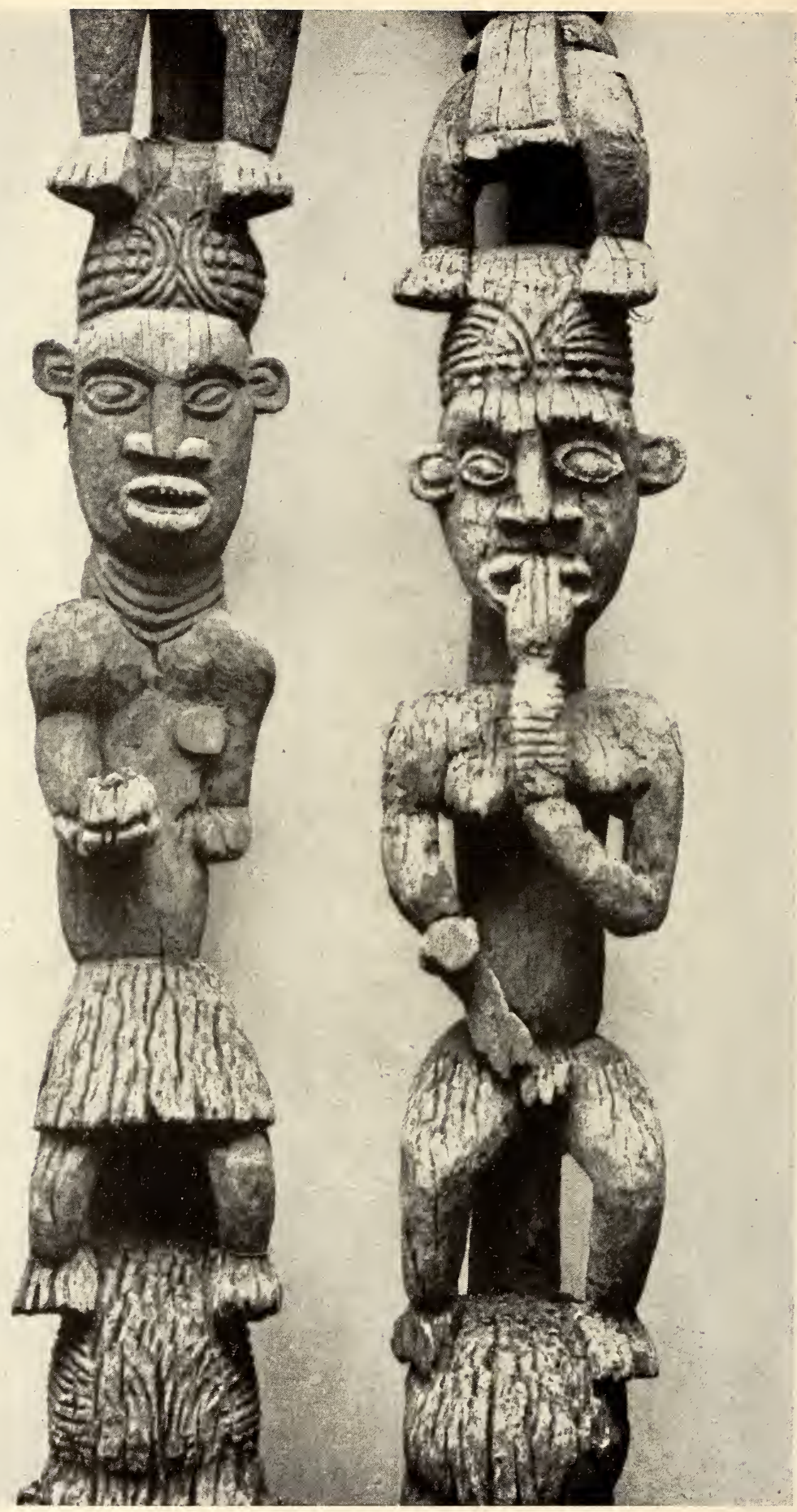




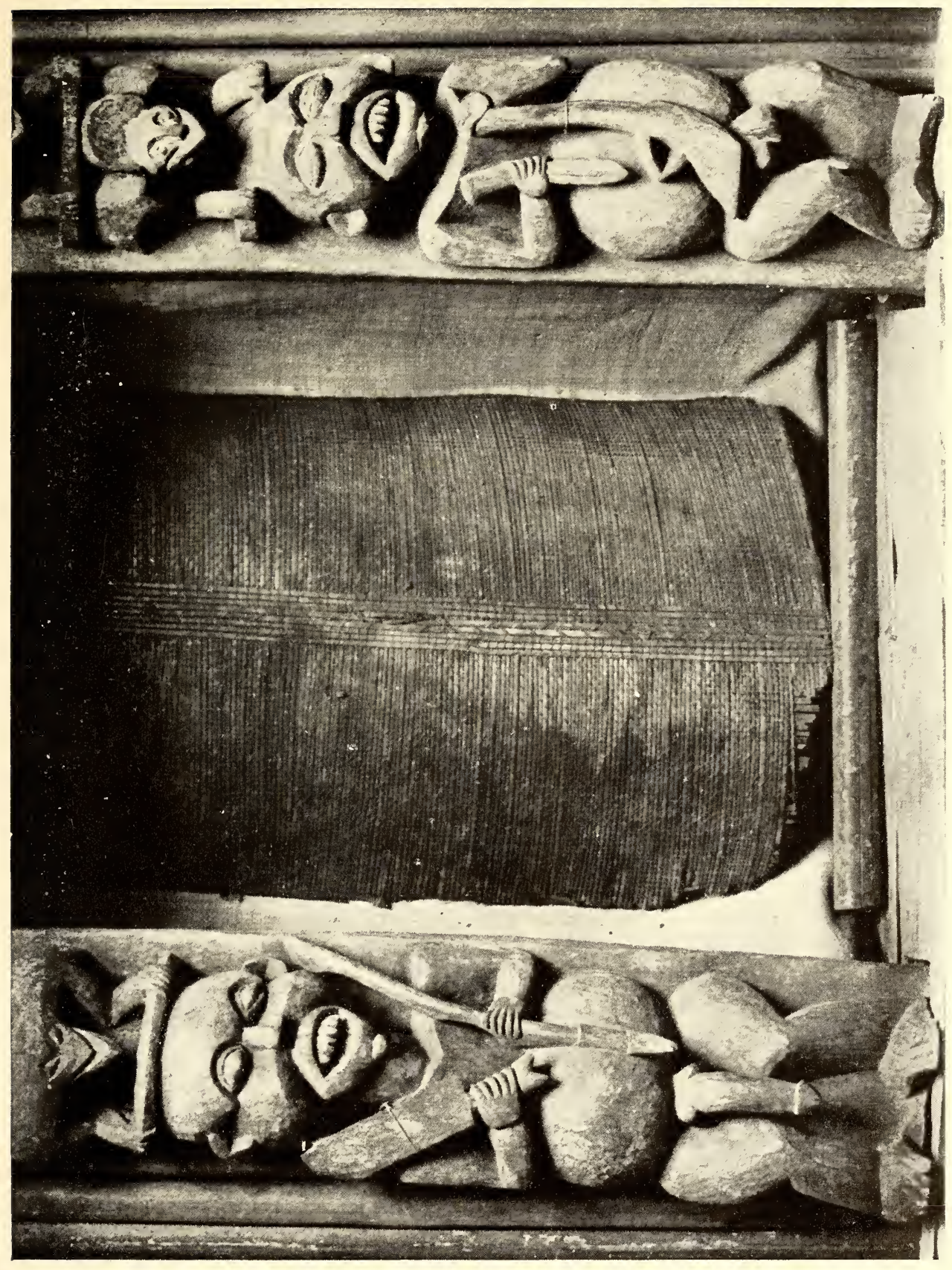




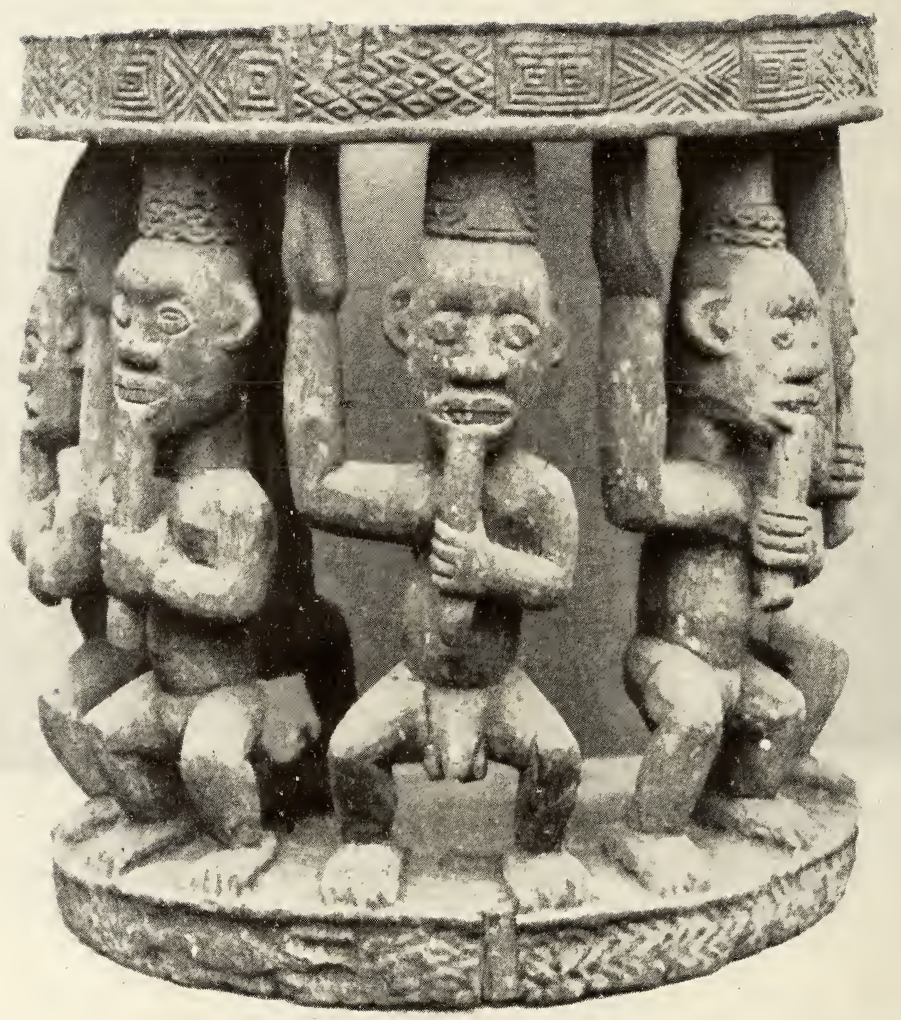

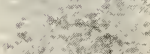




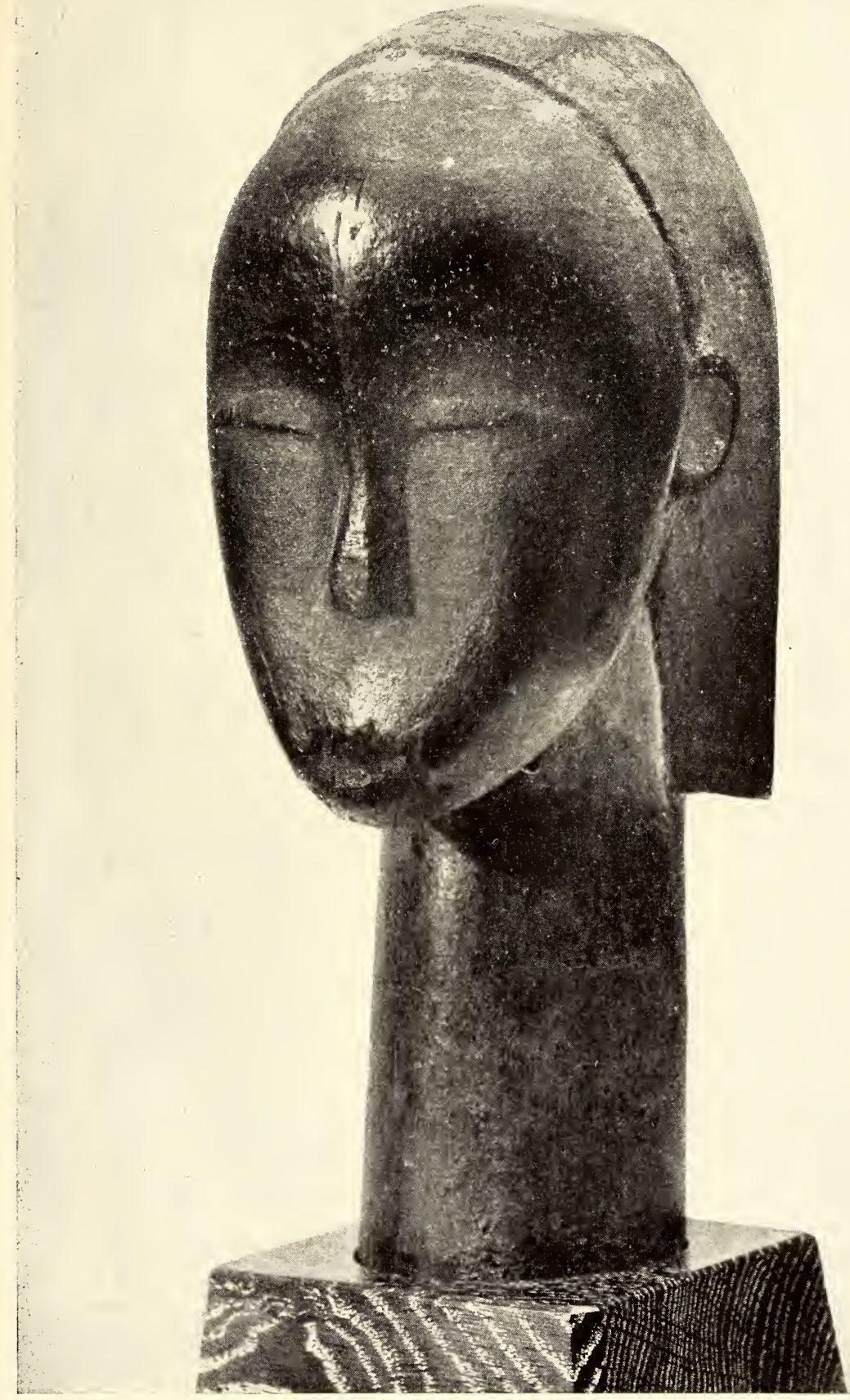




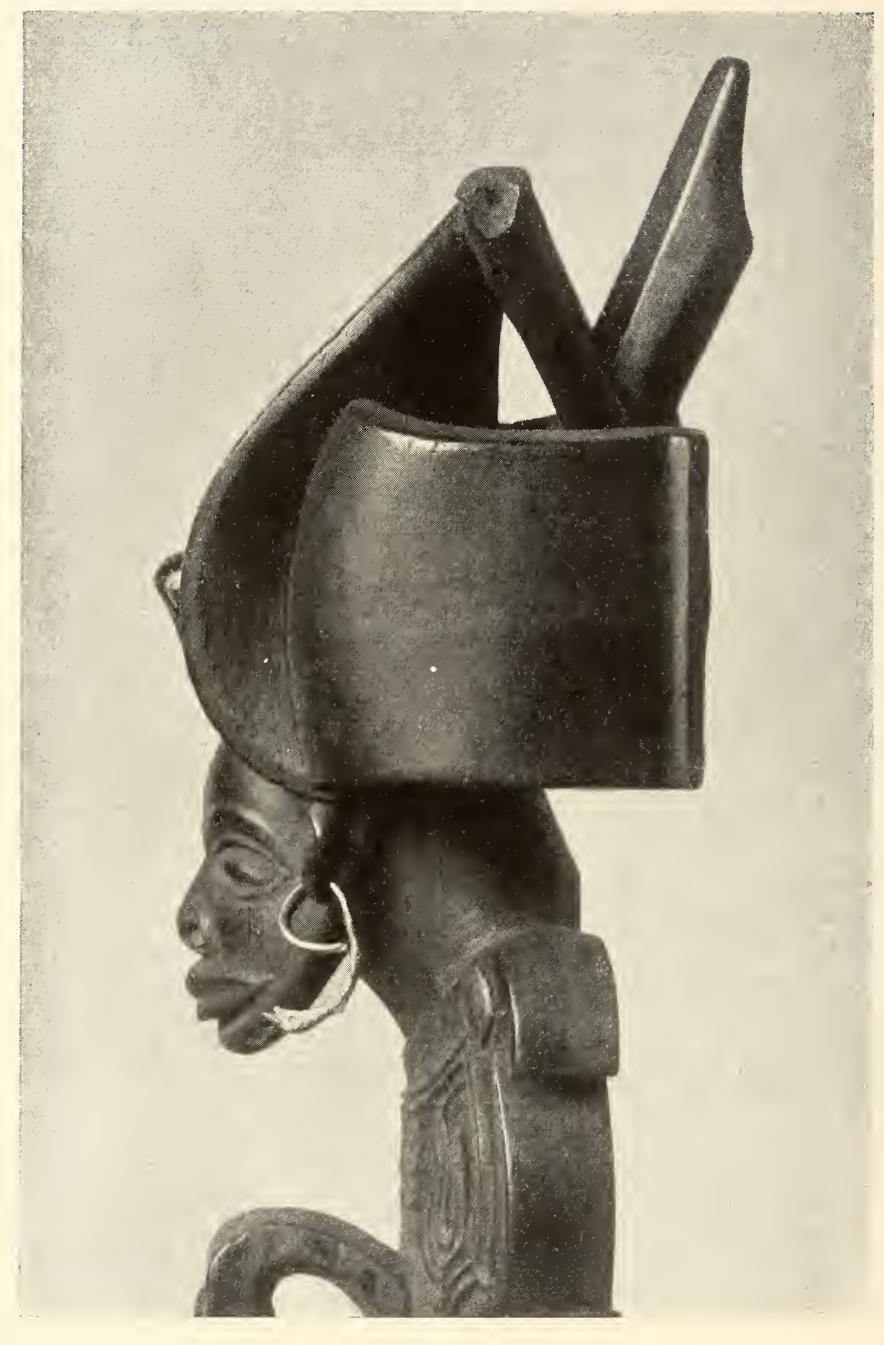



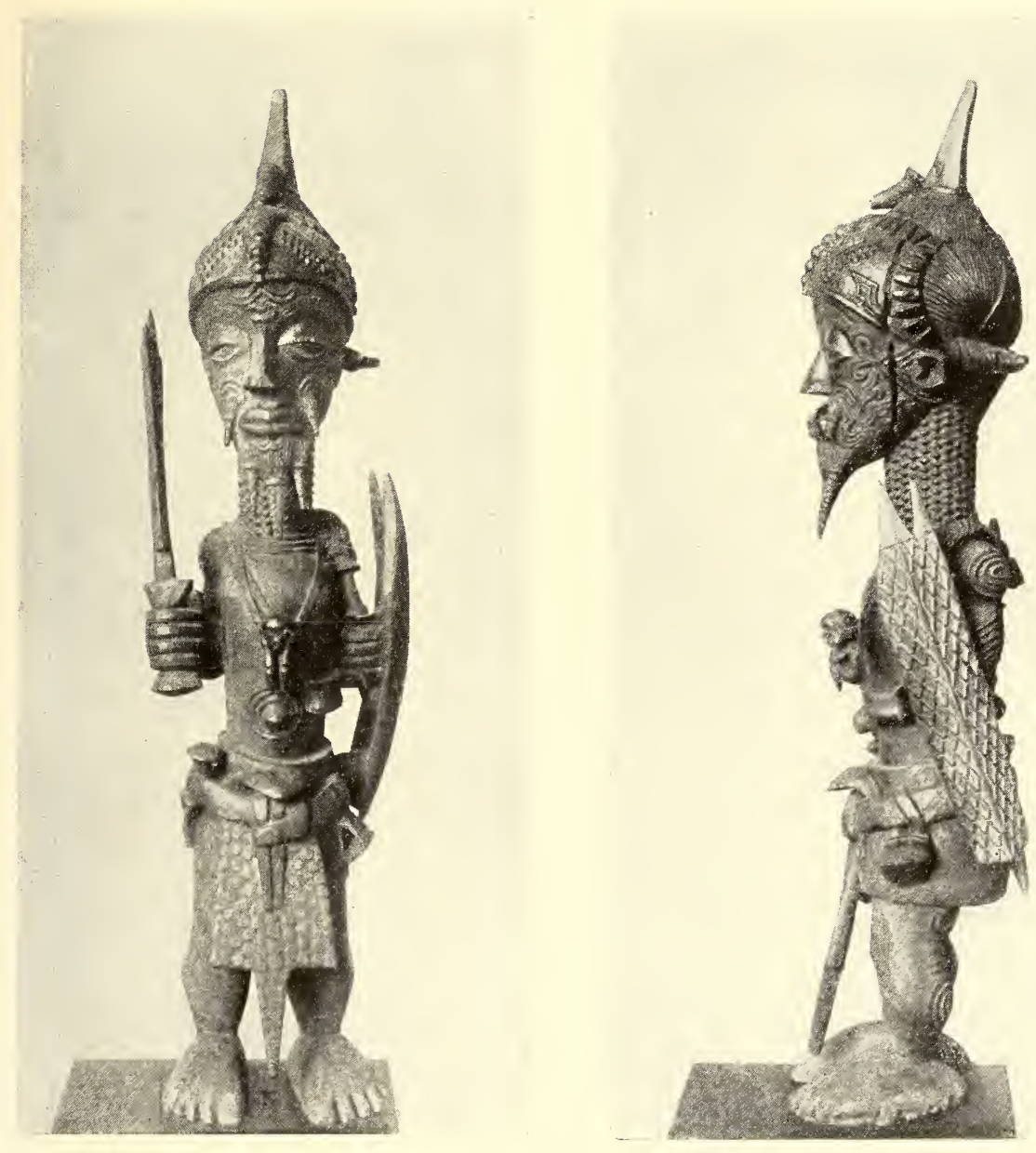


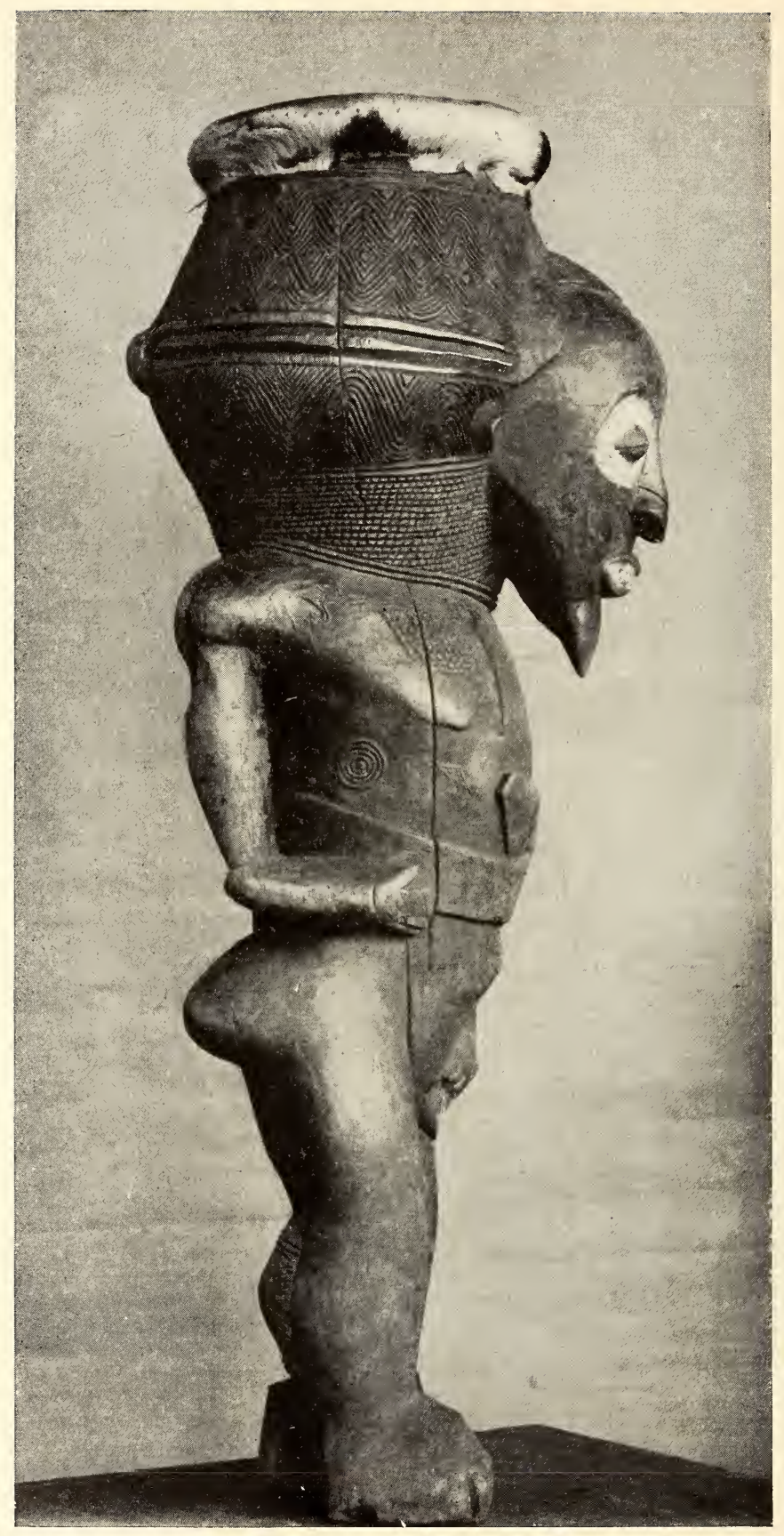




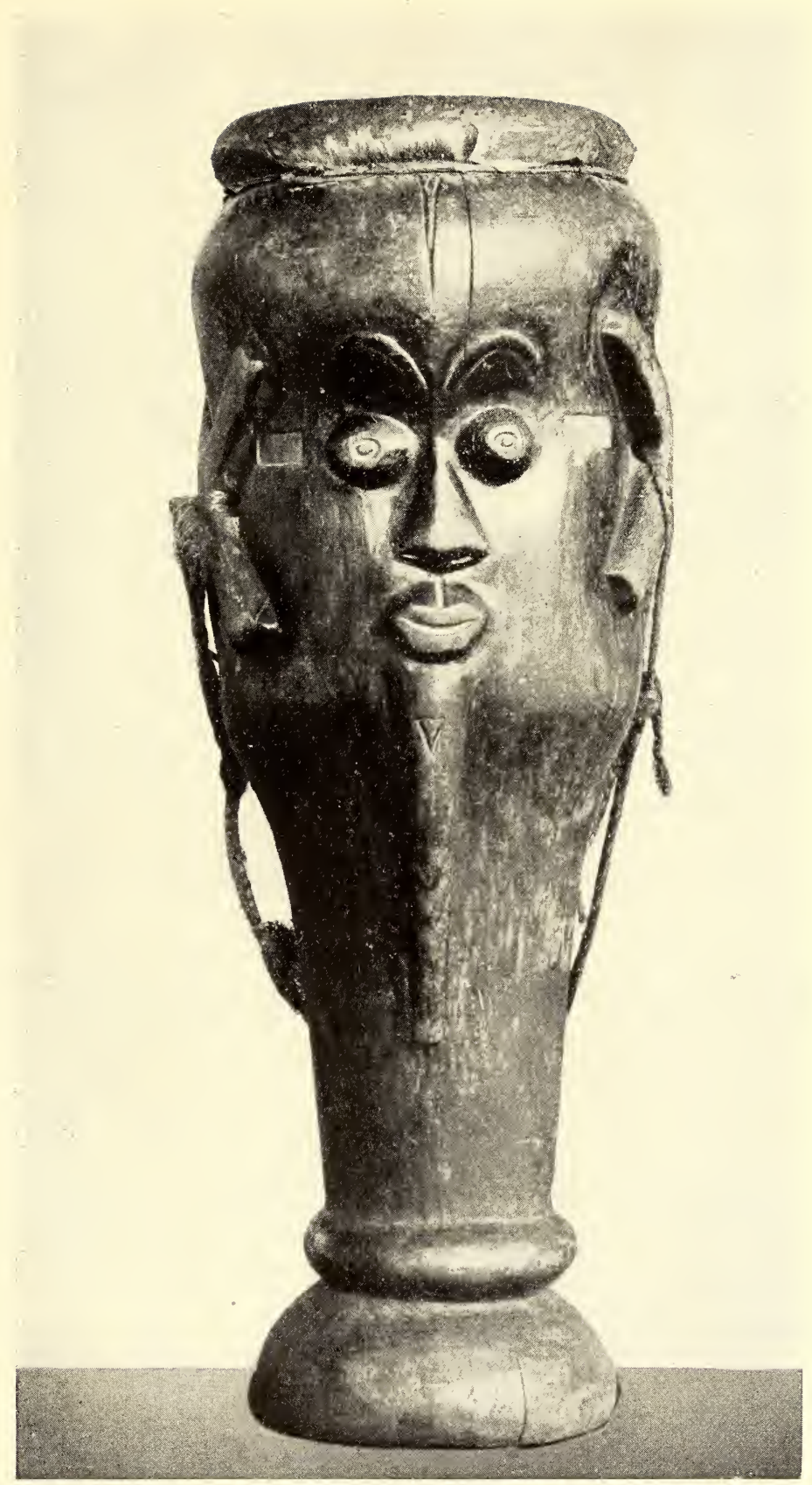




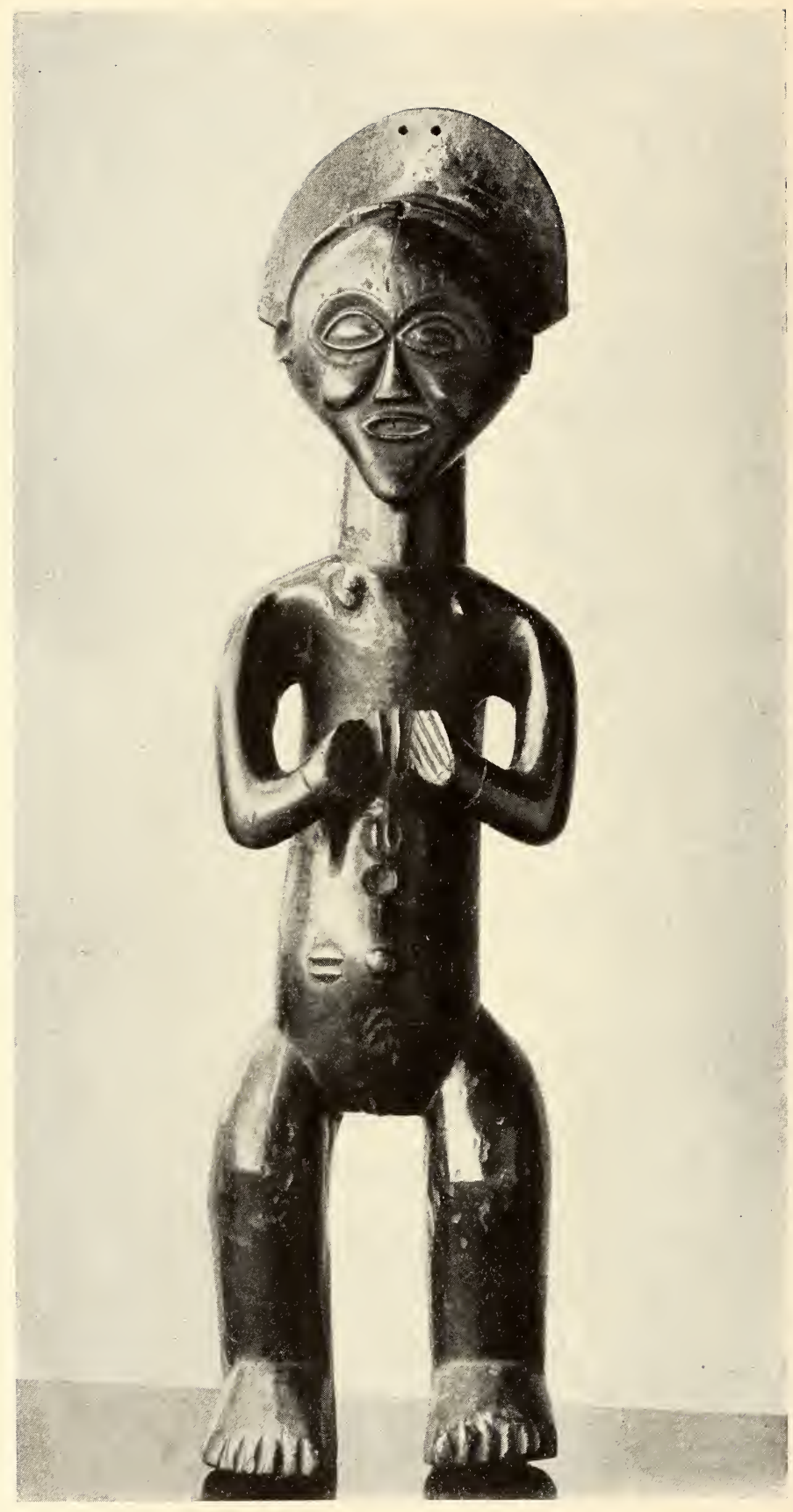




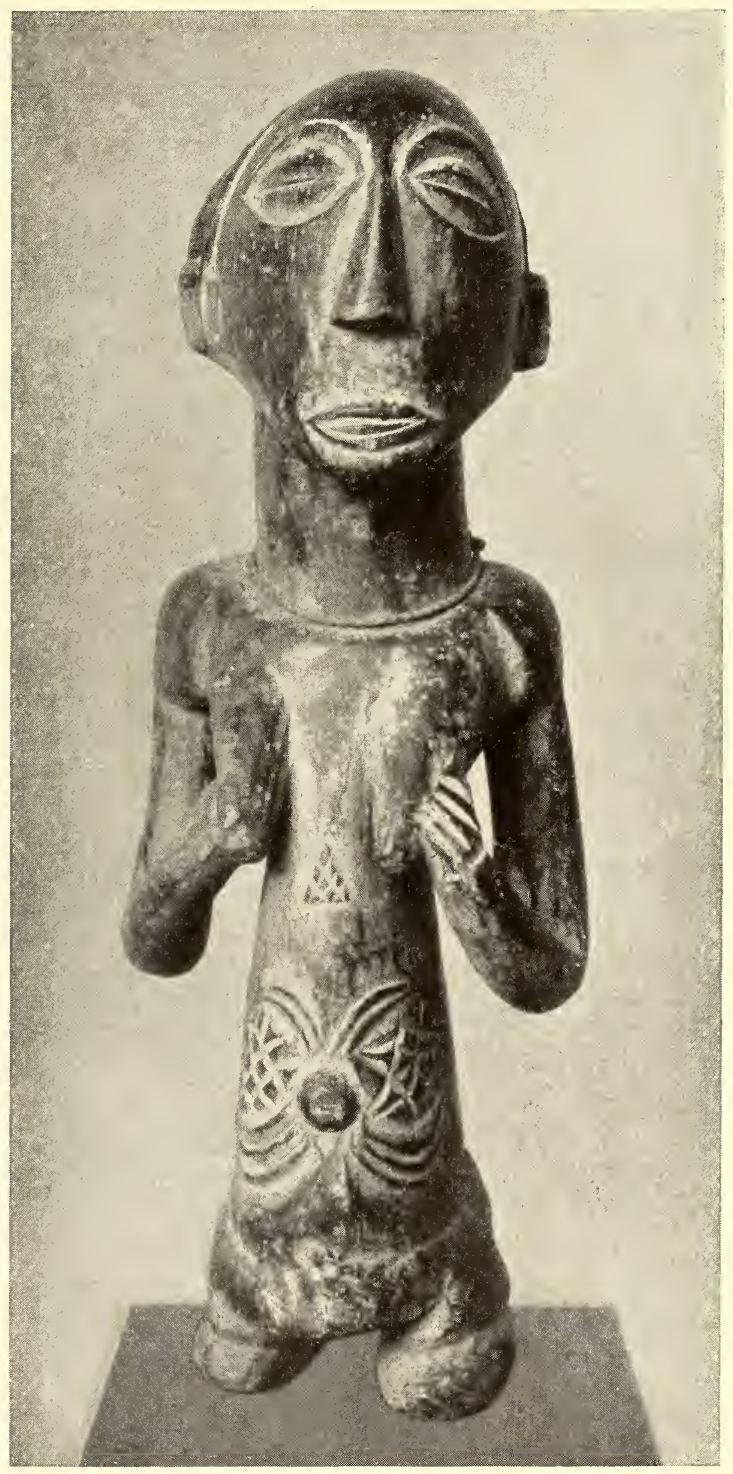




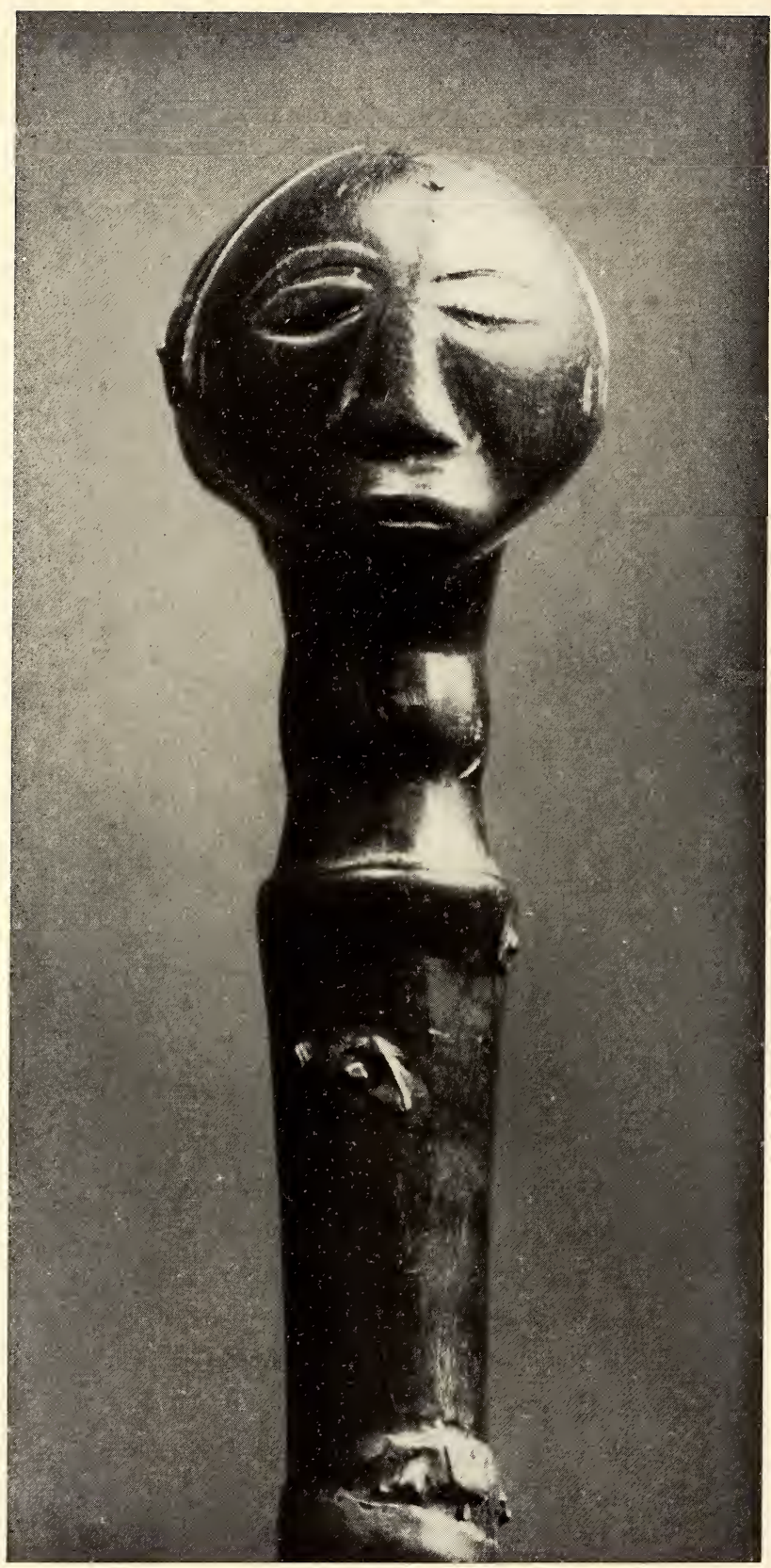




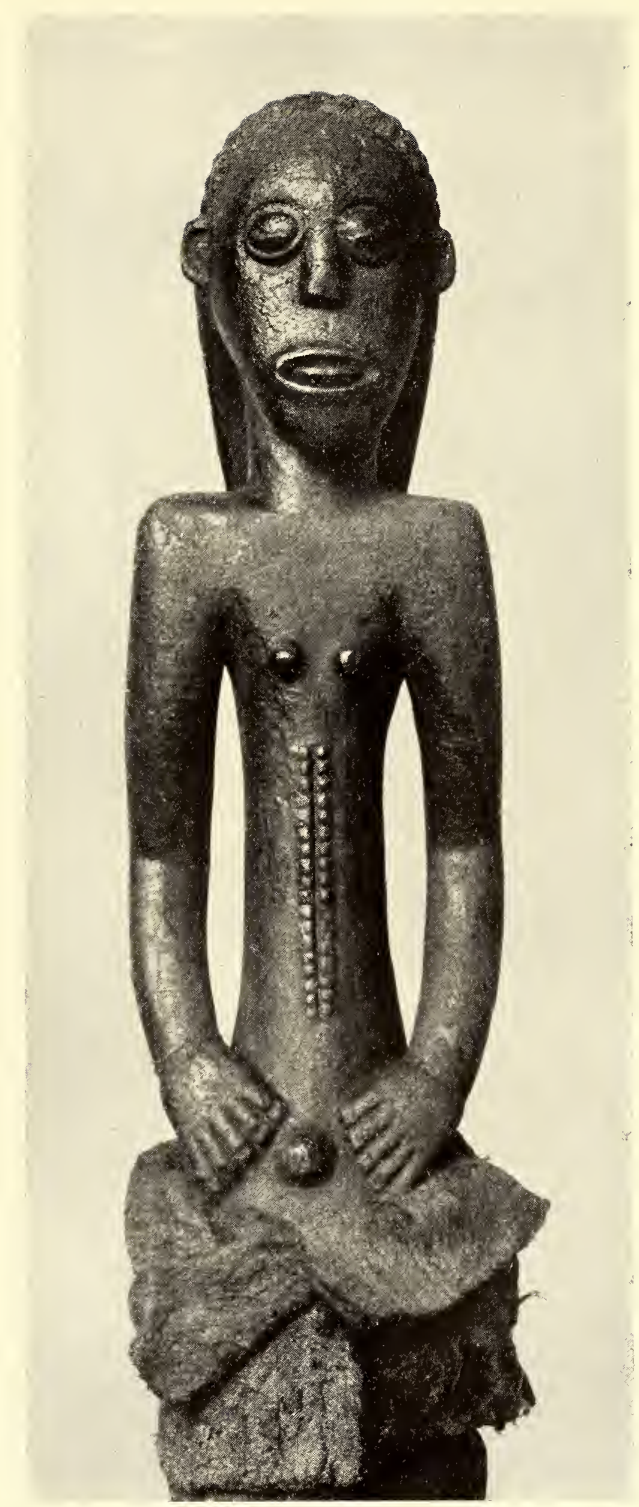



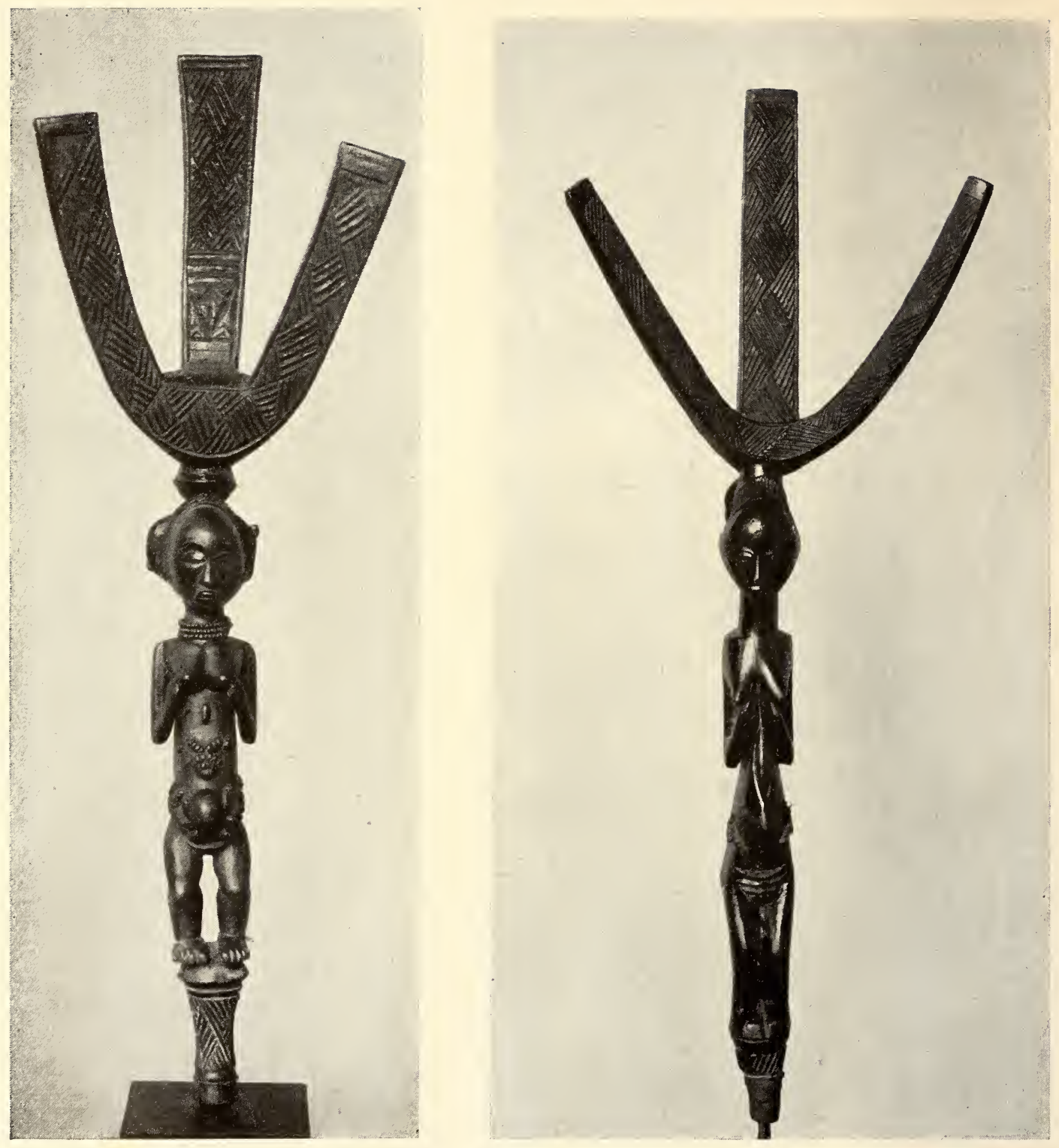


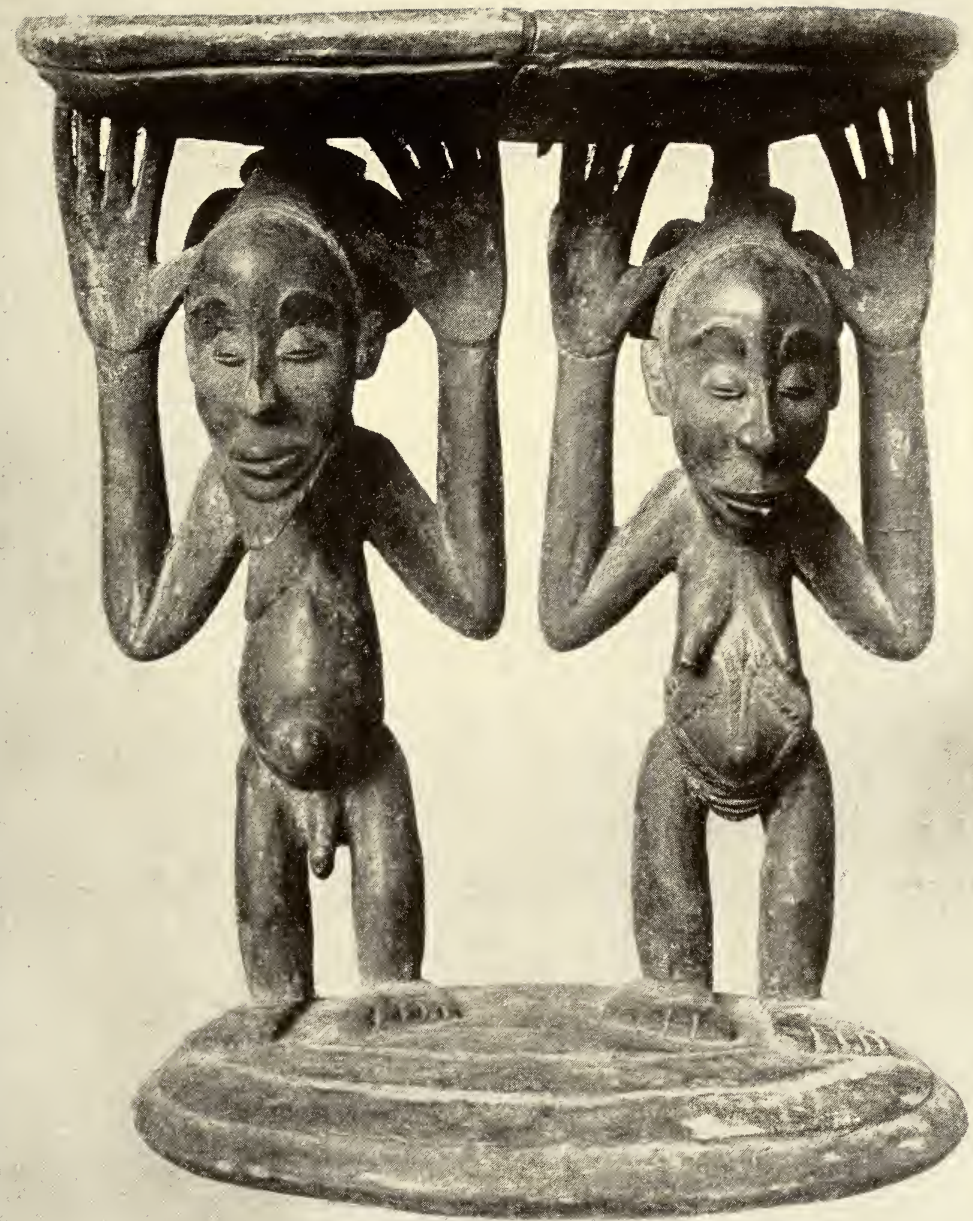




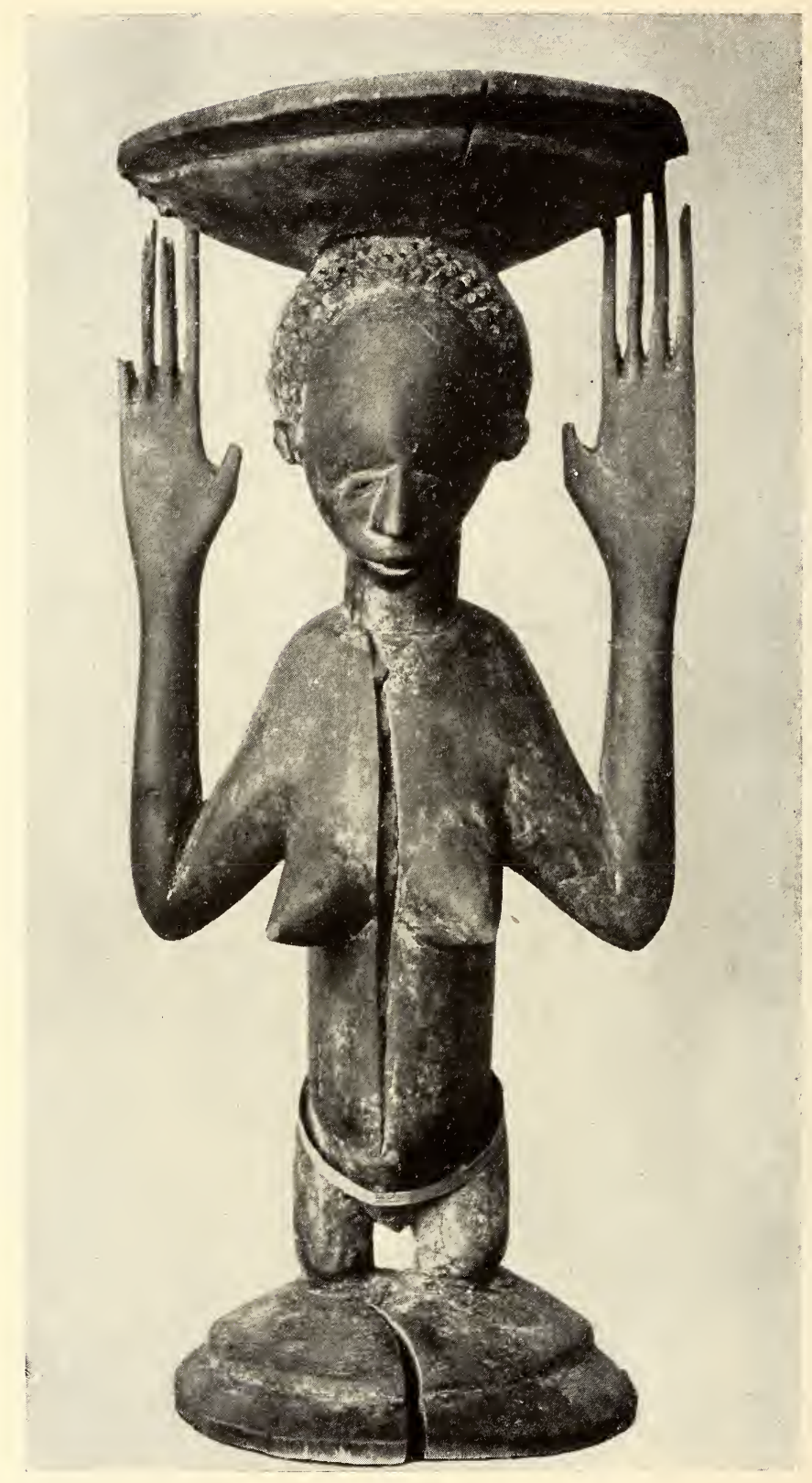




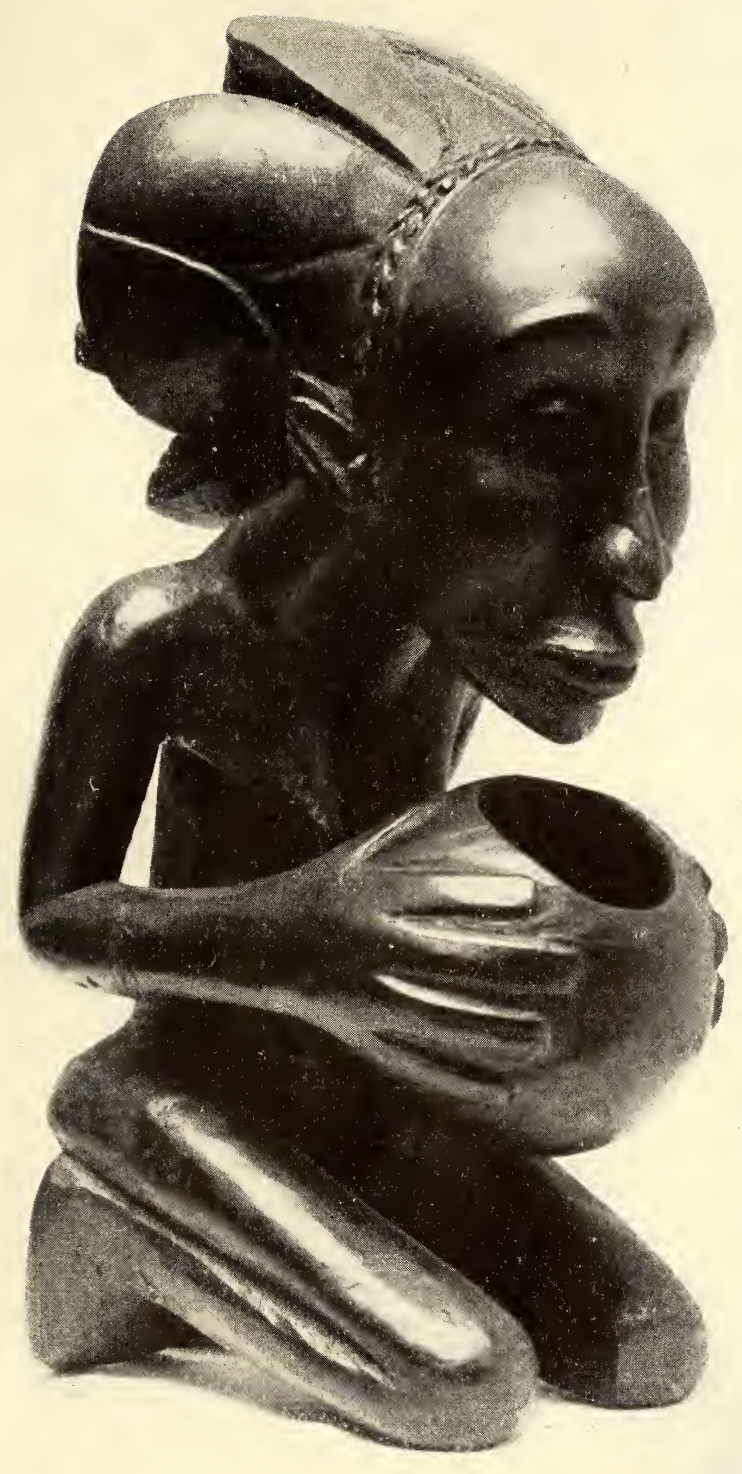




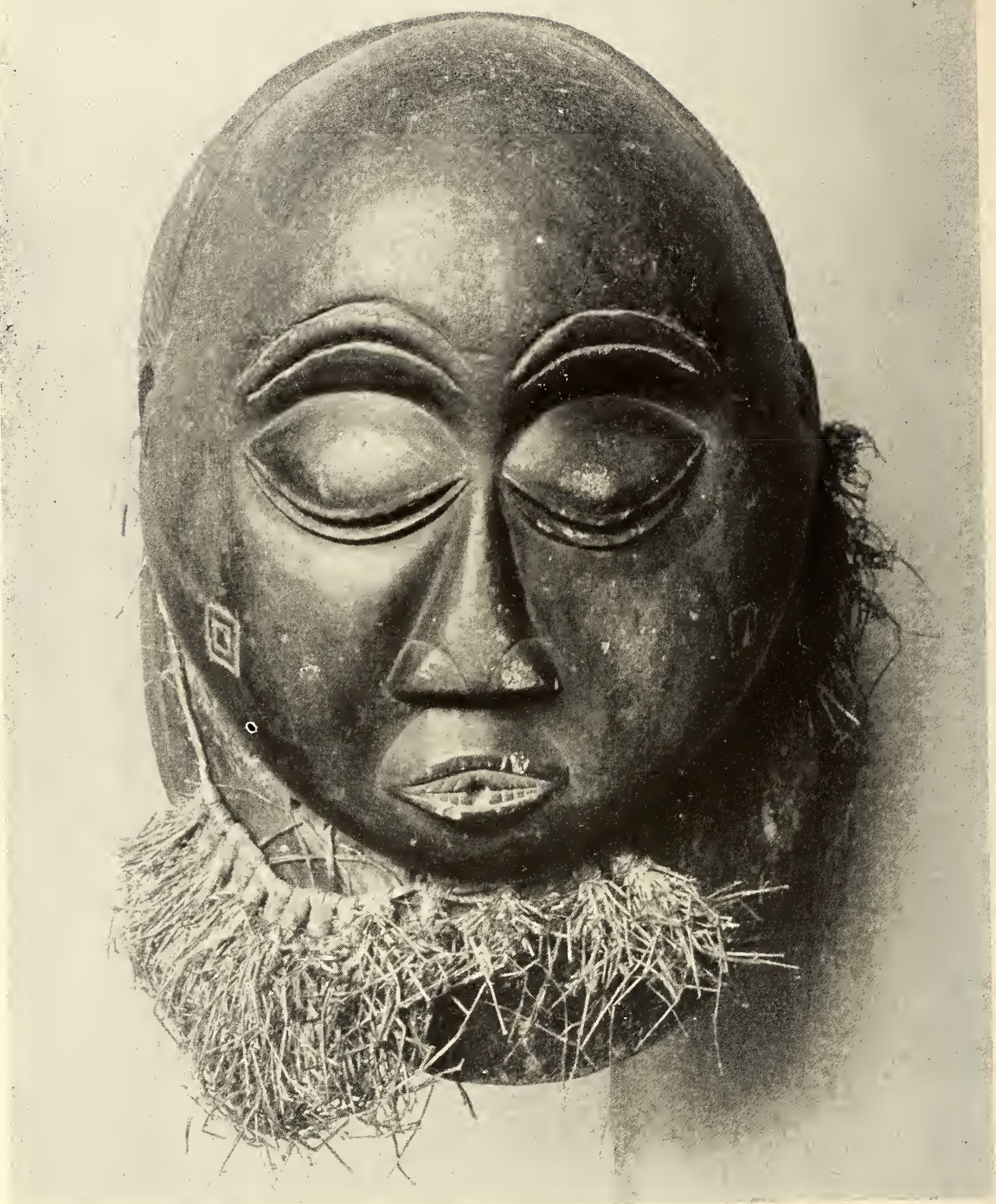




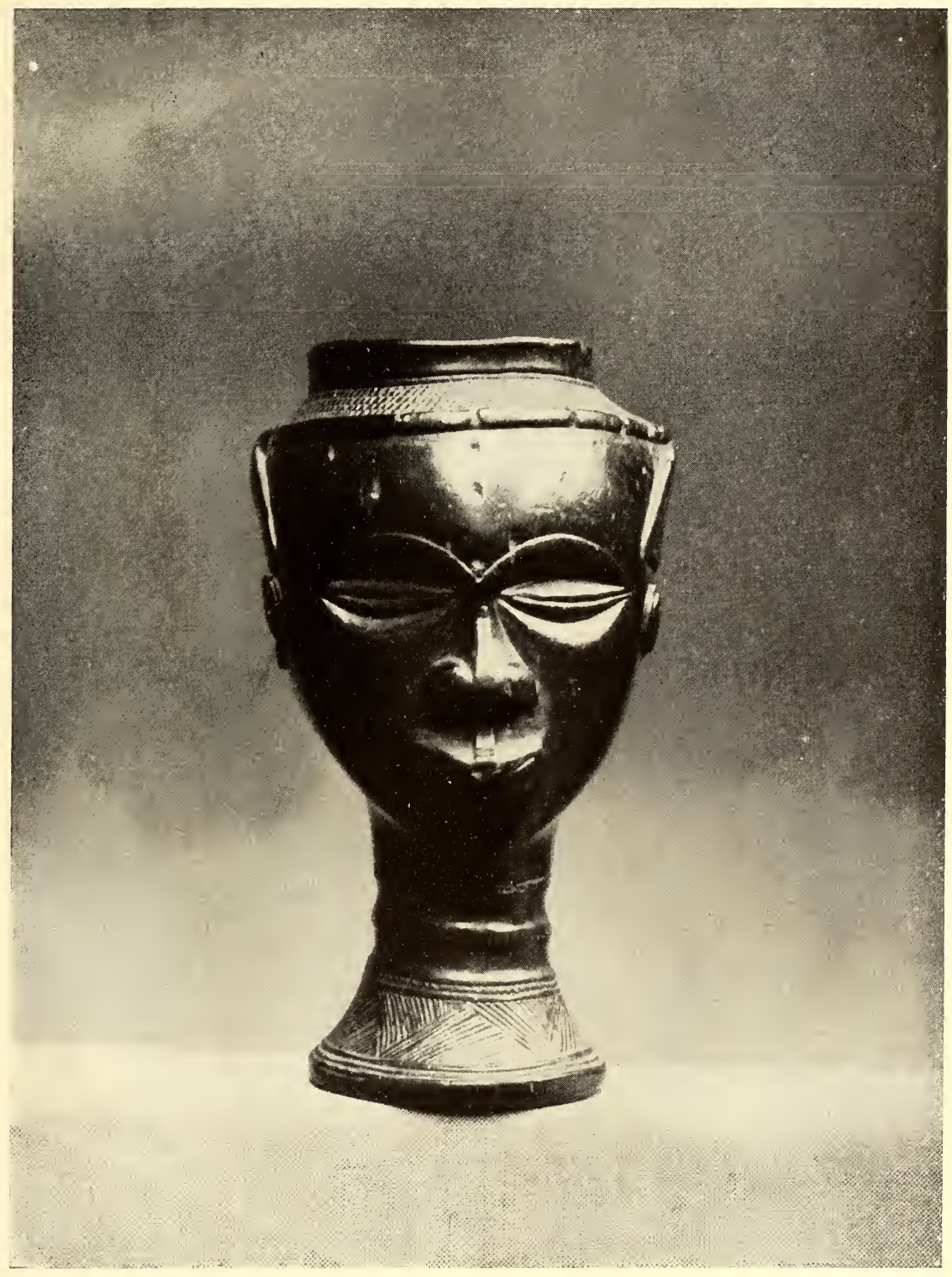




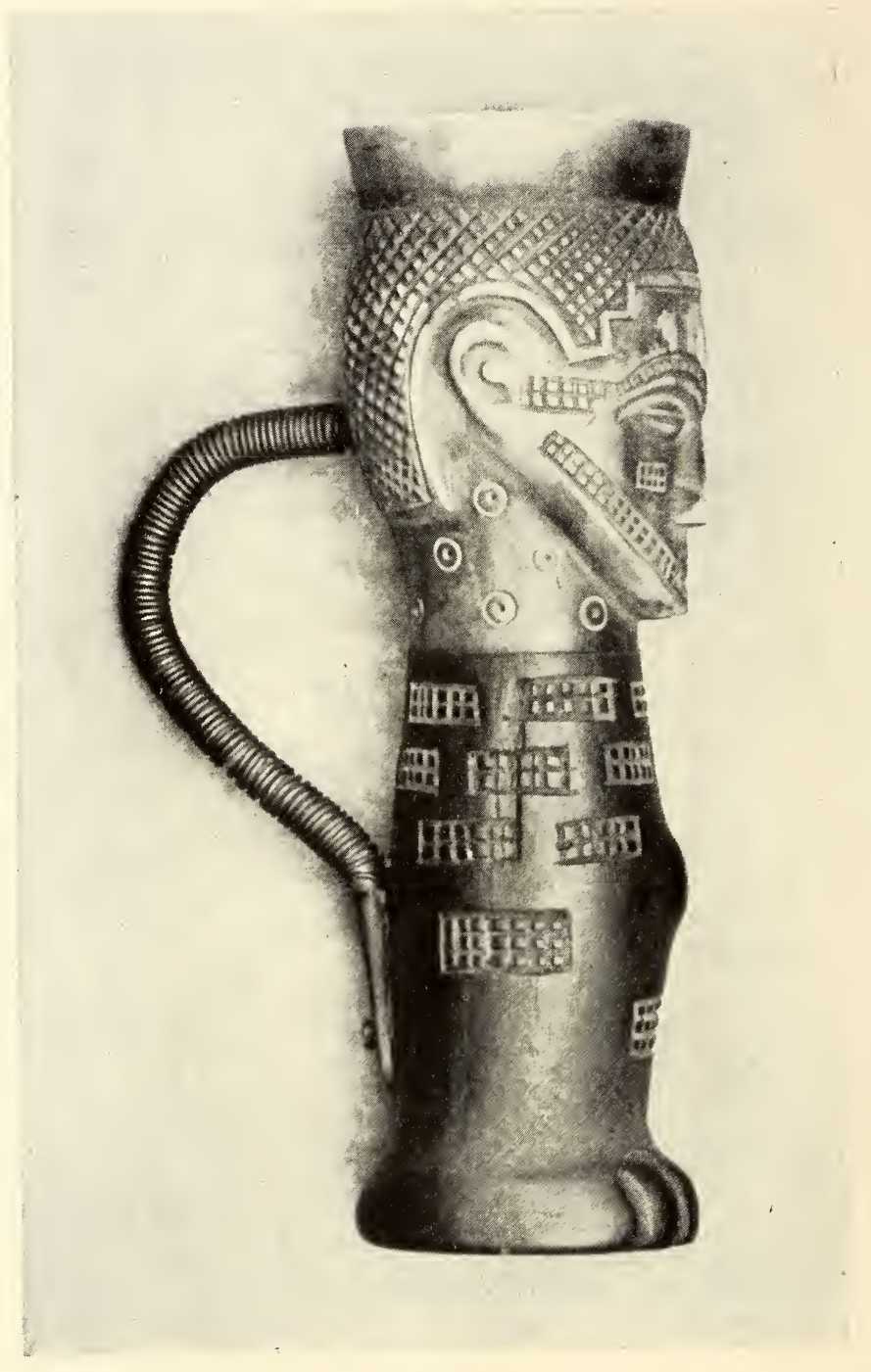




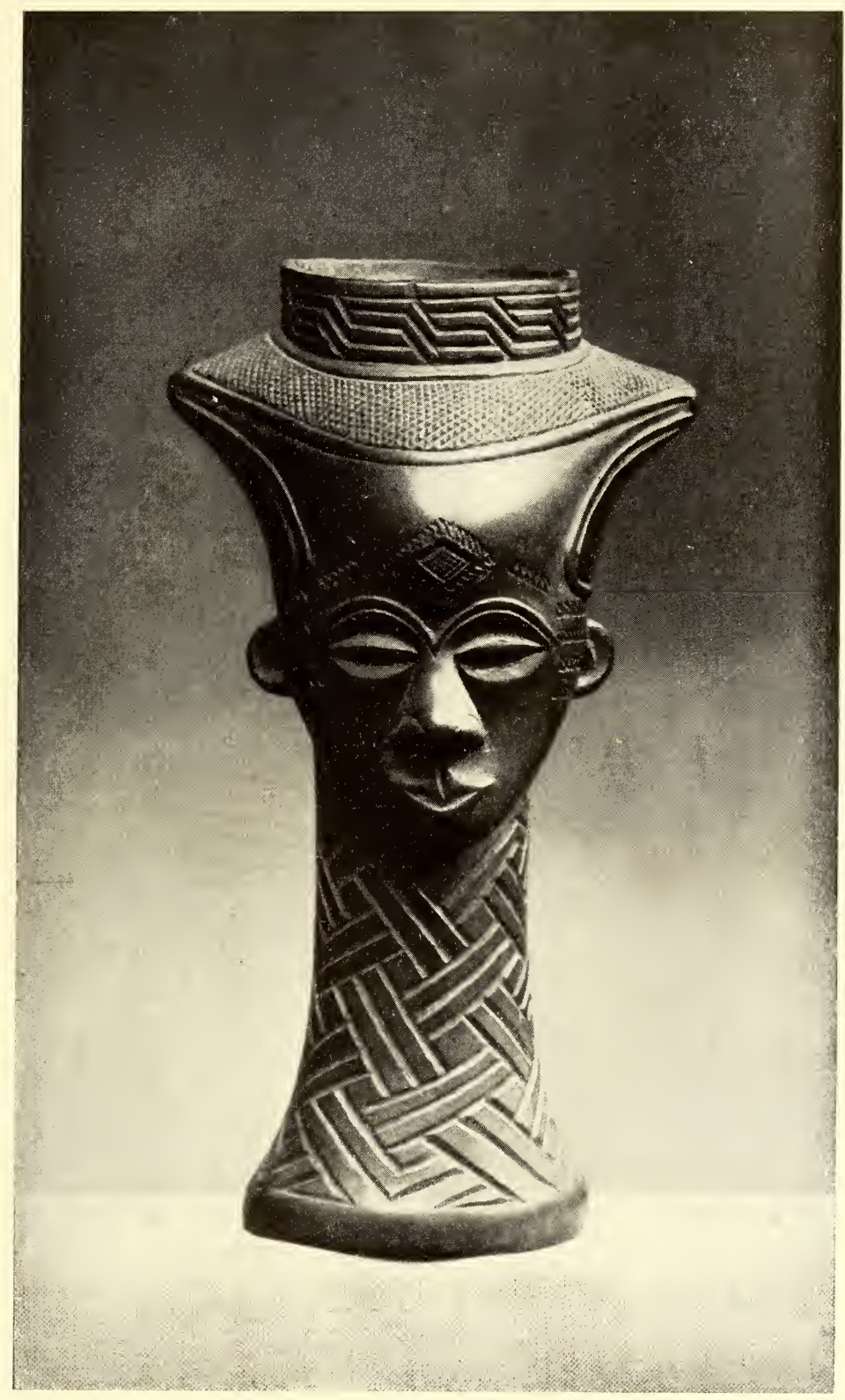




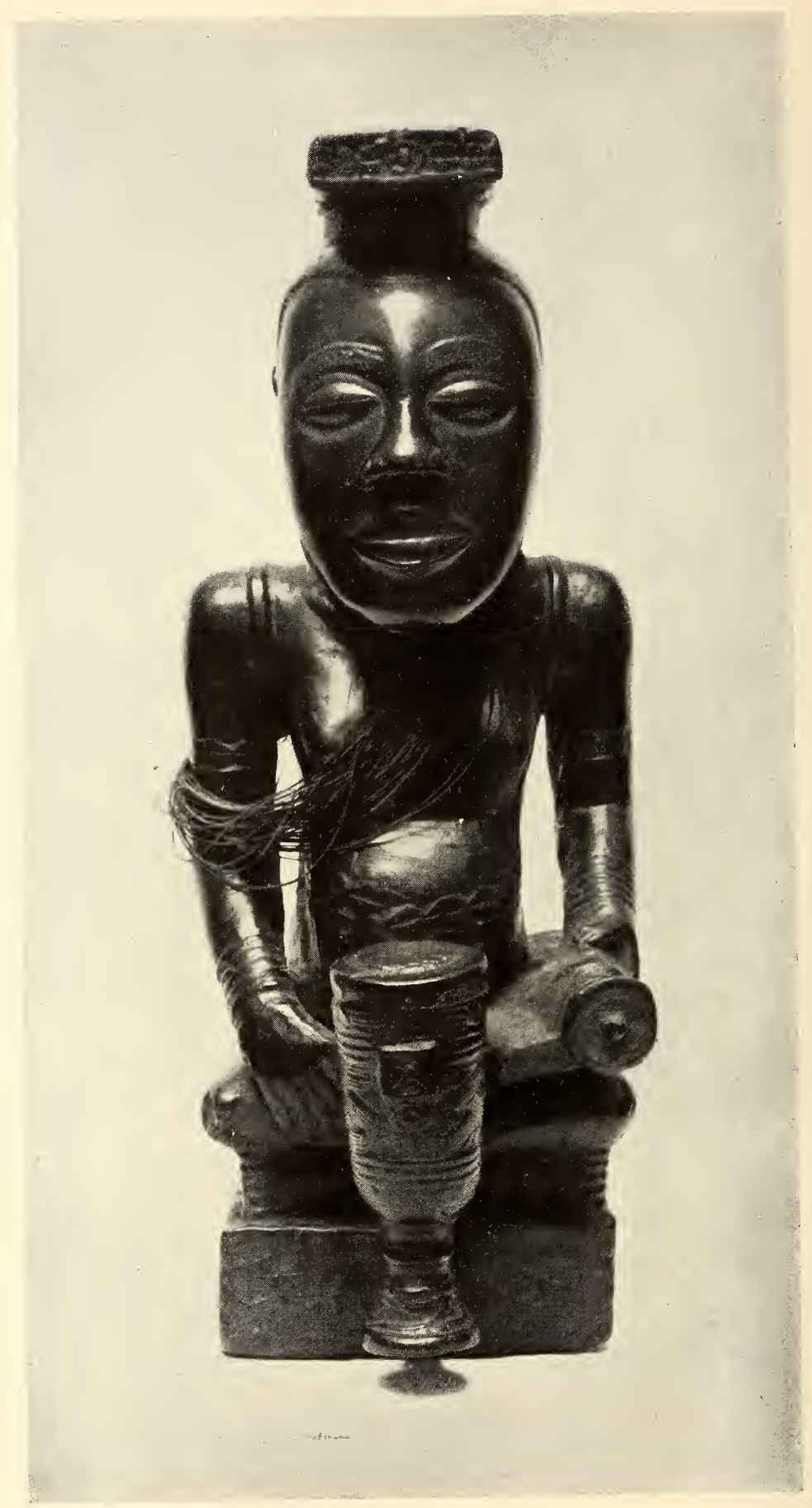




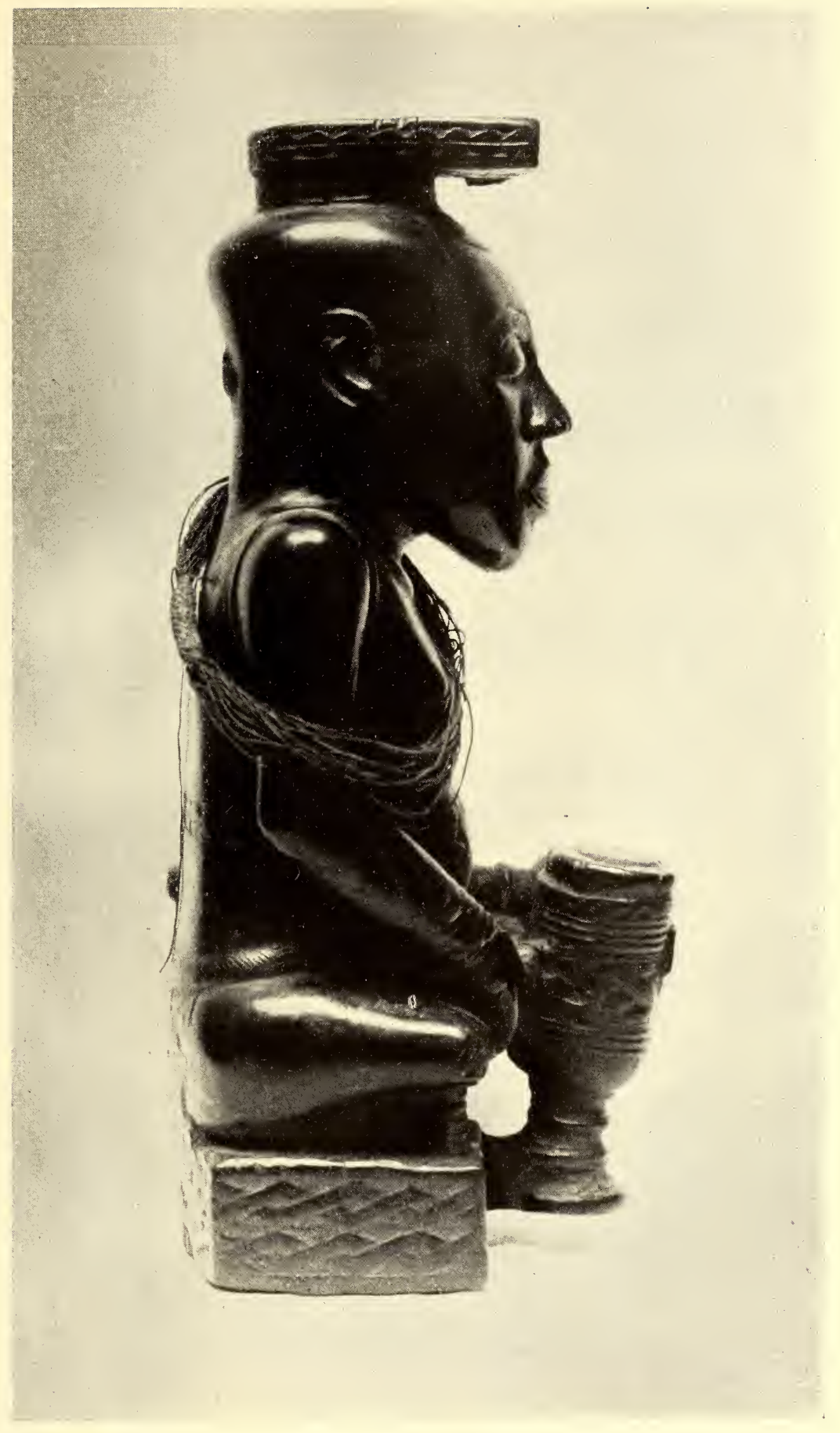




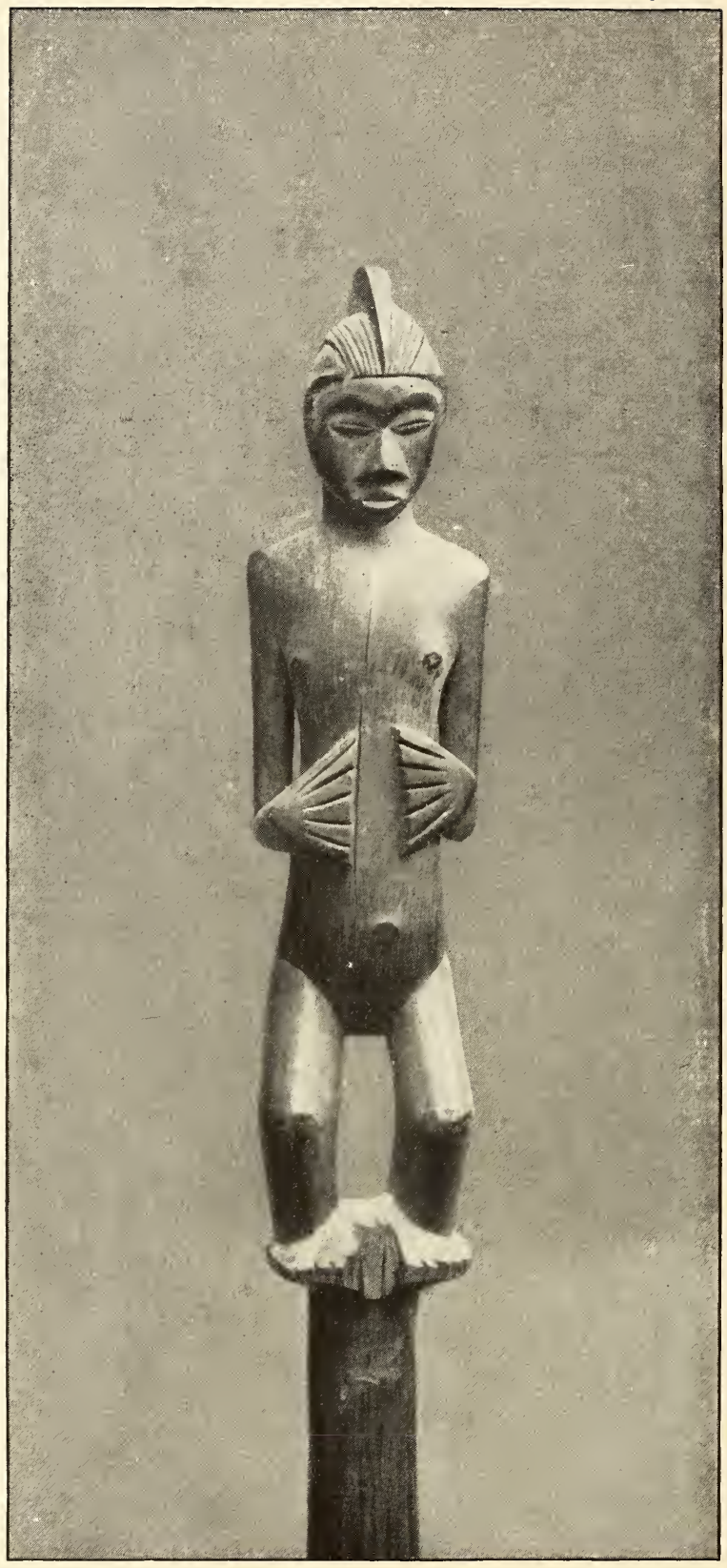




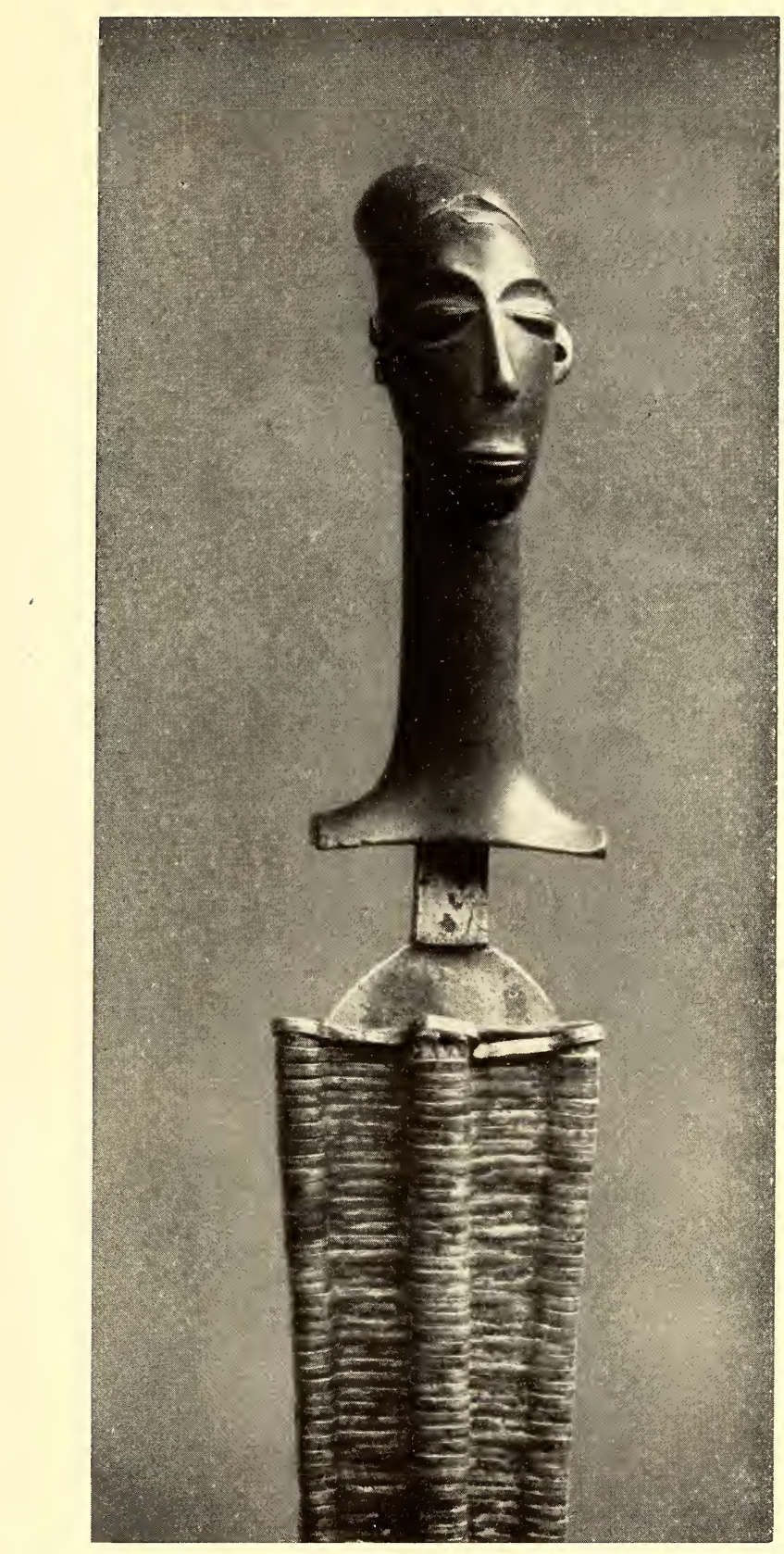



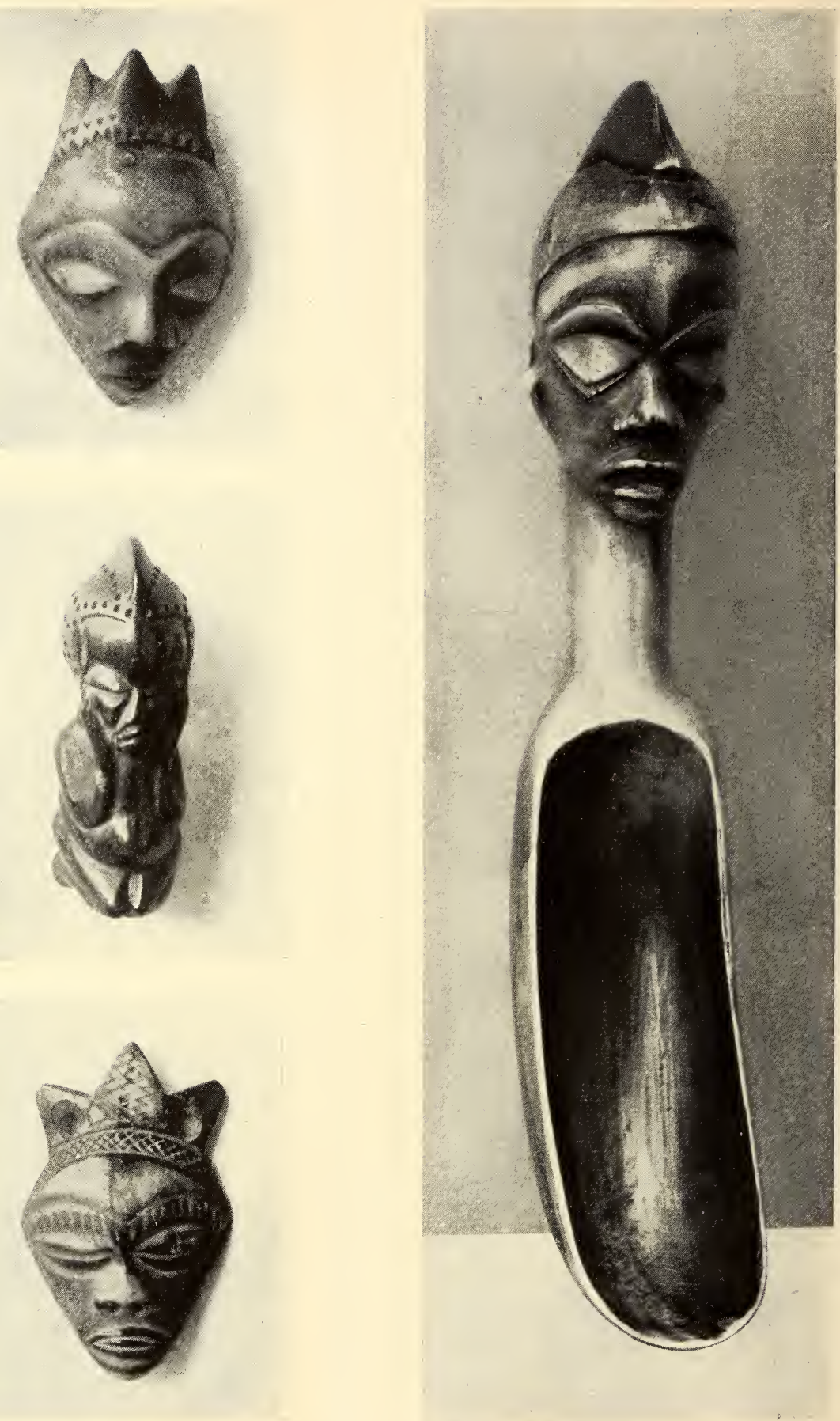


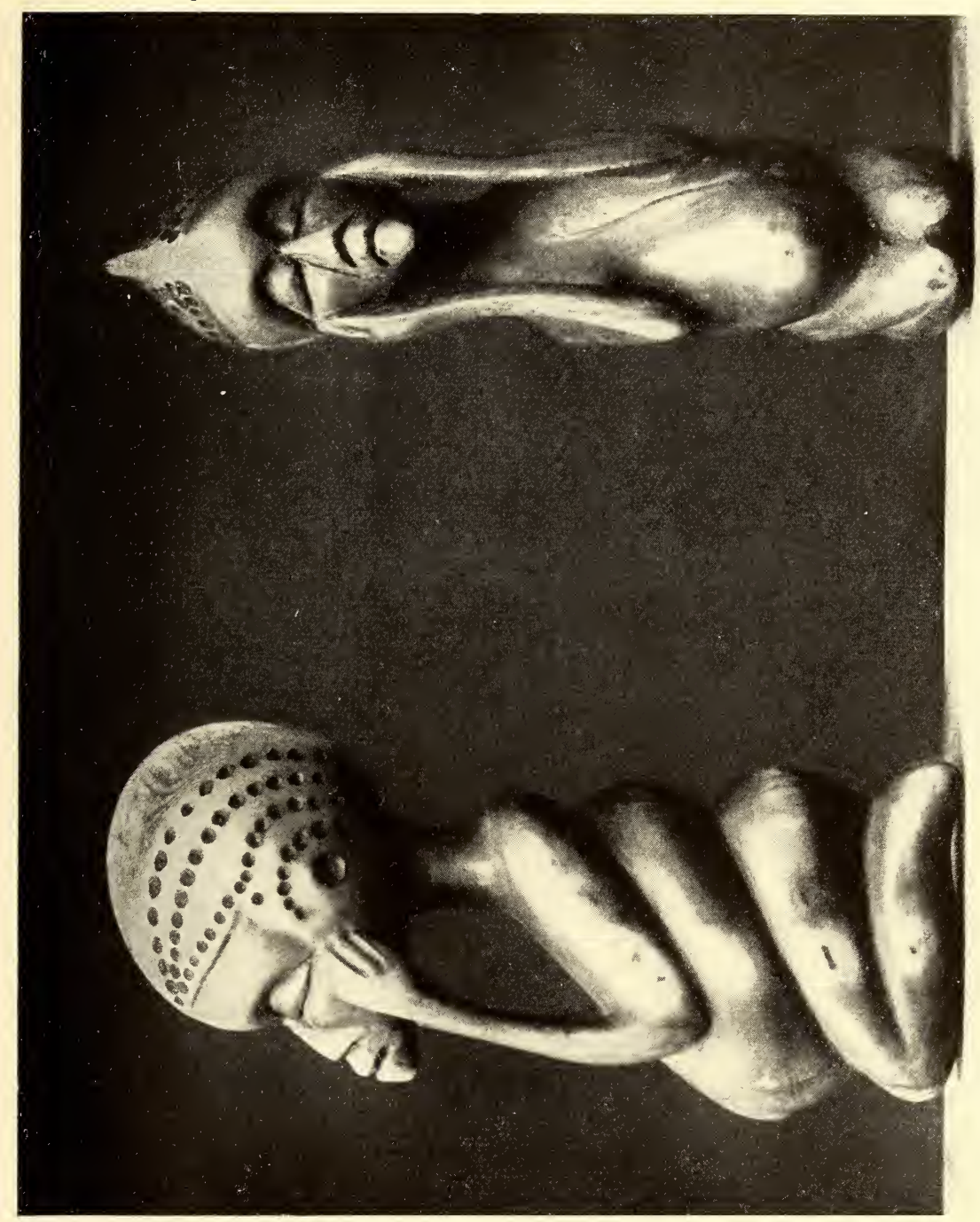



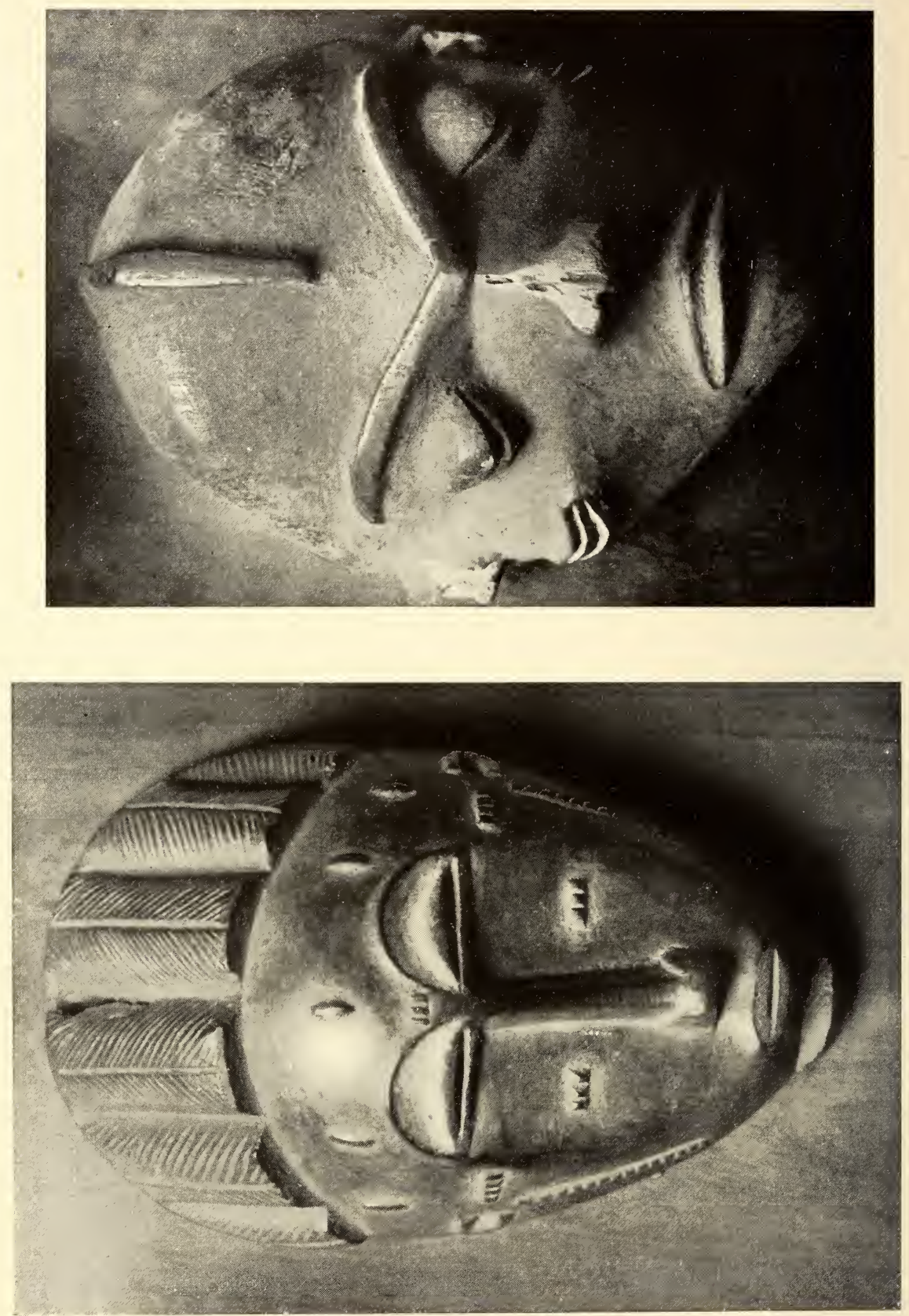


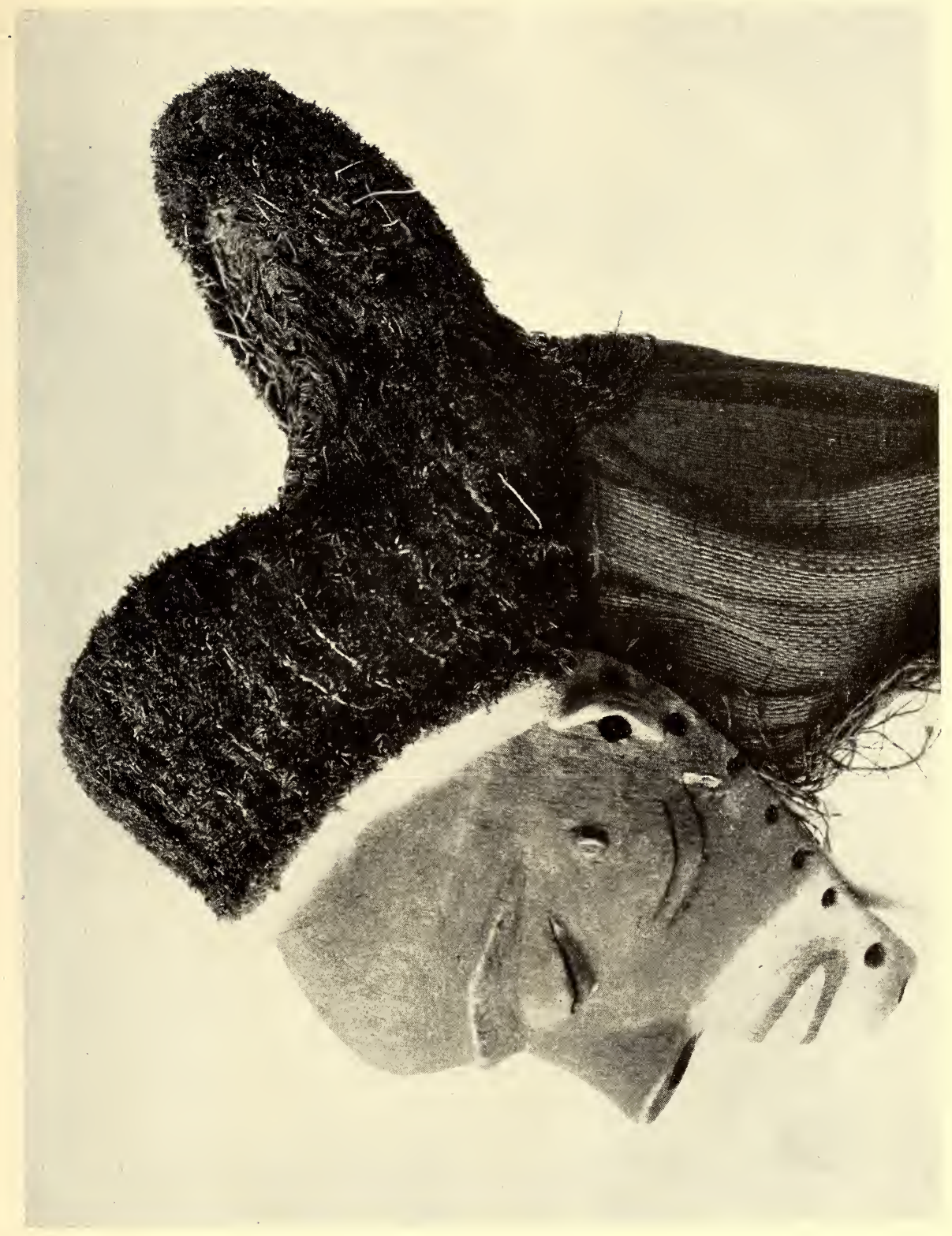




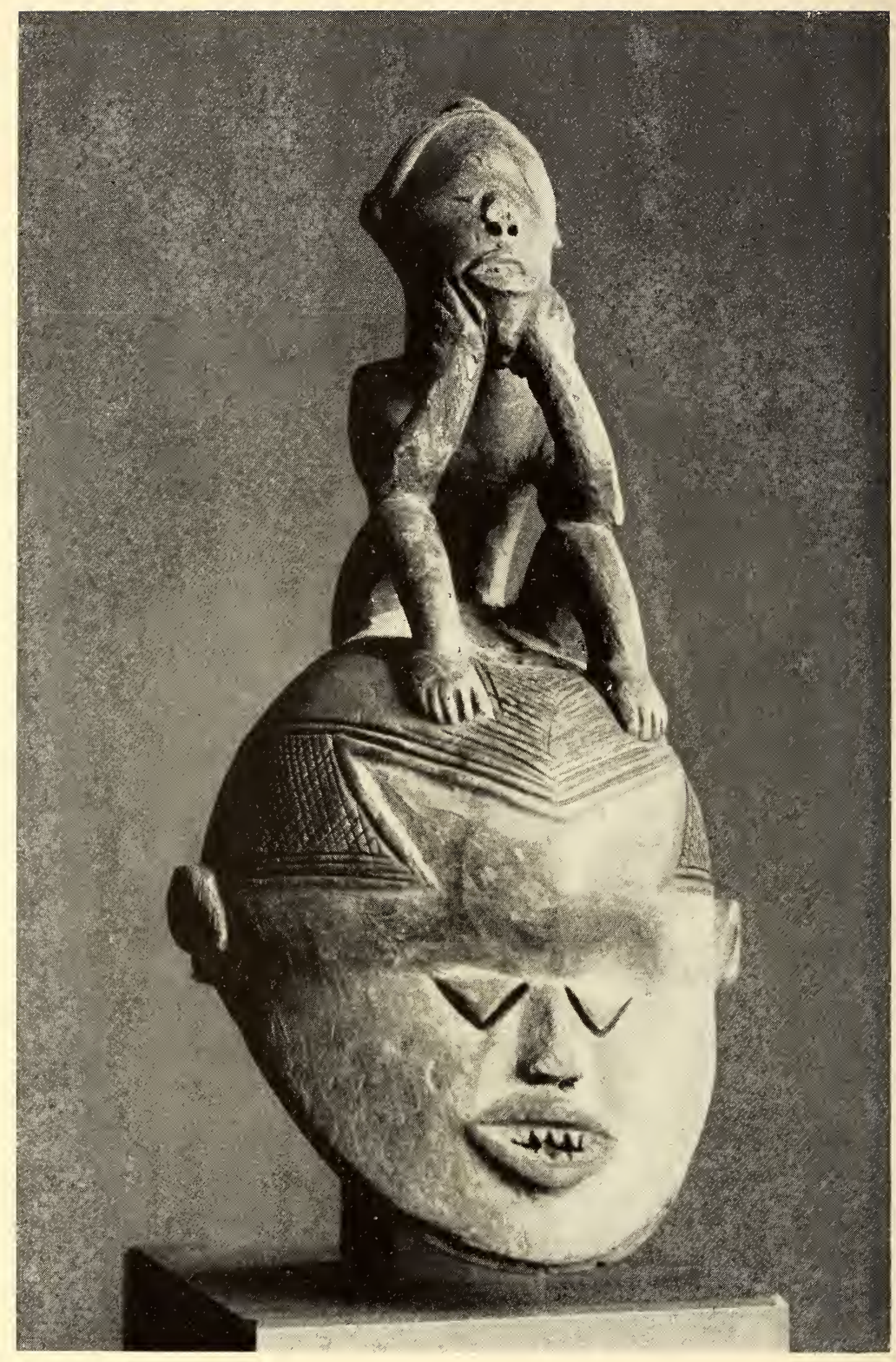



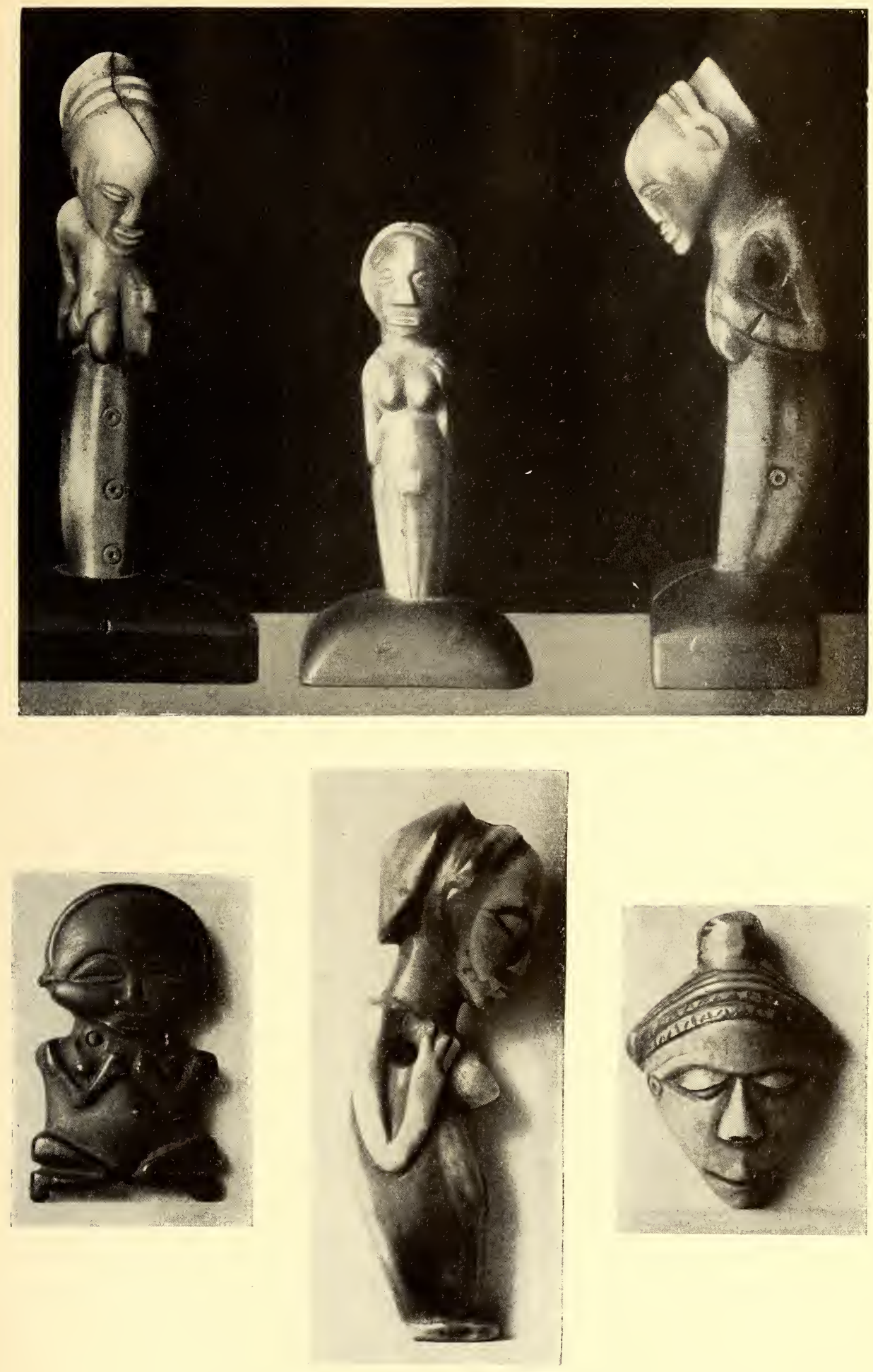

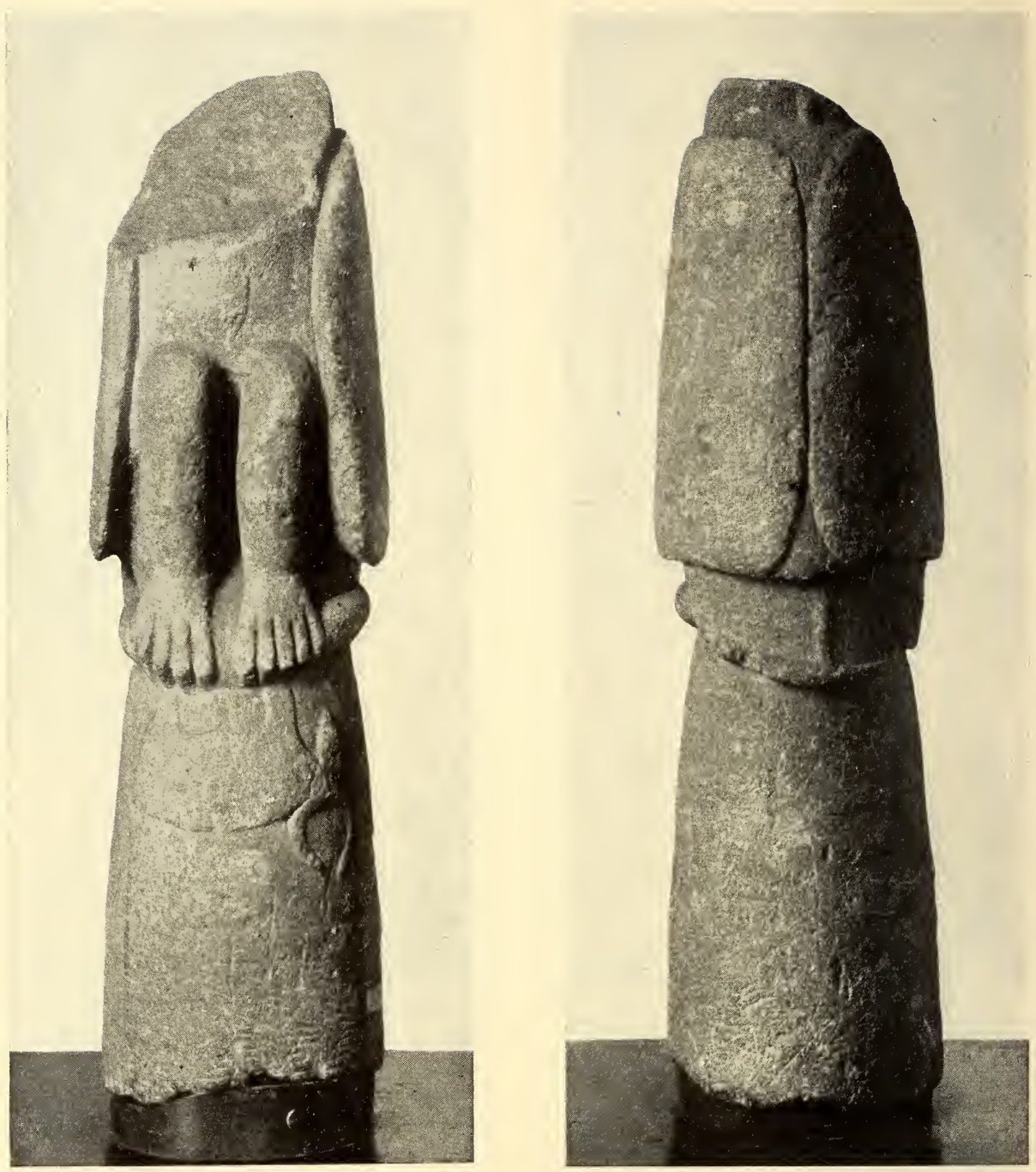


\section{$\begin{array}{llllllllllllllllll}\text { L } & \text { A } & \text { C } & \text { I } & \text { V } & \text { I } & \text { L } & \text { T } & \text { A } & \text { A } & R & \text { T } & \text { I } & S & T & \text { I } & C & A\end{array}$}

SERIE PRIMA

MINIATURE INDIANE testo di ItaloTavolato e Sattar Kheiri

PAESISTI CINESI testo di Alfredo Salmony

ARCAICI GRECI testo di Woldemar Uxkull

ARCHITETTURA INDIANA testo di Paolo Westheim

ARTE RUSSA ANTICA testo di Fannina Halle

STATUARIA ASIATICA testo di Carlo With

AVORI MEDIEVALI testo di Federigo Volbach

SCULTURA AFRICANA testo di Carlo Einstein

ARTE MESSICANA testo di Gualtiero Lehmann

PITTURA TEDESCA ANTICA testo di Enrico Ehl

ARTE DEGLI ITTITI testo di Ottone Weber

SCULTURA CINESE MINORE testo di Ottone Burchard

OGNI VOLUME LIRE 15.-

L A SERIE DI 12 VOLUMI LIRE 150

Si spedisce prospetto illustrato a richiesta

Rivolgersi all'Amministrazione di «Valori Plastici»

10, Via Ciro Menotti. Roma (49)

EDIZIONI DI «VALORI PLASTICI» ROMA 




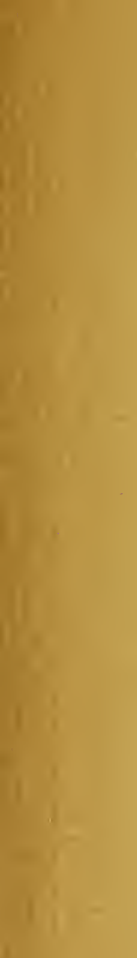


SMITHSONIAN INSTITUTION LIBRARIES 